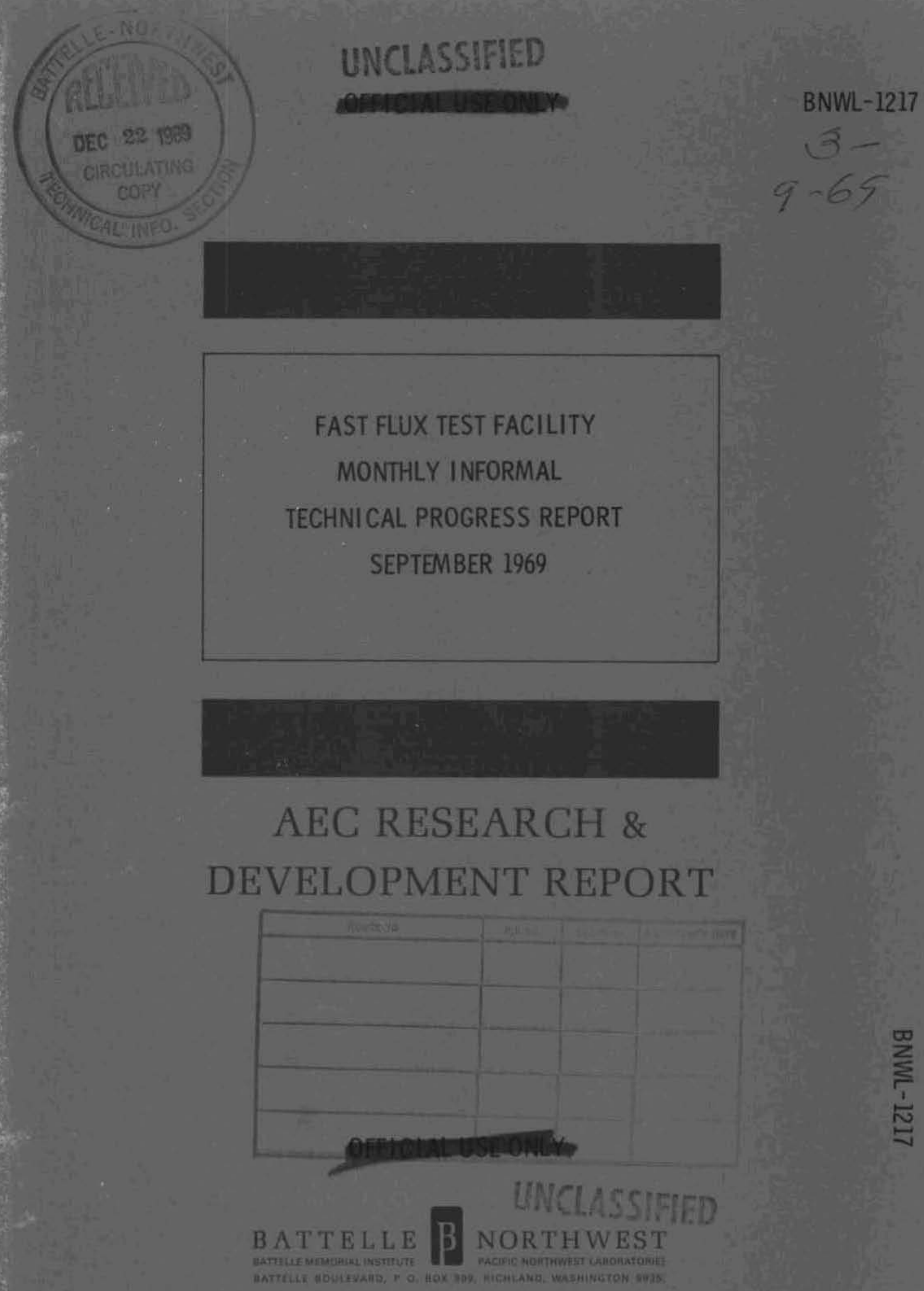




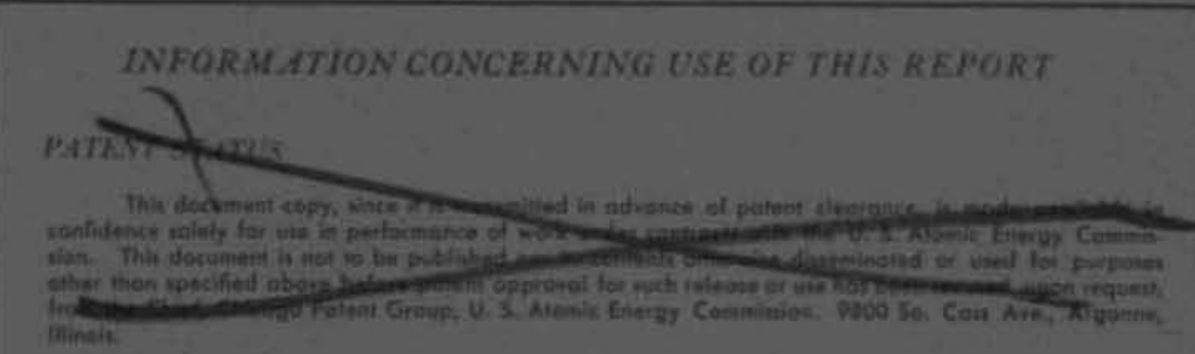

\section{PREIMASARY RKPVIET}

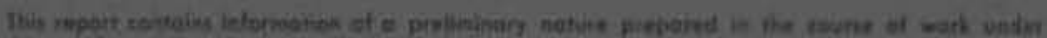

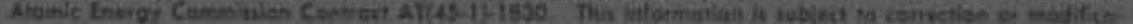

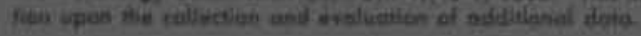

\section{HEGA AOTKE}

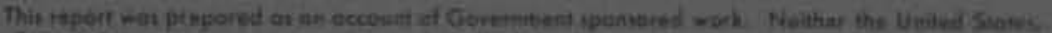

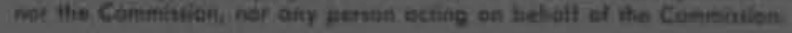

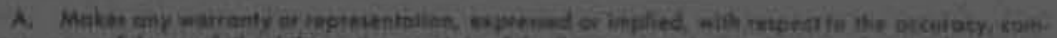

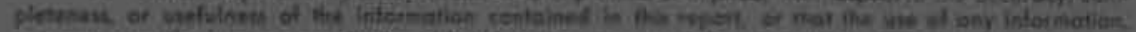

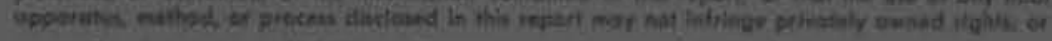

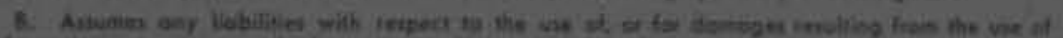

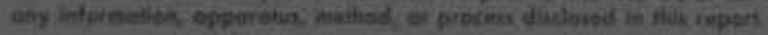

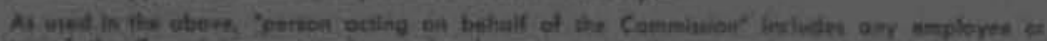

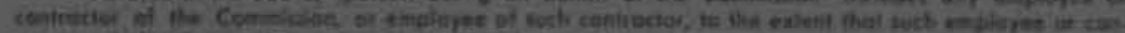

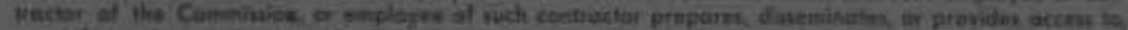

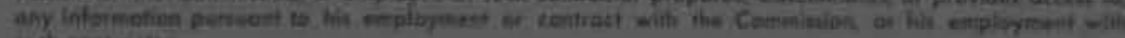
tach cantrotiser.

\section{PACIFIC NORTHWEST LABORATORY}

RICHLAND, WASHINGTON

aperated by

BATTELLE MEMORIAL INSTITUTE

for the

UNITED STATES ATOMIC ENERGY COMMISSION UNDER CONTRACT AT(45-1)-1830 


\title{
ERRATA
}

\author{
Page 2.1 A. OVERALl PLANT DESIGN--delete (PBS 2000) \\ 3.1 O. W. Priebe - - add ** \\ Add footnote - ** (7N91 - R. C. Walker) \\ 6.1 C. A. Munro** - - add * \\ Add footnote - - *** (7N91) \\ 8.1 M. J. Barr - - add ** (In both Section 2 and \\ Section 3) \\ Add footnote - ** (7N73 - R. E. Bardsley) \\ 8.4 E. T. Weber - - add * \\ 9.7 K. B. Stewart - add **, D. P. Taylor* - add * \\ Add footnote - - **7C00 \\ 9.8 C. L. Brown -- add **, C. A. Rogers* -- add * \\ Delete footnote - * $* 7 \mathrm{~N} 83$ - W. W. Little \\ Add footnote - **77C00
}




\section{UNCLASSIFIED}

33679000618233

FAST FLUX TEST FACILITY

MONTHLY INFORMAL TECHNICAL PROGRESS REPORT

SEPTEMBER 1969

E. R. Astley

Project Manager

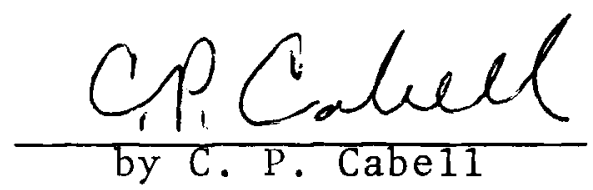

October 7,1969

BATTELLE MEMORIAL INSTITUTE

PACIFIC NORTHWEST LABORATORIES

RICHLAND, WASHINGTON 99352 


\title{
FAST FLUX TEST FACILITY
}

MONTHLY INFORMAL TECHNICAL PROGRESS REPORT SEPTEMBER 1969

\begin{abstract}
This report was prepared by Battelle-Northwest under Contract No. AT(45-1)-1830 for the Atomic Energy Commission, Division of Reactor Development and Technology, to summarize technical progress made in the Fast Flux Test Facility Program during September 1969.
\end{abstract}



TABLE OF CONTENTS

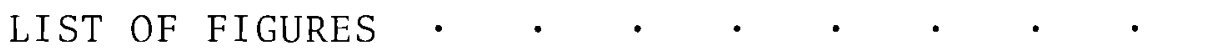

vii

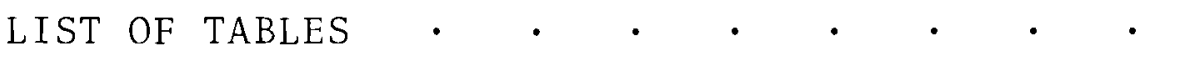

vii

INTRODUCTION

I. PROGRESS SUMMARY

ix

A. FFTF Wide Programs $\cdot$. $\cdot$. $\cdot$. 1.1

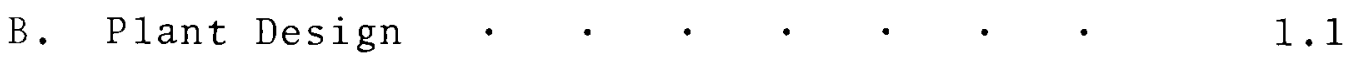

C. Components $\cdot$ •

D. Instrumentation and Control. . . . 1.1

E. Sodium Technology $•$ •

F. Core Design $• \cdot c \cdot c \cdot c \cdot c \cdot c$

G. Fuels and Materials. $\cdot$. $\cdot{ }^{\circ} \cdot{ }^{\circ} 1.2$

H. Fuels Recycle • $• \cdot \cdot \cdot \cdot \cdot \cdot \cdot$

I. Physics $\cdot$. $\cdot$.

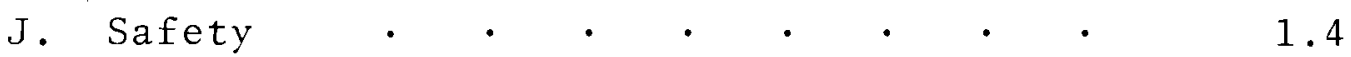

II. Plant DESIGN

A. Overall Plant Design (PBS 2000) • • • 2.1

III. COMPONENTS $\quad \cdot \quad \cdot \quad \cdot \quad \cdot \quad \cdot \quad \cdot \quad \cdot \quad \cdot \quad 3.1$

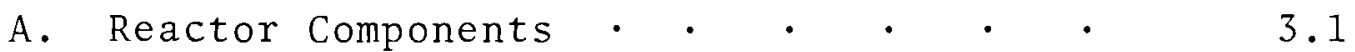

B. Heat Transport System Components. . . 3.5

IV. INSTRUMENTATION AND CONTROL • $\cdot$ • $\cdot$ • 4.1

A. Conceptual Design $\cdot$. $\quad \cdot \quad \cdot \quad \cdot \quad \cdot \quad 4.1$

B. Failed Fuel Detection and Location • . 4.2

C. Electrical Insulators for Sensors and Cables 4.5

D. Removable Driver Fuel Instrument Assembly 4.6

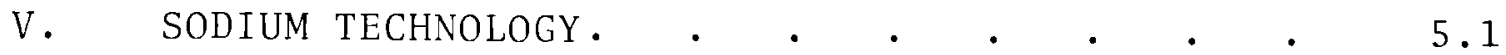

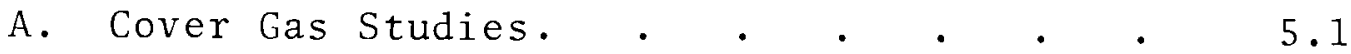

B. In-Line Sodium Instrumentation . . . 5.2

C. Sodium Facilities Operation . . . . 5.3

VI. CORE DESIGN • . . . . . . . . . . . 6.1

A. Core Conceptual Design and Development . 6.1

B. Closed Loops . . . . . . . . . . 6.5 
C. Driver Fuel Ducts. . . . . . . 6.9

D. Core Thermal Hydraulics . . . . . 6.20

E. Core Reactivity . . . . . . . 6.21

F. Core Instrumentation Requirements. . . 6.24

ViI. FUels AND MATERIALS . . . . . . . . 7.1

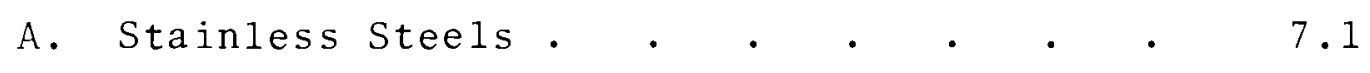

B. Materials Technology . . . . . . 7.13

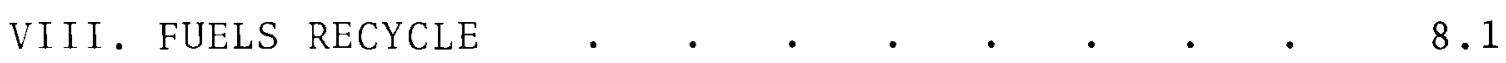

A. Fuels and Materials Evaluation . . . 8.1

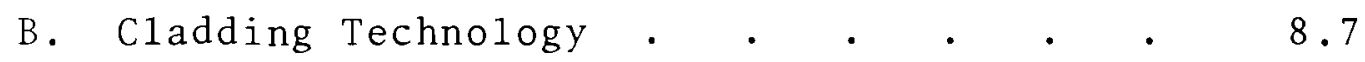

C. Fuel Pin Technology . . . . . . 8.10

D. Fuel Subassembly Technology . . . . 8.12

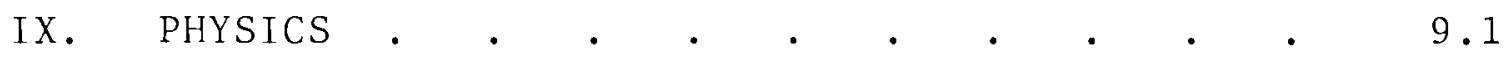

A. Verification of Pert-V Reactivity Coefficients 9.1

B. Use of Spatially Dependent Cross Sections. 9.3

C. FTR Stability Analysis . . . . . . 9.5

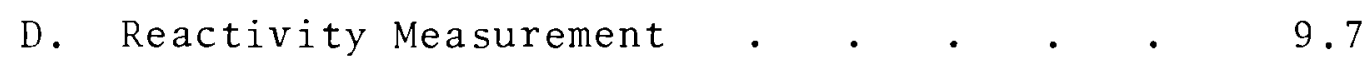

E. RSYN • . . . . . . . . . . . 9.7

F. Exponential and Critical Approach

Experiments with $25 \mathrm{wt} \% \mathrm{PuO}_{2}-\mathrm{U}(\mathrm{Nat}) \mathrm{O}_{2}$ Pins
in Water.

G. Status of Phase B Critical Experiments . 9.9

H. FTR-3 Planning Status . . . . . 9.10

I. Subcritical Reactivity Measurements . . 9.10

J. Pin-Fueled Sodium Void Experiments . . 9.11

K. Engineering Mockup - Material Status . . 9.11

SAFETY . . . . . . 10.1

A. Changes in the Effective Doppler
Coefficient During Large Accidents . .

B. DBA Calculations • • . . . . . 10.1

C. Sodium Voiding Mechanisms . . . . 10.3 
D. Reactor Vessel Response to Hypothetical DBA 10.9

E. China Syndrome Analysis . . . . . 10.10

F. Sodium Spray Fires . . . . . 10.13

G. Sodium Boiling $\quad$. $\quad$ • . . 10.13

H. Safety Programs . . . . . 10.15

\section{LIST OF FIGURES}

4.1 Simulation of Removable Driver Fuel Instrument 4.7

6.1 Internal View of Core Outlet Region Mode1 6.3

6.2 External Features of Core Outlet Region Model 6.4

6.3 Effect of Metal Swelling on Duct Behavior in 200 Days with Type 304 Solution Treated SS (Orificed Core).

6.11

6.4 Effect of Metal Swelling on Duct Behavior in 225 Days with Type 304 Solution Treated SS

6.12

6.5 Effect of Metal Swelling on Duct Behavior in 325 Days with Type 304 Solution Treated SS

6.6 Fluence Versus Axial Elevation of Type 304 SS Driver Duct Zone 1

6.15

6.7 Duct Wall Temperature Versus Axial Elevation for Type 304 SS Driver Duct Zone 1

6.16

6.8 Delta $V / V$ Versus Axial Elevation for Type 304 SS Driver Duct Zone 1

6.9 Bending Moment Versus Axial Elevation for Type 304 SS Driver Duct, Zone 6

6.18

6.10 Coolant Temperature Distributions in a Typical Control Bundle Located in Rod Bundle No. 14 as a Function of Degree of Insertion in Region II of the Core

6.11 FTR Fuel Temperature Response to a $5 \$ / \mathrm{sec}$ Reactivity Ramp with Protection Trip

6.12 Typical Effect of Thermocouple Trip Setting on Boiling Prevention Capability

7.1 Temperature Dependencies Predicted by Swelling Equations for Solution Treated Type 316 and 304 SS and for Type 316 SS with $20 \%$ Cold Worked

7.2 Comparison of Swelling in Type 348 and 316 SS 7.4 
7.3 Stress Versus Time to Rupture for Weldments at $1100^{\circ} \mathrm{F}$

7.4 Creep Rate Versus Stress for Weldment at $1100^{\circ} \mathrm{F}$

7.5 Average Crack Length Versus Load Cycles

7.6 Extraction Replica of Specimen from Avove Fue1 Midplane

8.1 Theoretical Density Versus Percent $\mathrm{PuO}_{2}$ in $(\mathrm{U}-\mathrm{Pu}) \mathrm{O}_{\mathrm{x}}$ Based on Lattice Parameters 2 in

9.1 Geometry Configuration

9.1

9.2 Comparison of Pert $\mathrm{V}$ and 1DX Reactivity Coefficients

9.4

10.1 Changes in the Effective Doppler Coefficient During a Hypothetical Pipe Rupture Accident

10.2

10.2 Transient Response for Large Zero Density Bubble Passing Through Core

10.4

10.3 Sodium Voiding During Flow Coastdown Accident 10.7

10.4 Sodium Voiding During Rapid Power Excursion 10.8

10.5 Vesse1 Wa11 Deformation (S1ug Effect) 10.11

10.6 Pressure in Containment Sphere for Sodium Spray Expulsion

\section{LIST OF TABLES}

2. I Current Design Data

2.3

3. I Total Flux at Select Locations

3.2

3. I Possible Radial Shield Fallback Arrangements

3.3

8. I Effects of Process Variations on Sintered Pellet Density

8.4

9. I Comparison of Reactivity Coefficients

Calculated by PERT-V and 1DX

9.2

9. II Material Compositions

9.3

9. III Zone Breakdown for Generating Spatially Dependent Cross Sections

9.5

9. IV Comparison of keff for Cross Sections Generated Using Fundamental Mode and Spatially Dependent Spectra

9.V Results of Exponential Experiments with $25 \mathrm{wt}_{0} \mathrm{PuO}_{2}-\mathrm{U}(\mathrm{Nat}) \mathrm{O}_{2}$ Fuel Pins in water

9.9

9.VI Results of Approach-to-Critical Experiments with 25 wt: $\mathrm{PuO}_{2}-\mathrm{U}(\mathrm{Nat}) \mathrm{O}_{2}$ Fuel Pins in Water 


\section{FAST FLUX TEST FACILITY \\ MONTHLY INFORMAL TECHNICAL PROGRESS REPORT \\ SEPTEMBER 1969}

\section{INTRODUCTION}

This report is structured on the basis of the nine LMFBR program elements. These program elements are employed as the subjects for Chapters II-X inclusive. Subdivisions of the chapters are based on specific FFTF systems, components and programs.

Each item in the report identifies the submitting author, and the authors FFTF organization code and his section manager.

FFTF organization codes shown in this report are as follows:

7N70 - Fue1s Dept. - E. A. Evans, W. E. Roake, T. W. Evans 7N71 - Offsite Fue1s Programs - G. A. Last

7N72 - Cladding Development - T. T. Claudson 7N73 - Fuel Element Development - C. A. Burgess

7N74 - Fue1s Quality Assurance - H. G. Powers

7N75 - Fuels Evaluation - J. E. Hanson

7N76 - Material Contro1 - A. W. DeMerschman

7N80 - Reactor and Plant Technology Dept. - P. L. Hofmann, D. E. Simpson

7N81 - Reactor and P1ant Engineering - L. M. Finch.

$7 N 82$ - Safety and Systems Analysis - R. E. Peterson

7 N83 - Nuclear and Process Technology - R. E. Heineman

7N90 - Engineering Dept. - D. L. Condotta, F. C. Gronemeyer W. B. McDonald

7N91 - Reactor Design - S. O. Arneson

7N92 - Fluid Systems - J. M. Batch

7N93 - Instrumentation Control - C. D. Swanson

7N94 - Facilities and Site - E. M. Johnston

7N95 - Engr. Coordination and Planning - J. R. Carre11

7N96 - Metals, Materials and Codes - J. C. Tobin 
When work is performed for FFTF by another BNW Division, that code is also included as shown in the following tabulation:

7400 - BNW Safety and Standards Division

7A00 - Chemistry and Metallurgy Division

7C00 - Physics and Engineering

$7 \mathrm{~K} 00$ - Environmental and Life Sciences Division

7M00 - Systems and Electronics Division 


\section{PROGRESS SUMMARY}

\section{A. FFTF WIDE PROGRAMS}

Major effort was concentrated on preparation of the Preliminary Safety Analysis and Review, and on the Overal1 Conceptual Design Optimization Program.

\section{B. PLANT DESIGN}

Detailed engineering design evaluation of the FFTF site is in progress. The first phase of the seismic survey has been completed. Well drilling has started to obtain samples of the underground soil 1 ayers at the site.

Several changes were made in basic thermal data for the reactor concept. The ultimate value of reactor bulk inlet temperature was reduced to $750^{\circ} \mathrm{F}$ and the initial value of reactor bulk outlet temperature was reduced to $850^{\circ} \mathrm{F}$.

\section{COMPONENTS}

Specifications for the reactor vessel, guard vesse1, head and associated equipment are being revised prior to contract negotiation for equipment design.

Test facility modifications have been started at LMEC in preparation for testing of the Roller Nut Control Rod Drive Mechanism.

Contract negotiations for fabrication of prototype fue 1 ducts are in progress with two vendors.

\section{INSTRUMENTATION AND CONTROL}

An evaluation was completed on the xenon gas tagging concept for location of failed fuel in the FTR. It was concluded that xenon tagging is a feasible concept for locating failed fuel in the FTR. It is simple in design and operation and requires very little in-vessel equipment. 
BNWL -1217

\section{E. SODIUM TECHNOLOGY}

Work has begun on design of an integrated instrument "package" for in-line monitoring of sodium. The package will contain meters for carbon content, oxygen content, and plugging. F. CORE DESIGN

$\mathrm{BNW}$ and Westinghouse have agreed to recommend $\mathrm{B}_{4} \mathrm{C}$ as a poison material for the FTR.

Initial qualitative test results from the core outlet feature model indicate that coolant mixing in the outlet region of the vessel is reasonably good. Quantitative tests are in progress.

Preliminary drawings have been made for the 2 -MW closed loop systems. Initial tests of remote cutters, for separation of the welded closure between the closed loop nozzle plug and the plug and the reactor top face spool piece, have given promising results.

An active program is in progress to evaluate the amount of radiation-induced swelling and resultant bending, that will occur in driver fuel ducts. Calculated data are given for typical ducts. BNW and Westinghouse agreed that a full size core simulation would be required to test core radial restraint designs.

\section{G. FUELS AND MATERIALS}

Revisions have been made in the swelling equation for solution-treated AISI Type 316 and 304 SS. The revised equation predicts a maximum swelling of about $31 / 2 \%$ for a fluence of $5.0 \times 10^{22} \mathrm{n} / \mathrm{cm}^{2}(\mathrm{E}>0.1 \mathrm{MeV})$. No change has been made in the swelling equation for Type 316 sS with $20 \%$ cold work. Maximum swelling of about $2 \%$ is predicted under the fluence defined above. 
Fatigue crack growth tests of Type 304 SS indicate that the crack growth rate for the same stress intensity factors is increased by a factor of about $600 \%$ in going from room temperature to $1000^{\circ} \mathrm{F}$ in air.

H. FUELS RECYCLE

Pellet fabrication for PNL-6 was completed. Development is in progress to identify pellet process changes required to produce dished, low-density pellets for PNL-9, 10 and 11 .

CAR TECH has produced 4,000 ft of high quality Type 316 SS tubing.

The FFTF Fuel Demonstration Facility has fabricated 310 fuel pins to date with an assembly yield of $86.8 \%$. Twelve pins were tagged with various helium/xenon mixtures for FP-33 and FP- 37 .

The three contractors participating in the program for prequalification as LMFBR field suppliers are processing raw materials.

\section{PHYSICS}

The FTR shielding experiments were started on September 3 in ZPPR following a 4-week outage for a containment test.

Requirements for the FTR-3 zone core experiments have been specified and sent to ANL for use in the preparation of time schedule estimates and detailed experimental plans. This program emphasizes measurements of typical FTR control worths, Doppler effects, sodium void, and power density measurements in a 2-zone 1000 liter critical assembly. The zone atom densities will approximate those of 2 -zone homogenized FTR.

Exponential and critical approach experiments with 25 wt: $\mathrm{Pu}_{2}-\mathrm{U}(\mathrm{Nat}) 0_{2}$ fuel pins in water were continued. To date, measurements have been completed for two lattice pitches: 0.779 and 0.900 in. 


\section{J. SAFETY}

Application of the Monte Carlo fault tree simulation program to the $\mathrm{Na}$ boiling fault tree for loss-of-coolant flow indicated that the probability of $\mathrm{Na}$ boiling resulting from independent failure of coolant loops and protective system components is less than $10^{-10}$.

Calculations of the reactor response to the passage of a large void through the center of the core are presented to illustrate a hypothetical DBA initiating event. 


\section{II . PLANT DESIGN}

A. OVERALL PLANT DESIGN (PBS 2000)

1. FFTF Site Investigation

F. H. Shade1*

The Weston Geophysical Engineers, Inc., under contract to the Bechtel Corporation, completed the first phase of the seismic survey. The Hatch Drilling Company is proceeding with the well drilling to obtain samples of the underground soil layers at the site. Five holes will be drilled.

2. Primary Power

M. F. Wiitala**

A decision was made to proceed with design using phasedistance ground overcurrent relaying rather than with the faster (and costlier) carrier current transfer trip relaying. This decision was reached because in the event of an electric outage on either the Midway or the Benton substation line feeders, it could not be cleared in less than $1 / 2 \mathrm{sec}$ even if transfer trip relaying were used. Calculations have shown that if one primary pump loses electric power for more than $1 / 3 \mathrm{sec}$, fuel cladding temperatures will rise to exceed the allowable limit of $1200^{\circ} \mathrm{F}$. Thus, restoration of power is required within $1 / 3 \mathrm{sec}$ to obviate the need for a scram. Since this cannot be accomplished in less than $1 / 2 \mathrm{sec}$, even with the more rapid relaying scheme, there is no incentive to assume the extra cost.

A small amount of additional protection could be provided for the 115 to $13.8 \mathrm{kV}$ transformers by a transfer trip relaying scheme, but the disparity of cost versus additional protection provided is too great.

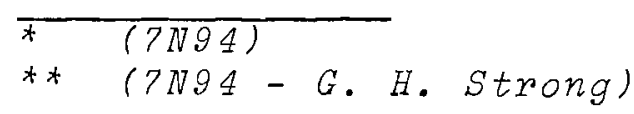


3. Neutron Radiography

W. S. Chenault,* D. J. Meyers*

An evaluation of technical and cost incentives for substituting sources other than a reactor for neutron radiography was completed by BNW. As a result of the evaluation, BNW from a technical standpoint - still supports its recommendations (Monthly Technical Progress Report, May 1969, BNWL-1097) that a reactor be installed for neutron radiography. In view of the desirability to reduce costs, BNW agreed with the decision to defer neutron radiography and make design provisions for possible future installation of a neutron radiography reactor.

4. Development Facilities

H. Leigh**

a. Hydraulic Core Mockup

Final negotiations with Atkins and Merrill for the HCM $1 / 2$ scale model contract have been completed and the contract is now in the AEC approval process.

b. FFTF Sodium Facilities - 335 Building

Construction work is continuing on the building for FFTF Sodium Facilities. The $100 \mathrm{ft}$ by $60 \mathrm{ft}$ building and the personnel area are completely erected and work is progressing on the interior of the building and on service tie-ins. The outdoor switchgear has been received and set on the concrete transformer pad.

c. LMFBR Core Segment Development Facility

Design work by Vitro Engineering is continuing on the LMFBR Core Segment Development Facility and is about $60 \%$

\footnotetext{
* (7N94-C. L. Boyd)

* (7N95 - K. G. Toyoda)
} 
complete. Reviews of the worksheet and comment drawings are being made to ensure that design effort is being optimized.

d. Fast Reactor Thermal Engineering Facility

The design of the Fast Reactor Thermal Engineering Facility is currently $25 \%$ complete.

\section{TABLE 2.I. Current Design Data}

Summary of Principal Concept Characteristics and Data as of 9-22-69-C. W. Higby*

Units

Values

$\underline{\text { Status }^{(a)}}$

A. General Plant Data

1. Core Arrangement

2. Design 1ife

years

vertical

1

3. Peak flux

$\mathrm{n} / \mathrm{cm}^{2}-\mathrm{sec}$

20

1

4. Total power,

initia1

$\mathrm{MW}_{t}$

$7.2 \times 10^{15}$

2

initial

5. Reactor coolant

400

1

6. Core volume

sodium

1

7. Total reactor flow

liters

1033

2

$\mathrm{ga} 1 / \mathrm{min}$

42,240 initial

43,290 ultimate

2

8. Reactor pressure drop design maximum

9. Reactor bulk inlet tempera-

ture initial

ultimate

10. Reactor bulk out-

let temperature

initial core

${ }^{\circ} \mathrm{F}$

850

1

design maximum and ultimate

(7N95)

(a) 1 - Firm requirement or definite concept characteristic. 2 - Current reference design value. 
TABLE 2-I. (contd)

Units Values Status (a)

11. Core tempera-

ture rise

$$
\text { average initial }
$$

ultimate

design maximum

12. Reactor cover gas

B. Reactor Vessel

1. Diameter

2. Height

3. Wall thickness

4. Wall fluence, total (at $1000^{\circ} \mathrm{F}$ )

5. Material

C. Core Design

1. Number of core lattice positions

2. Number of driver fuel subassemblies

${ }^{\circ} \mathrm{F}$
${ }^{\circ} \mathrm{F}$
${ }^{\circ} \mathrm{F}$

$$
300
$$

1

350

1

400

1

$$
\text { argon }
$$

1

$\begin{array}{lll}\text { feet } & 17 & 2 \\ \text { feet } & 50 & 2 \\ \text { inches } & 2 & \\ \text { nvt } & 2 \times 10^{22} & 2 \\ & 304 \text { SS } & 1\end{array}$

3. Number of closed 10op positions

91

1

$76-2$

6

2

4. Number of contact instrumented in-core open test positions

5. Number of proximity instrumented open test positions

6. Number of in-core safety rods

7. Number of in-core control rods

8. Number of periphera 1 control rods

9. Equivalent core diameter

inches

$\sim 48$ 


\section{TABLE 2-I. (contd)}

10. Active core height

11. Radial reflector material

12. Reflector thickness

$$
\text { axia } 1
$$$$
\text { radia } 1
$$

13. Fuel pin heat transfer area

14. Core coolant velocity, maximum

15. Direction of coolant flow

D. Driver Fuel

1. Fuel composition

2. Cladding material

3 . Linear heat generation rate, average (at $90 \%$ total power)

4. Overpower factor

5. Peak linear heat generation at overpower (at $90 \%$ total power)

6. Target burnup, average

7. Cladding heat transfer coefficient

8. Maximum fuel temperature (steady state)

9. Fue 1 assembly length

$\frac{\text { Units }}{\text { inches }}$

$\frac{\text { Values }}{36}$

$\frac{\text { Status (a) }}{2}$

nicke 1

2

inches

rows

6

2

3

2

$f t^{2}$

2980

$\mathrm{ft} / \mathrm{sec}$

30

2

upward

1

18 to

26 wt\%

$\mathrm{PuO}_{2}$

74 to

$82 \mathrm{wt} \mathrm{UO}_{2}$

Type 316 SS 1

$\mathrm{kW} / \mathrm{ft}$

7.0

2

1. 20

2

$\mathrm{kW} / \mathrm{ft}$

14.6

2

MWd/tonneM $\quad 45,000$

2

$\mathrm{Btu} / \mathrm{hr}-{ }^{\circ} \mathrm{F}-$

$\mathrm{ft}^{2}$

37,500

2

${ }^{\circ} \mathrm{F}$

4230

2

feet

12

2 
TABLE 2-I. (contd)

\begin{tabular}{|c|c|c|c|c|}
\hline & & Units & Values & Status (a) \\
\hline 10. & Fuel geometry & & $\begin{array}{l}\text { Hexagonal } \\
\text { pin cluster }\end{array}$ & 1 \\
\hline 11. & Pin diameter & inches & 0.230 & 2 \\
\hline 12 . & $\begin{array}{l}\text { Spacer wire } \\
\text { diameter }\end{array}$ & inches & 0.056 & 2 \\
\hline 13. & $\begin{array}{l}\text { Number of pins } \\
\text { per assembly }\end{array}$ & & 217 & 2 \\
\hline 14. & $\begin{array}{l}\text { Subassembly cross- } \\
\text { section outside } \\
\text { dimension (across } \\
\text { flats) }\end{array}$ & inches & 4.615 & 2 \\
\hline 15. & Lattice spacing & inches & 4.715 & 2 \\
\hline 16. & Duct wall thickness & inches & 0.140 & 2 \\
\hline
\end{tabular}

E. Physics Data

1. Delayed neutron fraction

2. Neutron lifetime

3. Doppler

$\begin{array}{lll} & 0.003 & 2 \\ \text { seconds } & 4.0 \times 10^{-7} & 2 \\ \text { T (dk/dt }) & -0.004 & 2 \\ \text { MW/1iter } & 0.75 & 2 \\ & & \end{array}$

4. Power density, peak

5. Power distribution (peak/average)

$\begin{array}{lll}\text { radial } & 1.40 & 2 \\ \text { axial } & 1.24 & 2 \\ \text { total } & 1.74 & 2\end{array}$

F. Test Facilities

1. Closed loops

- number of positions

$\begin{array}{ll}6 & 2 \\ 2 & \text { adjacent to } \\ \text { core center } & 2 \\ 1 & \text { at mid- } \\ & \text { radius } \\ 3 & \text { at core } \\ & \text { periphery 2 }\end{array}$


TABLE 2-I. (contd)

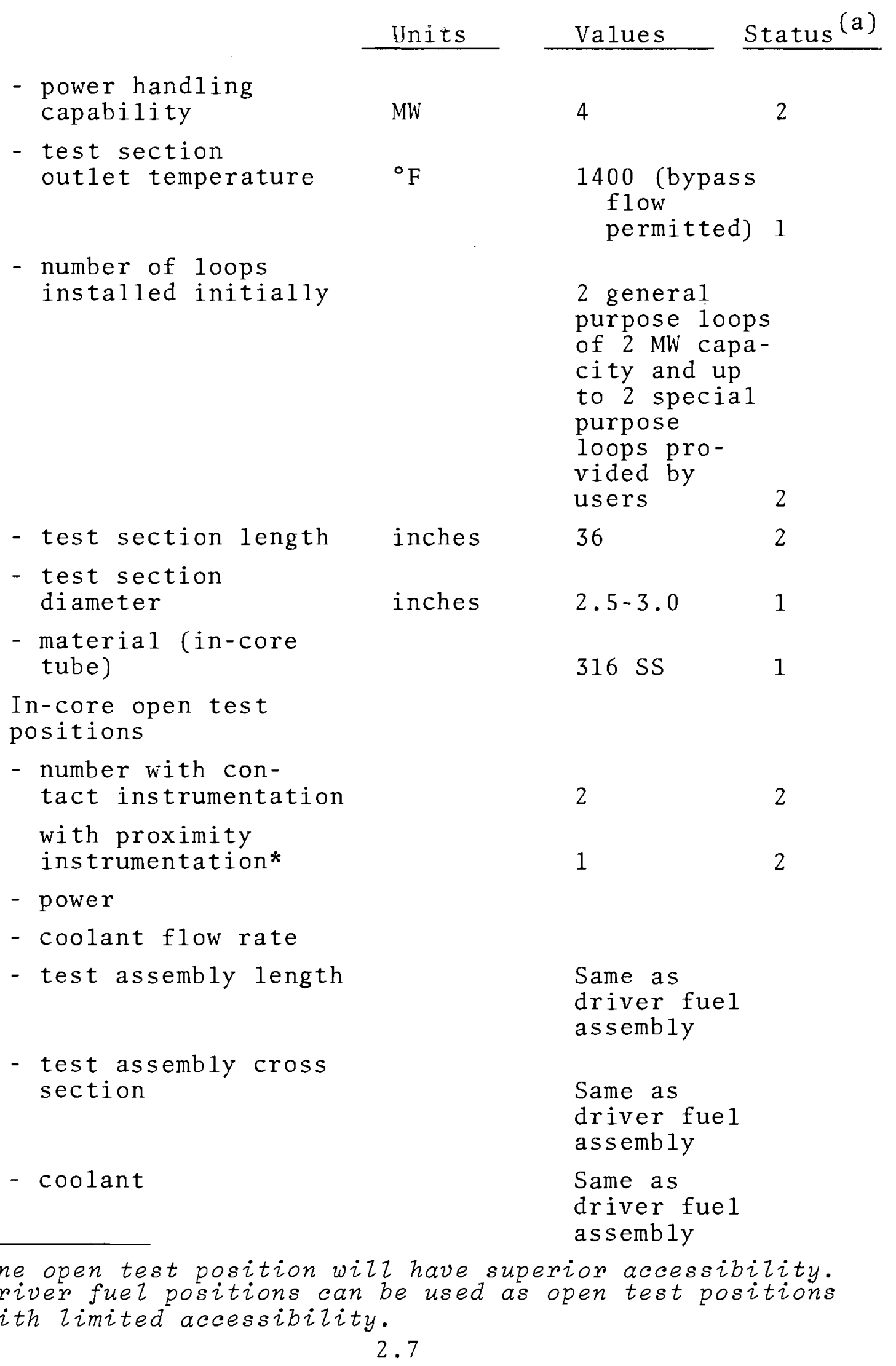


TABLE 2-I. (contd)

Units Values Status (a)

3. Short term irradiation

facility (capability

for future

insta1lation)

- type

- number

- location

- minimum irradiation time at constant f1ux minutes

trail cable 1

1

core

periphery 2

- sample length

inches

1

2

sample cross section, maximum

inches

24

2

2.5

2

G. Heat Transport System

1. Primary loops

- number

3

- primary loop material

304 SS

1

- primary loop flow (per loop) (initial)gal/min

14,080

2. Primary pumps

- number

- design flow rate gpm

3

1

- design pump head feet

14,500

1

- available net positive suction head feet

500

1

- design temperature ${ }^{\circ} \mathrm{F}$

51

1050

2

- speed control

wound rotor motor with

liquid

rheostat

- motor power

brake

HP

1800

2

rated

HP

2500

2 


\section{TABLE 2-I. (contd)}

Units Values Status (a)

3. Intermediate heat exchangers

- number

3

1

- type

- LMTD

initial

ultimate

${ }^{\circ} \mathrm{F}$

$85 \quad 1$

vertical

shell and

tube

1

- capacity

initial

MW

99.1

2

ultimate

MW

133

1

157

1

H. Shielding

1. Within reactor vessel

- material

stainless

stee 1

2

- configuration

hexagonal

assemblies 2

- thickness

rows

5

2

2. Cover shield

- material

low a110y stee 1

- thickness

feet of stee 1

4

2

- coolant

argon,

helium or

$\mathrm{Na}$

2 


\section{COMPONENTS}

\section{A. REACTOR COMPONENTS \\ 1. Vessel and Shield \\ o. W. Priebe}

Present preliminary design work by Westinghouse on the reactor vessel and shield is primarily devoted to revisions of the equipment specifications in preparation for contract negotiations for the reactor vessel, guard vessel, head, and associated equipment. These revisions are a result of engineering effort completed since the specifications were issued with the RFP.

The proposals received from Combustion Engineering Co. and Chicago Bridge and Iron have been evaluated and recommendations have been submitted to the Commission.

Design reviews are in progress to:

- Review the evaluation of alternative materials for the guard vessel;

- Review the revised equipment specifications;

- Review resolution of the vessel length and head depth;

- Review plans for resolution of the certified design criteria for vessels and head design;

- Review plans to promote vendor design; and,

- Review problems of design and fabrication and establish plan of action.

2. Shielding

a. Concept V-A Above-Core Shielding Calculations E. T. Boulette*

Two-dimensional diffusion theory calculations were made on Concept V-A to evaluate the adequacy of the shields specified in that design. All calculations were normalized to a $400 \mathrm{MW}$ two-zone core, and neutron flux intensities and spectra

* (7N81-W.L. Bunch) 
were calculated throughout the regions above the core midplane. Some of the calculated results are listed in Table $3 . I$.

\section{TABLE 3.I. Total Flux at Select Locations}

\section{Location}

Vessel wall at core midplane

Vessel wall at $\mathrm{Na}$ outlet

Vessel wall-cover intersection

Bottom of cover at core centerline $\frac{\text { Total Flux }\left(\mathrm{n} / \mathrm{cm}^{2}-\mathrm{sec}\right)}{2.3 \times 10^{12}}$

$6.0 \times 10^{7}$

$3.0 \times 10^{5}$

$2.0 \times 10^{5}$

These flux values satisfactorily meet the end of life fluence criteria for critical components.

b. FTR Radial Shield Alternatives

E. T. Boulette*

Shielding is required to protect the reactor vessel from excessive radiation damage and thereby ensure its structural integrity throughout the design lifetime of the facility. For a fixed diameter vessel, a number of radial shield concepts were examined to establish potential shielding fallback positions that might be employed. For a vessel $17 \mathrm{ft}$ in diameter, a 19.2-in. thick radial shield composed of 66 vol\% stainless steel and 34 vol\% sodium is calculated to be adequate. To meet more restrictive criteria, or to accommodate modifications in the design, it would be possible to employ more efficient shielding materials and/or to increase the shield thickness. Results of calculations for five fallback positions are given in Table 3.II, where a total fluence criterion is assumed to control. The 31.2-in. thick shield appears to be a reasonable maximum value for fixed storage locations in the annulus. Such a thickness might not be achievable if carrousel storage is employed.

* (7N $\overline{1} \overline{1-W \cdot L \cdot}$ Bunch $)$ 
TABLE 3.II. Possible Radial Shield Fallback Arrangements

Shield Arrangement

Base case - 19.2 in., 66 vol\% SS, 34 vol\% $\mathrm{Na}$

(1) 19.2 in., 75 vo $1 \%$ SS, vol\% $\mathrm{Na}$

(2) 19.2 in., 37.2 vol\% $\mathrm{SS}$,

35 vol\% $\mathrm{Na}, 27.8$ vol\% $\mathrm{B}_{4} \mathrm{C}$

(3) 31.2 in., 66 vol\% SS,

$$
34 \text { vo } 1 \% \mathrm{Na}
$$

(4) 31.2 in., 75 vo $1 \%$ SS, 25 vol\% $\mathrm{Na}$

(5) 31-2 in., 37.2 vo $1 \%$ SS, 35 vo $1 \% \mathrm{Na}, 27.8$ vo $1 \% \mathrm{~B}_{4} \mathrm{C}$
Calculated $\frac{20-\text { Yr Fluence }}{8.3 \times 10^{20}}$

$8.3 \times 10^{20}$

$6.8 \times 10^{20}$

$5.3 \times 10^{19}$

$1.8 \times 10^{20}$

$1.3 \times 10^{20}$

$2.8 \times 10^{18}$
Relative Lifetime

1

1.2

15.7

4.6

6.4

296.4

\section{Reactor Nuclear Control Mechanisms}

a. Roller Nut CRDM Testing at LMEC

J. C. Noakes*

The revised Test Request was accepted by LMEC, and LMEC's Test Plan was submitted to RDT. The test facility modifications at LMEC have been started in preparation for the experiment.

To supplement the results of the above CRDM testing, a series of tests at Galveston (Todd Shipyards) were proposed to evaluate the drive in an argon gas environment. Three tests at different drive line loads are planned.

b. CRDM Independence Study

P. K. Telford*

The final report on the CRDM Independence Study recommending a single drive design for use on the FTR was received from WARD. The report is currently under review by BNW.

* (7N91-C.A. Munro) 
4. $\quad$ Fue 1 Ducts
a. Duct Procurement Activities
R. N. Johnson*

Contract negotiations have continued with the two vendors selected on the basis of their proposals for the fabrication of prototype fuel ducts. Substantial progress has been made in achieving cost reductions over the original estimates, but final cost figures are not yet available from one vendor. Additional information was requested from both vendors, and final negotiations can proceed when this information becomes available.

In meetings with Westinghouse at Waltz Mil1, BNW obtained the RPD's concurrence with the present duct design, (drawing SK-3-15149) for development purposes, and established a design input schedule by which Westinghouse will determine the complete prototype duct design by January 15, 1970. Fabrication of Phase II ducts will not begin until that design is available. (Phase I involves the development of fabrication procedures and techniques for attaching wear pads; Phase II is the demonstration of the vendors capability to produce the prototype ducts on a production basis.)

b. Duct We1ding Development

R. N. Johnson* and W. F. Brown**

(1) Automatic Welding System. The conceptual design for an automatic welding head capable of welding hexagonal sections is approximately $95 \%$ complete. Detail design was started and is approximately $25 \%$ complete. Hardware fabrication started the third week of September. The welding power supplies and electronics for this system are on order.

$*(7 N 96)$
$* *(7 A 00)$




\section{B. HEAT TRANSPORT SYSTEM COMPONENTS}

1. Intermediate Heat Exchangers

L. A. Whinery*

a. Babcock and Wilcox Studies

The Babcock and Wilcox Company has essentially completed their IHX design study effort. They are presently preparing a final report which is scheduled for completion and submittal by october 15. The Babcock and Wilcox preferred concept is a vertically-mounted unit featuring a straight-tube bundle with floating lower head to accommodate differential thermal expansion between tubes and she11. The tube bundle is removable for maintenance and is also arranged to permit in-place tube plugging using an explosive welding technique. Babcock and Wilcox concludes that this concept offers significant cost savings over the alternative helical coil tube bundle configuration which they have also investigated as a backup design.

During the 1 ast technical progress review meeting, Babcock and Wilcox verbally recommended the following major development programs in support of their IHX concept:

- Flow model testing to verify uniformity of both primary and secondary flow distribution.

- Model testing to ensure acceptable tube vibration limits.

- Experimental testing to verify structural design analysis related to potential tube buckling induced by radial temperature gradients across the bundle diameter.

- Development testing to demonstrate acceptability of explosive welding for tube plugging.

Babcock and Wilcox has reported that they do not currently believe that sodium proof testing of a 35 -MWt test unit at the SCTI will materially improve performance risks for the FFTF IHX's.

* (7N92-T.W. Withers) 


\section{b. Ward and Foster Wheeler Studies}

The LMFBR low capacity IHX design studies being performed by Westinghouse (WARD) and Foster Wheeler (FW) are progressing essentially on schedule. Final reports are expected by November 15, 1969, from FW and by January 15, 1970, from WARD.

Work during the past month has been devoted mainly to tasks associated with mechanical design details, hydraulic/vibration studies and preliminary stress analysis. Both contractors have resolved definitive concepts for use as a basis to proceed with the design studies. Foster wheeler has prepared and submitted a guideline IHX specification for informational use by the Reactor Plant Designer (RPD). A similar specification will be submitted by WARD by October 15, 1969.

A November 1, 1969, completion schedule has been established for W (RPD) preparation of an IHX procurement specification for the FFTF units.

2. $\quad$ Pumps

W. Babcock*

Final reports have been received for the Westinghouse Phase II Low Capacity Pump Study. Evaluation of these reports is in progress.

A task force composed of BNW, Westinghouse, (RPD), and LMEC members met at Waltz Mill on September 4, 5, and 6 to finalize the RDT pump standards and specifications for the LMFBR Low Capacity Sodium Pump, the FFTF primary and secondary pumps, and the specifications for test bearings and seals. These standards and specifications were completed and agreed upon and are being transmitted to RDT for approval. The schedule date for distribution to potential suppliers of the RFP package is Ocotober 15 , 1969 .

* (7N92-T.W. Withers) 


\section{Overall Heat Transport System}

J. P. Petrek*

Sections 2 through 5 of the Heat Transport System CSDD-51 was completed. A copy of the document was sent to Westinghouse for review and comment by october 1 . Westinghouse review will determine if the reference concept meets the baseline requirements set forth in Section 1.0 of CSDD-51.

4. Dump Heat Exchanger Analys is

R. N. Madsen**

The DHX simulation study is nearly complete with the study of mode1 performance at highly unbalanced flows. Comparisons of the 4-node, 6-node and 12-node model with the TAP reference model have been made for a number of cases.

The improvement in the distribution resulting from more nodes is evident. However, there is very little deviation from the reference exit temperatures in any of the simple models. 5. Sodium Hammer Analys is

J. E. Krajicek**

The digital computer program WHAM (Water Hammer - Advanced Mode1) has been obtained from the Argonne Code Center to determine if it is capable of being used for FFTF sodium hammer analysis. Several executions of the WHAM code have been made for simple problems using sodium properties, and it appears that it is possible to use WHAM. Modifications must be made to the check valve and pump subroutines, but a large amount of time will not be required before useful information can be obtained. It is anticipated that some analysis will be completed by the next report period.

\footnotetext{
* (7N92-T.W. Withers)
}

** (7N82-H. G. Johnson) 



\section{INSTRUMENTATION AND CONTROL}

A. CONCEPTUAL DESIGN

1. Plant Instrumentation

M. O. Rankin*

The Conceptual System Design Description (CSDD) for Plant Instrumentation (System 93) was revised to satisfy comments from RDT and to incorporate suggestions made by Bechtel in their Conceptual Design Support Document for that system (BCL-368). The principal changes made in the CSDD are:

- Where requirements were previously imposed on the Plant Protection System (System 99), they have been replaced by references to the CSDD for System 99.

- Plant Protection System signals originating from Plant Instrumentation System components are clearly identified.

- Concept changes have caused the Non-Irradiated Fuel Handling System (System 42) to be deleted. Therefore plant instrumentation serving that system has also been deleted.

- The Irradiated Fuel Handling System (System 43) has been incorporated into the Reactor Refueling System (System 41). This change is reflected in the Plant Instrumentation serving System 41 .

- Bechtel's report No. 74, Instrument Grounding, was added as an Appendix to this CSDD. This report defines grounding procedures and practices, but does not alter the Plant Instrumentation System concept in any way.

- A study on the feasibility of using Venturi tubes for flow measurement and calibration in the Primary Heat Transport System was included as an Appendix to this CSDD.

* (7N93-J.W. MitcheZZ) 
This study does not recommend use of Venturi tubes. It suggests that a study be made of an alternative method whereby magnetic flowmeters and pump speed (tachometers) can be correlated for flow measurement and calibration using "bootstrapping" techniques.

- Requirements were added for surveillance instrumentation on pipes, vessels and sodium components.

2. Reactor Instrumentation

The Conceptual System Design Description for the Reactor and Vesse1 Instrumentation System (System 92) was sent to RDT on $8 / 29 / 69$. This document was revised to satisfy comments from Westinghouse and RDT.

B. FAILED FUEL DETECTION AND LOCATION

1. Failed Fuel Location by Xenon Gas Tagging

C. R. F. Smith** and 7N00-7C00

An evaluation was completed on the Xenon Gas Tagging concept for location of failed fuel in the FTR. (This concept is currently under development at ANL-Idaho for use in the EBR-II Reactor.) In this concept about $1 \mathrm{~cm}^{3}$ of mixed isotopes of $x e$ is implanted in each fuel pin along with the helium fillgas. Xenon tags of identical istotopic composition are implanted in each pin within a given subassembly. The tag associated with each subassembly must be distinguishably different from that in any other subassembly in the reactor. Some independent means (such as fission gas detection) is required to annunciate fuel failure. When a fuel pin fails, part or all of the xenon tag is released to the sodium coolant stream whence it finds its way into the reactor cover gas plenum. When fuel failure is annunciated, a fraction of the cover gas is passed through a cooled charcoal bed designed to absorb the xenon constituent. Subsequently, the xenon is desorbed from * $(7 N 93-R \cdot R$. Cone $)$ 
the charcoal and directed to a mass spectrometer which measures the isotopic composition of the gas. The isotopic ratios of certain light xenon nuclides identify the subassembly containing the failed fuel pin.

Following are the major conclusions resulting from the evaluation of this concept:

- Xenon tagging is a feasible concept for locating failed fuel in the FTR. However, it will not infallibly locate all failed fuel under all circumstances. For example:

a. In the event of two or more nearly-simultaneous failures in different subassemblies, xenon tagging cannot be used to identify the failed subassemblies.

b. Failed fuel location by xenon tagging is not feasible where the reactor is deliberately operated with failed or vented fuel.

c. Xenon tagging is not a reliable concept for locating failures if fuel swelling inhibits the diffusion of tag gas throughout the fuel pin. Further analyses and experiments are required to establish the importance of this mechanism.

On balance, however, the xenon tagging concept is attractive because it is simple in design and operation, and it requires negligible in-vessel plumbing. It is also low in capitalcost because the cost of the tag and the cost of implanting the tag are not capital-cost items.

- The xenon isotopes which qualify for tagging are ${ }^{124}$ Xe, ${ }^{126} \mathrm{Xe}$ and ${ }^{129} \mathrm{Xe}$. The fission yield of ${ }^{128} \mathrm{Xe}$ in the FTR fuel precludes its use as a tagging isotope. It is recommended that ratios of ${ }^{129} \mathrm{Xe} /{ }^{124} \mathrm{Xe}$ and of ${ }^{126} \mathrm{Xe} /{ }^{124} \mathrm{Xe}$ be used as the basis for tags. Should it be necessary to implant a given tag ratio in more than one subassembly, then the measurement of the ${ }^{128} \mathrm{Xe} /{ }^{124} \mathrm{Xe}$ ratio can be used to identify the age (cumulative exposure) of a failed pin. Thus, ${ }^{128} \mathrm{xe}$ can be used to extend the number of useful tags. 
- Isotopic burnup is the principal determinant in establishing the number of unique tags which can be synthesized from available xenon mixtures.

- The maximum number of unique tags which can be synthesized (for FTR conditions) by utilizing only the ${ }^{129} \mathrm{Xe} /{ }^{124} \mathrm{Xe}$ ratio is estimated to range from 37 to 200. A closer estimate requires a more precise calculation (or measurement) of spectrum averaged cross sections of the xenon isotopes.

- The Xenon Tagging Concept can be used to locate a failed fuel before an appreciable fission product inventory is generated in a fue 1 pin providing the reactor cover gas is analyzed routinely for xenon isotopes following a fuel loading. Of a11 fuel failure location concepts, Xenon Gas Tagging is unique in this respect.

- The presence of xenon contamination in the cover gas may tend to mask the identity of a released tag unless both the xenon isotopic ratio and the xenon concentration in the cover gas is accurately measured both before and after the fuel failure event. It is not known at this time whether xenon contamination might prove to be a real problem in actual practice.

Fission Gas Detector Evaluation Report

W. Dalos* and 7MOO

A draft was completed of a BNW laboratory study comparing the sensitivity of GM tubes, gamma energy detector-analyzers, and charged wire detectors in detecting gamma-ray activities. The intent of this study was to determine which of the three detection methods should receive development testing effort. However, as a result of this study, no single method can be recommended for additional development effort at this time.

$\bar{*}(7 \mathrm{N93}-R \cdot R \cdot$ Cone $)$ 
This results from the many assumptions which were required and to certain unknown factors (such as fissile contamination in the coolant) which cannot be confidently estimated. Efforts are being made to establish a minimum gamma-ray activity detection limit. This, in conjunction with the fission gas detector study, will aid in identifying development problems.

C. ELECTRICAL INSULATORS FOR SENSORS AND CABLES

D. C. Thompson* and J. L. Stringer**

1. Dependence of Electrical Conductivity of Cable

Insulation on Reactor Power Level (at Constant Temperature)

During the month, the data analysis for the TRIGA test on Mgo insulated coaxial cables was completed. This test was conducted to determine the dependence of the insulator conductivity upon the peak reactor pulse power and insulator temperature. The lower level dependence measurements at $92^{\circ} \mathrm{F}$ and $1350{ }^{\circ} \mathrm{F}$ showed that the insulator conductivity increases linearly with reactor power at constant temperature over the temperature range from $92^{\circ} \mathrm{F}$ to $1350^{\circ} \mathrm{F}$. This increase results primarily from the effect of gamma radiation on the insulator.

2. Dependence of Electrical Conductivity of Cable Insulation on Temperature (at Constant Reactor Power Level)

The second part of the test measured the temperature dependence of the induced $\mathrm{MgO}$ insulator conductivity at a nominal reactor peak pulse power of $1500 \mathrm{MW}$ and at temperatures of $1350,700,525,425,365$, and $92^{\circ} \mathrm{F}$. This choice of temperatures gives data points which are approximately equally spaced on the reciprocal temperature scale. These data and the data from the August 1968 TRIGA tests show that insulator conducttivity increases by a factor of about two at constant reactor power as temperature increases from 92 to $1200^{\circ} \mathrm{F}$. It should be noted, however, that the rate of change of conductivity increases sharply above $700^{\circ} \mathrm{F}$. 
BNWL - 1217

\section{REMOVABLE DRIVER FUEL INSTRUMENT ASSEMBLY}

J. W. Kolb*, B. G. Smith*, L. R. Besel*, R. F. Gilmore* and $7 \mathrm{C} 11$

The purpose of this work is to determine by simulation testing, the feasibility of the proposed Concept V-B Driver Fue 1 Instrument Assembly design with regard to installation and removal from the reactor.

The function of the instrument assembly is to measure flow and temperature of the sodium at the outlet of the driver fuel duct. Should a single malfunction occur in the instrument package, the total assembly must be capable of replacement.

Figure 4.1 shows the specimens that were fabricated for testing. The instrument assembly simulation consists of a dummy flow meter and thermocouple assembly separated by a ball socket joint and five tubular links connected together with ball joints. A total of eight stainless steel clad, magnesium oxide insulated leads run up through the center of the tubular links. The leads are fixed on the probe end and free to slide axially on the upper end. The guide tube was made from nominal 2.375-in. OD $\times 0.154$-in. wall stainless steel with 36 -in. radius bends .

Results obtained were in the range of one to four pounds of friction drag. While these test values cannot be directly extrapolated to determine the total forces that would be acting on a full length assembly passing through multiple guide tube bends, the proposed design concept appears to be sound. The loads encountered during installation and removal of the instrument assemblies should be handled adequately by conventional means. Planned sodium environmental testing of the entire instrument assembly and complete guide tube will establish the requirements for an installation assist device should this be needed.

$\bar{*}(7 N 91-C \cdot A$. Munro $)$ 


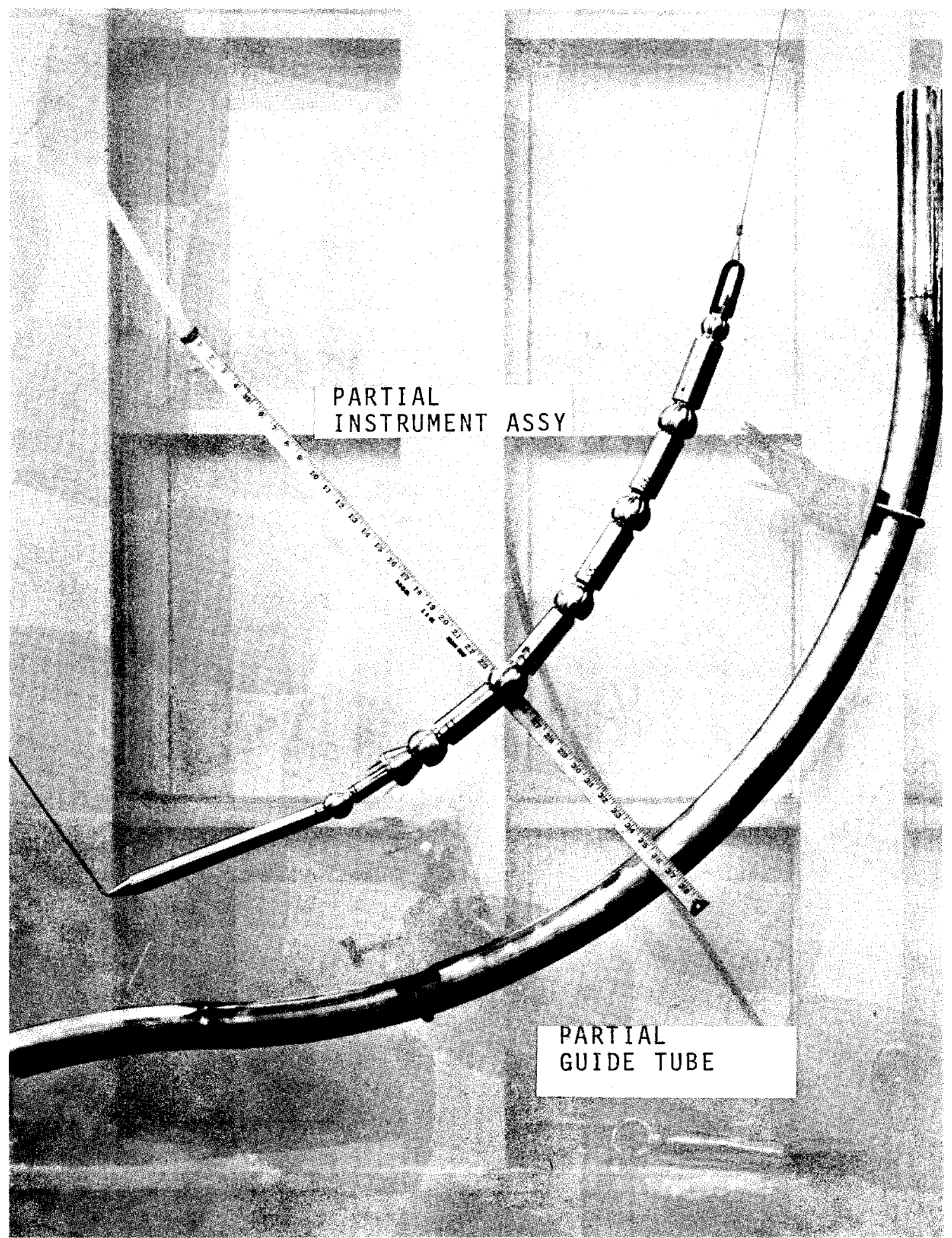

Neg 693375-2

FIGURE 4.1. Simulation of Removable Driver Fuel Instrument 
$+$

.

• 


\section{SODIUM TECHNOLOGY}

A. COVER GAS STUDIES

W. R. Wykoff*

1. Cover Gas Impurity Reactions over Sodium

G. B. Barton,** H. P. Maffei**

The objectives of this activity are to establish cover gas purity specifications for each gas application in a sodium reactor, to determine that the gas purity can be produced, and to define the design criteria for special purity requirements.

Measurements of the hydrogen concentrations in the cover gases of a sodium system are usually made either on grab samples or on samples drawn to an in-line instrument through small sample lines. Neither method has resulted in a quantitative hydrogen analysis, because the hydrogen interacts with sodium vapor.

Development has been started on a detector which is capable of measuring hydrogen concentrations directly in the gas plenum. It is based on the selective diffusion of hydrogen through a nickel membrane followed by the oxidation of the hydrogen to water and quantitative measurement of the generated water. A $0.50-$ in. diameter nickel tube with a $9 \mathrm{mil}$ wall thickness is being used in the first development model. A mixture of $8 \%$ oxygen in nitrogen is being used as the oxidizing gas.

Initial results prove the technical feasibility of the new probe. One test using a $100 \mathrm{ppm}$ hydrogen standard produced an apparent 75 ppm moisture monitor response. 
Selection and Testing of Cover Gas Instruments and Sampling

Systems

G. B. Barton, *H. P. Maffei*

The objective of this activity is to provide proven sampling and analysis equipment and technology for the cyclic on-1ine monitoring of impurities, including fission gases, in the FFTF sodium cover gas.

The prototype sodium vapor trap described in last month's report has been completed and laboratory evaluation has been initiated. Temperature profiles have been measured with 13 and 19-in. packing lengths and adjustments made to match the measured values with the desired values. Problems were encountered matching the desired values in the entrance region. As soon as these are overcome, trap performance characteristics will be measured.

B. IN-LINE SODIUM INSTRUMENTATION

W. R. Wykoff, ** W. H. Kaplinger,* J. J. McCown*

Work has begun on the design of an integrated instrument package containing carbon, oxygen and plugging meters. The design will incorporate al1 of the features needed for use on the FFTF i.e., size power requirements, on-1ine calibration and probe replacement equipment. This prototype instrument package will be used on the Prototype Applications Loop (PAL) and the Sodium Chemical Technology Facility (SCTF).

$* \quad(7 A 00)$
$* *(7 N 92)$ 


\section{SODIUM FACILITIES OPERATION}

J. G. Berg* and L. J. Defferding**

The objectives of this section and description of equipment were given in BNWL-915(1) and BNWL-1062(2). The status of the sodium facilities is given in the tabulation below:

Sma11 Component

Evaluation Loop

This loop has remained shut down since discovery of the failed EM pump braze joint on 7-21-69 (reported last month). A replacement pump was obtained from excess CANEL equipment. This pump was disassembled and found to be unacceptable for service. The buss braze joints were dye penetrant checked and found to be cracked. General appearance of the entire pump showed extreme use with charred coils and highly oxidized conductors. A new pump throat has been ordered. Meanwhile, the test fuel subassembly (7-pin loose wire wrap) has been removed from this $100 \mathrm{p}$ and installed in the Small Heat Transfer Loop for continued testing.

Sma11 Heat

Transfer Loop

After completion of the flow meter test last report period, the test flow meter was removed from the loop and returned to the test sponsor for shipment to LMEC for calibration. Loop instrumentation was calibrated prior to retesting of the first 7-pin electrically heated simulated fuel assembly. The test consisted of isothermal runs before and after tests where power was.

\footnotetext{
* (7N95-K.G. Toyoda)

$* *(7000)$ 1. FETF Monthly Informal Technical Progress Report BNWL 915.

2. FFTF Montriy Informal Technical Progress Report. BNWL 1062 .
} 
applied to the assembly. The power tests included twenty runs at various flows and power settings up to $26 \mathrm{GPM}, 200 \mathrm{~kW}$ and a sodium temperature of $900^{\circ} \mathrm{F}$ out of the test section. The loop functioned properly with no difficulty encountered in dissipating the $200 \mathrm{~kW}$ of heat in the heat dump section. Tests were completed 8-29-69. The electrically heated fuel assembly has been removed from the loop and replaced by the 7 -pin loose wire wrap fuel cluster (from Small Component Evaluation Loop) test. The loop will be returned to operation at required test conditions for this fretting corrosion study.

Static Sodium

Pots

Testing of the pressure transducers in pots 3 and 4 continued without interruption throughout this report period. The test transducer which was installed in static pot No. 1 last month underwent testing on 8-19-69. On 8-22-69, the cartridge heaters on this pot failed, terminating this test. While attempting replacement of the failed heaters, it was discov :d that one had swelled and could not be removed from the thermowell. To compensate, a large capacity heater was installed in the other thermo well. Meanwhile, an alternative design for heating these vessels has been completed. The new design utilizes the spare Conoseal on top of the pot for a new thermowell installation. This design will permit heater replacement regardless of swelling or heater failure (if necessary, the thermo well can be replaced).

Sodium Purification

Loop

Operation of this loop was interrupted three times during this reporting period--first, for recharging 
the expansion tank with sodium from a shipping container, and on two other occasions to exchange sodium inventories with the Fission Product Screening Loop. Following each of these rechargings, the system was cold-trapped down to minimum oxygen levels. Other than the above interruptions, this loop has remained in service throughout this report period.

Fission Product

Screening Loop

This loop was started up on 8-1-69 in preparation for testing of candidate bellows seal valves (to evaluate cleaning processes reported last month). Following startup, sodium samples were removed for chemical analysis to verify that the system bulk sodium met the test requirements of oxide and carbon content $(<20$ ppm) prior to achieving test conditions. This sodium was not acceptable (oxygen $>20 \mathrm{ppm}$ ). A transport line was installed between the Fission Product Screening Loop and the Sodium Purification Loop and sodium inventories of the two systems exchanged twice. Samples taken following each transfer were still too high to meet the test condition requirement of $<20 \mathrm{ppm}$. Consequently, the decision was made to shut down the Fission Product Screening Loop and install the planned cold trap assembly to permit purification in place.

Mechanica 1

Properties Loop

Fabrication of the test section is complete and "tiein" of the test assembly to the loop is underway. Following completion of this work, it is planned to start up the loop for checkout of this new assembly. The design effort required for unattended operation is $90 \%$ complete. 
Sodium Cleaning

Facility

The equipment for this facility has been acquired.

Installation of the equipment will be delayed until modification to $3718-\mathrm{F}$ is complete. The modification will be started as soon as FY-70 capital work order funds are released.

Portable Sodium

Me1t Station

A mobile hoist, a scale, and drum heaters, which make up the primary items for a melt station, have been purchased. The design of the melt station incorporating these items is in progress.

Sodium Facilities Building (335 Bldg.)

A master Critical Path Method (CPM) schedule for moving the Small Components Evaluation Loop, Small Heat Transfer Loop, and the Static Sodium Pots, into the 335 Building is complete. Movement of the facilities, which is controlled by the availability of the 335 Building, would start no er than 10-15-69 and be completed by 12-15-69. 


\section{CORE DESIGN}

A. CORE CONCEPTUAL DESIGN AND DEVELOPMENT

1. Nuclear Control Component Poison Tip Design

D. Marinos,* H. C. F. Ripfe1*

A design review held with Westinghouse has resulted in an agreement to use $\mathrm{B}_{4} \mathrm{C}$ as a poison material in the FFTF.

The dominating aspect for the decision to adopt $\mathrm{B}_{4} \mathrm{C}$ as a reference poison material was that the control system must be consistent with the flux and power goals of the FTR. While reactivity worth requirements could be met without utilizing enriched $\mathrm{B}_{4} \mathrm{C}, \mathrm{flux}$ and power objectives are unattainable with the large number of control rods required. A mixed system, which would consist of control components containing $\mathrm{B}_{4} \mathrm{C}$ as a poison material and others containing tantalum, is precluded for the same reason. A maximum Ta volume design (65\% volumetric efficiency) would be equivalent to the worth of $\mathrm{a}_{4} \mathrm{C}$ component containing natural (not enriched) boron.

\section{Core Support}

J. F. Wett**

BNW and WARD established a procurement schedule for the reactor core support component. The schedule results in planned release of an RFP to bidders by December 9, 1969 and contracting for the structure by March 10, 1970. In order to meet this schedule, WARD must submit the design of the core structure to BNW for review by October 14, 1969.

3. Core Radial Restraint Testing Requirements G. R. Waymire,* C. A. Munro**

Meetings held between Westinghouse and BNW have resulted in an agreement on testing required in support of the radial restraint system design.

*(7N81-D. Marinos)
$* *(7 N 91-R \cdot$ C. Walker $)$ 
Several design options were investigated including a planar bridging model (which could be provided on an accelerated time scale) and a full size core simulator.

Although the planar model (CRM-1) would provide data in the shortest possible time, it would leave unanswered the effect of three-dimensional interaction.

The initial conceptual simulator design utilizes a $1 / 3$ core sector, additional analysis and discussions have indicated that to determine the desired sequence of loading and problems associated with bridging, a full core design is required. The proposed model is therefore being expanded into a full core design.

4. Core Outlet Region Tests

H. Leigh,* J. Spalek,** L. R. Sweetin,** G. W. Riedeman,**

D. L. Ballard,** P. M. Jackson**

Installation of the upper pool hardware in the $1 / 3 \mathrm{size}$ outlet region mode 1 has been completed. The model now contains simulated control rods, instrument leads, instrument trees with support plates, and fuel handling machines. These are shown in Figure 6.1, a view of the model internals hoto PNL 0693607-1).

Figure 6.2 is a view of the external features of the model showing the vessel, observation ports, dye and electrolyte injection manifold, outlet piping, and access platform (Photo PNL 0693324-2). Initial qualitative tests were performed. With the internal hardware installed, outlet nozzles at the instrument probe outlet elevation, and pool level equivalent to $20 \mathrm{ft}$ in the reactor, it was observed that the pool surface was agitated at $3600 \mathrm{gal} / \mathrm{min}$. The center "hump" and sloshing was very slight ( $\sim 1-i n$. in the model, hence, about 3 -in. in the reactor) indicating that impingement on the vessel cover will not occur in the reactor if the gas space is one foot or greater. Gas entrainment was negligible in the pool. At the model flow rate * (7N95-K. G. Toyoda) 


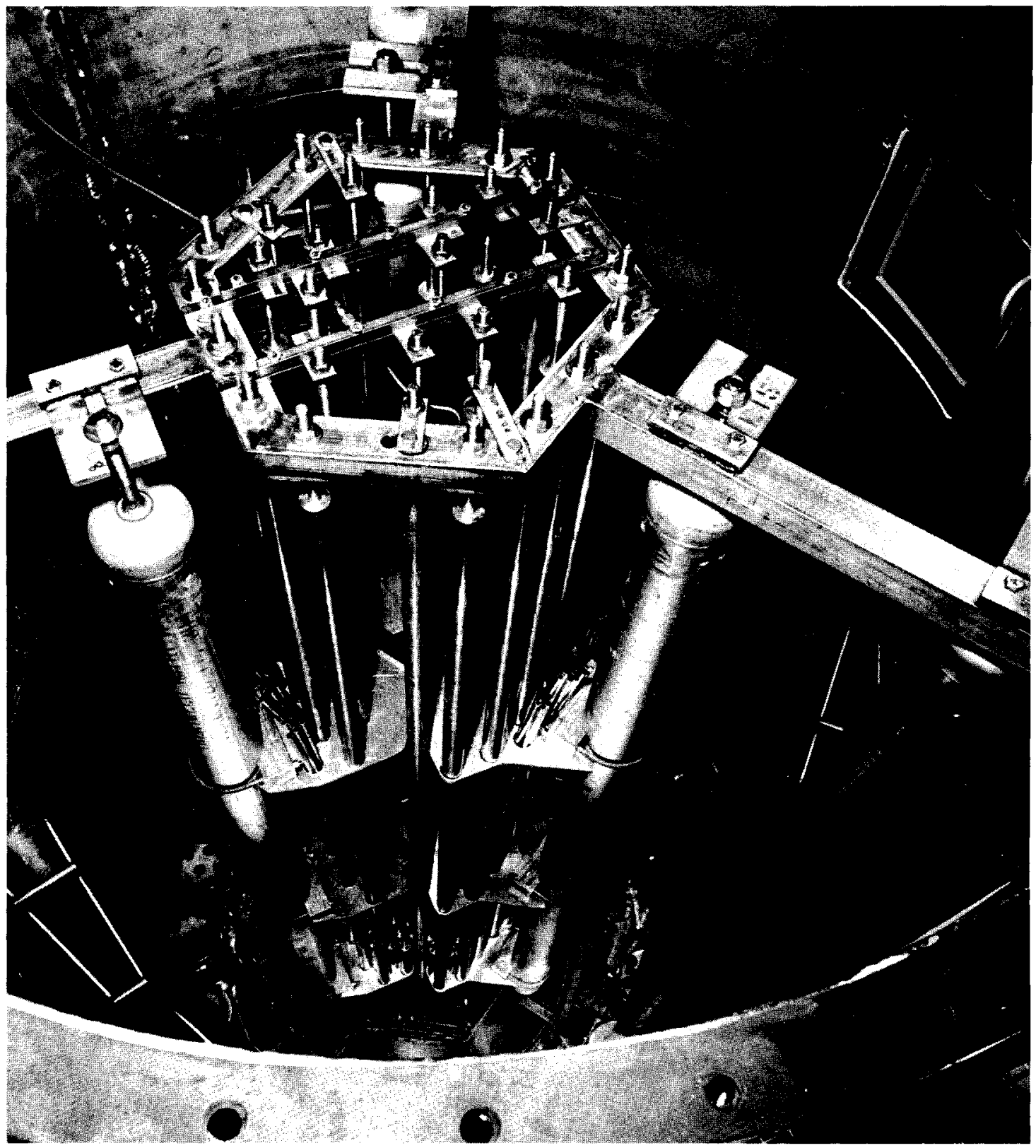

Neg 0693607-1

FIGURE 6.1. Internal View of Core outlet Region Model 


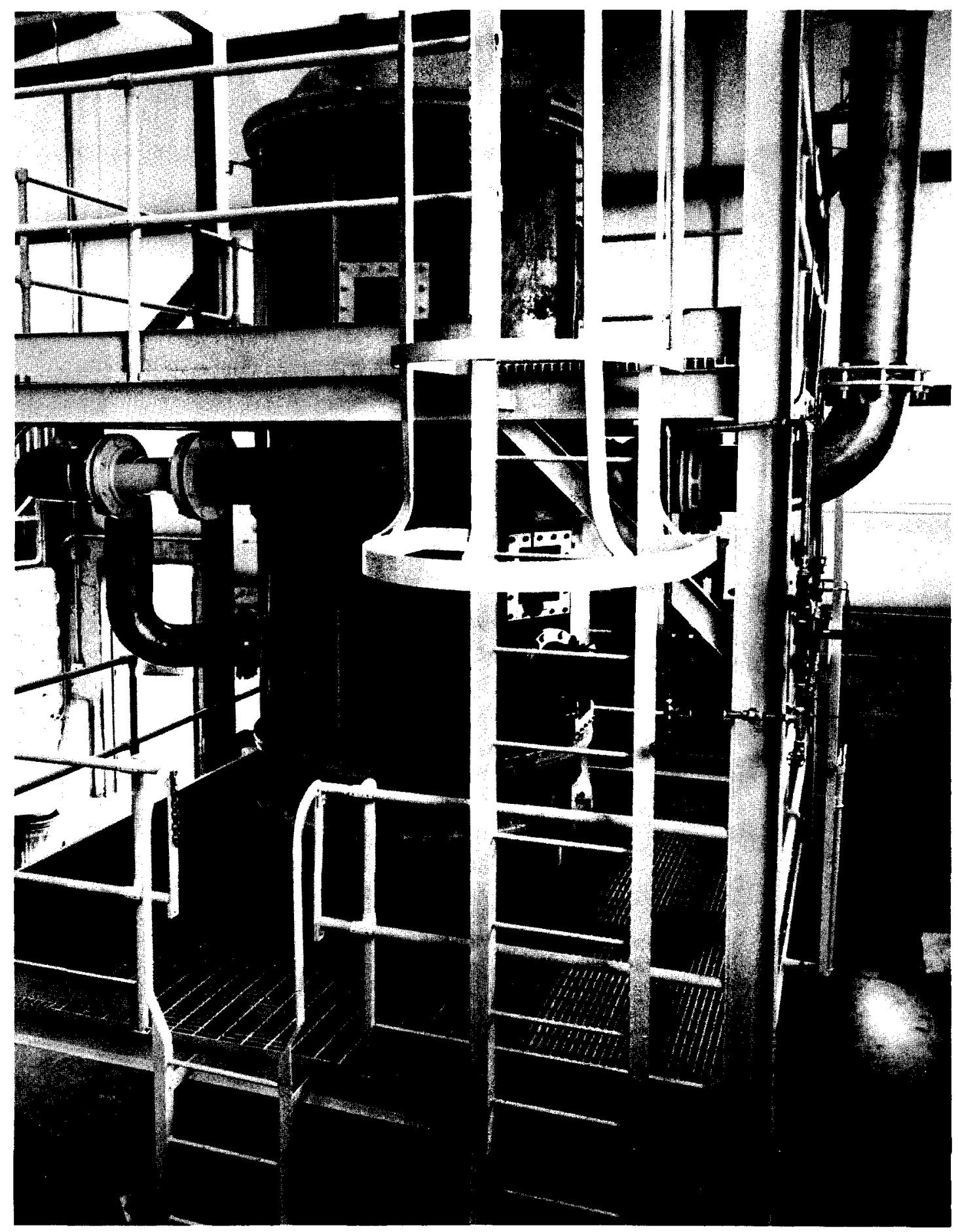

Neg 0693324-2

FIGURE 6.2. External Features of Core outlet Region Model 
of $3600 \mathrm{gal} / \mathrm{min}$, carry-under of cover gas into the outlet nozzles did not occur until the pool level was lowered to $121 / 2$ foot equivalent reactor depth.

From initial dye injection tests, it would appear that mixing in the outlet region is fairly good. Quantitative tests using electrolyte tracers are being run to further characterize mixing in the pool.

B. CLOSED LOOPS

1. AI Closed Loop Design Progress

M. A. Voge $1^{*}$

The 2-MW loop concept rescoping and the 4-MW cell size assessment studies are in progress at Atomics International under the technical direction of Westinghouse. Work plans for the above effort were approved by BNW.

The Atomics International technical plan for performing closed loop design was reviewed and will be incorporated into an overall logic schedule chart now in preparation.

AI submitted summary recommendations as a result of their review of the 6-MW closed loop conceptual design. Major concept changes or additions recommended were as follows:

a. Provide loop process temperature control by a "feedforward" signal based on reactor power. Reduce the process operating range requirements.

b. Make specific provisions for contact as well as for remote in-ce11 equipment mainterance.

c. The closed loop cell design should limit cell atmosphere leakage to $5 \%$ per day at 15 psig pressure. The ce11s should be filled with an inert atmosphere of not more than $2 \%$ oxygen.

*(7N92-P.F. Shaw) 
d. The parallel primary pumps should be provided with individual flow measurement. Electromagnetic pump flow should be controlled electrically, instead of by valve thrott1ing.

e. The entire closed loop secondary heat transport system should be rearranged to provide natural circulation cooling during pump shutdown.

The above recommendations will be factored into the ongoing $2-\mathrm{MW}$ closed loop concept rescoping effort.

2. Schematic Arrangement of 2-MW Closed Loop System

R. E. Keyes*

Three preliminary drawings necessitated by the need for closed loop definition for the PSAR were prepared to describe the schematic arrangement of the 2-MW closed loop system.

Details of the closed loops concept are still under development by Westinghouse. Numbers and titles are as follows:

SK-3-14679, Closed Loop System 61, Schematic Arrangement (1)

SK-3-14680, Closed Loop System 61, Flow Niagram (1)

SK-3-14681, Closed Loop System 61, In-R tor Tube Schematic (1)

The single closed loop arrangement contains the following principal features:

- Two independent emergency lines, each of which has a separate suction connection with the primary storage tank, and a separate EM pump with check valves on the discharge.

- An emergency line discharge into the main primary as close as possible to the closed loop tube inlet.

- Two check valves in tandem on the main primary supply line located immediately ahead of the emergency cooling supply connection.

* (7NB1-D.'P. Schively)

1. Preliminary work not shown in this report. 
- Encased main primary piping between the inlet to the closed loop tube and return. The encasement includes the two main checks and the check on each emergency supp1y.

- Independent emergency power supply to each emergency cooling pump.

3. Prototype Closed Loop Tube Procurement

S. M. Gi11*

Two complete prototype closed loop tube assemblies are scheduled for delivery to the Prototype Closed Loop Development Installation by January 1, 1972. These are to permit functional and endurance testing prior to use in the reactor. Current activities are aimed at preparing specifications and a Request for Proposal package to be sent to potential manufacturers.

During the month the specifications and drawings for the prototype closed loop tube assembly were reviewed and approved by a formal FFTF Technical Evaluation Board.

Additional design information is required on the thermal conductivity of the double-walled tubes with felted metal sandwich insulation. It is planned to mock up tests where the thermal conductivity may be determined for several densities of felted metal. The following configuration will be used in the test: molten sodium/0.125-in. Type 316 SS/0.002-in. Argon gas gap/0.095-in. felted austenitic stainless stee1/0.002-in. Argon gas gap/0.100-in. Type $316 \mathrm{sS} / m o l t e n$ sodium. These tests will be carried out in an isothermal sodium test loop in Building 314. It is expected that the felted metal preforms will be received in the next two weeks, and testing can begin.

* (7N96) 


\section{Closed Loop Tube Remote Cutter}

R. F. Gilmore*

The objective of this program is to develop and demonstrate a reliable remote cutting machine for the separation of the welded closure between the closed loop nozzle plug and the reactor top face spool piece.

Design studies and feature testing of various mechanical cutters have centered around the development of tool configurations that will consistently produce small metal chips that are capable of being completely vacuumed away from the nozzle area. Two concepts have evolved from this effort and have been incorporated into separate cutterhead test assemblies, namely a "Multiple Tooth" trepanning test assembly, and a side mill cutter. Tests are in progress.

\section{a. Trepanning Cutter}

A multiple tooth trepanning tool, based on orthogonal cutting geometry coupled with a pulsed feed rate was tested.

The chip formation was generally good with only a minimum of chips more than 3/4-in. 1ong. Those that e longer, curled and were picked up by the vacuum. The majority of the chips were about 3/8-in. long and were flat. All chips were composed of smaller connected segments.

Metallography of chip formations is being studied to determine the optimum frequency and amplitude that should be programmed into the cutter to obtain the best chip for cutter design. The test assembly will then be modified to incorporate this pulsed feed motion.

b. Side Mil1 Cutter

The test assembly consists of four rotary cutters equally spaced in a tool holder. Rotary motion is provided by a beveled * (7N91-C.A. Munro) 
ring gear that runs a small beveled pinion gear fixed to each cutter. The module as yet does not include automatic circular feed control and proper results must be obtained by turning the work piece. A shroud around the head assembly is coupled into a vacuum source to provide chip removal. The assembly is presently equipped with 4 T-1 HSS tungsten steel cutters patterned after the modified early Woodruff key cutter. This design had 14 teeth and has yielded excellent results cutting welded steel plates. The final cutters are expected to be solid carboloy carbide blanks with 22 to 24 teeth. This type of rotary cutter is not normally used in machine practice to make circular cuts. Therefore, special side cutters must be designed to provide side cutting surfaces in order to cut the inside surfaces of the gland.

C. DRIVER FUEL DUCTS

1. Duct Bending (Core Structures Study Group)

R. J. Jackson*

The interaction between driver ducts and the other core components is presently being examined. There is no obvious single criterion for a burnup limitation based upon driver duct swelling and bending.

Some possible limiting criteria are:

a. Increase in across-the-flats dimension by 0.100 in. (i.e. $\Delta \mathrm{D}=0.100 \mathrm{in.}$ ).

b. $\Delta \mathrm{D}$ plus bending deflection increase by 0.100 in.

c. Duct top motion limit established by the limitations of the refueling machine or by capability to refuel.

d. Duct-to-duct contact during operation.

e. Radial force limitation between a driver duct and a control rod guide tube.

f. Radial force limitation between any two core components. 
The swelling equation (1) for solution treated Type 304 SS was used to calculate the swelling on two opposite sides cf the duct. The differences between the swelling values were used to calculate the bending. The average of these two values was used to calculate the increase in distance across flats of the hexagona1 duct.

Figure 6.3 is a scale representation of this combined effect on the six rows of driver ducts associated with 200 days residence time in reactor.

These effects on portions of the ducts outside the core are insignificant. Therefore, only the in-core portions of the ducts are shown. The duct bending is represented by the curve of the dashed center 1 ine. These center 1 ines are 0.100 in. apart at their extremities. This simulates the $0.100 \mathrm{in}$. separation between ducts. The increase in distance across the flats is represented by distance between the two solid lines which enclose the center line for each duct row.

Figure 6.3 shows that the Row 1 duct has swelled the most and remained straight. The Row 6 duct has sh ${ }^{-1}$ led the least and bent the most. It can be noticed that the irwur wall of duct Row 2 has moved inward (toward the core center) by 0.050-in. from both bending and swelling. Similarly, the inner wall of duct Row 3 has moved toward the core center by 0.065 -in. Bending caused the center to move inward 0.045-in. and swelling causes an additional 0.020-in. inward movement of the innermost duct wa11. However, there is no duct-to-duct contact at 200 days.

In a similar manner Figure 6.4 shows the duct configuration at 225 days. The increase in swelling in Rows 1,2 and 3 is evident. Row 2 would have bent $0.009-i n$. farther toward core center if it had not been pushed outward to the position shown

1. Letter, E. R. Astley to J. M. Shiviey, "Interim Swelling Equations for Austenitic Stainless Steel," August 22, 1969. 
BNWL - 1217

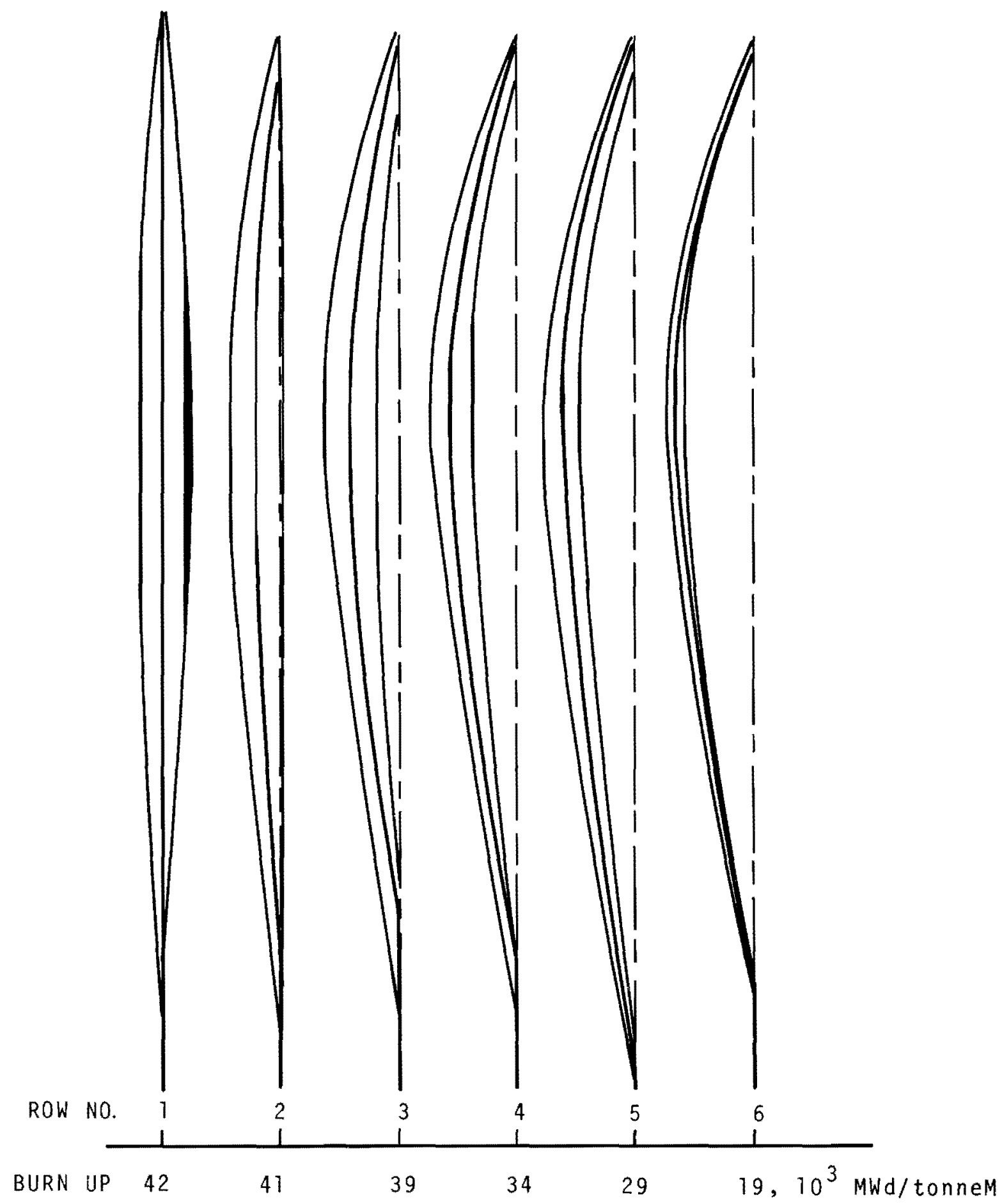

$$
\begin{aligned}
& \text { FIGURE 6.3. Effect of Metal Swelling on Duct Behavior } \\
& \text { in } 200 \text { Days with Type } 304 \text { Solution Treated } \\
& \text { SS (Omificed Core). }
\end{aligned}
$$


BNWL- 1217

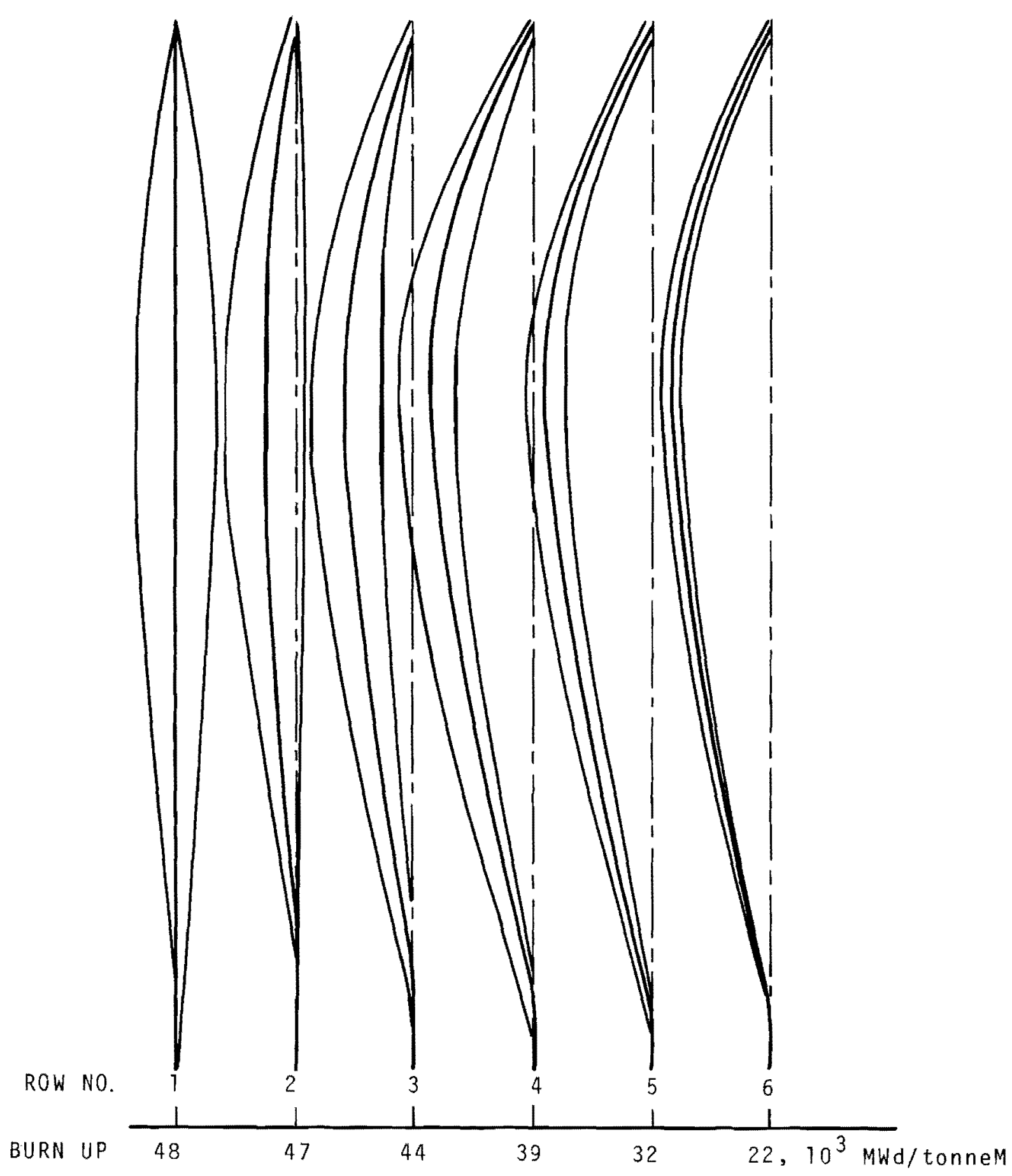

FIGURE 6.4. Effect of Metal Swelling on Duct Behavior
in 225 Days with Type 304 Solution Treated
SS (Orificed Core). 
by Row 1 swe11ing. As a result, duct Rows 1,2 and 3 are in contact. At 325 days exposure, shown in Figure 6.5 , swe11ing has increased to the point that al1 duct rows are in contact. It can also be noted that all rows except Row 6 have been forced to bow outward by the duct swe11ing.

2. Radiation Induced Swel1ing In Driver Ducts

C. L. Wheeler*

The purpose of this task is to determine the amount of radiation induced swelling and resultant bending that will occur in the driver ducts. A computer program was written which calculates fluence, duct temperature, volumetric increase, and bending moment as functions of axial elevation and time. The data generated in this study will be used to calculate the duct deflections using the beam bending code. The analytical model assumes that the radial flux factor and duct temperature varies linearly with time in each loading cycle. The volume swelling is calculated using the current recommended Type 304 SS swelling equations. It is assumed that the incremental volume change over a given time increment is a function of the total fluence at beginning and end of the time increment and the average temperature over the increment. The bending moments are proportional to the differential swelling between the hot and cold side of the duct, and are determined using elastic theory. Four loading cycles of 100 days each are used in this analysis.

The greatest fluence, temperature and volume change will occur in the central duct of an unorificed core. Typical plots of these variables are given in Figures 6.6,6.7, and 6.8. The largest bending moment occurs in ducts located on the periphery of an orificed core. Bending moments for a typical duct located on the periphery are given in Figure 6.9.

* (7N83-P.D. Cohn) 
BNWL -1217

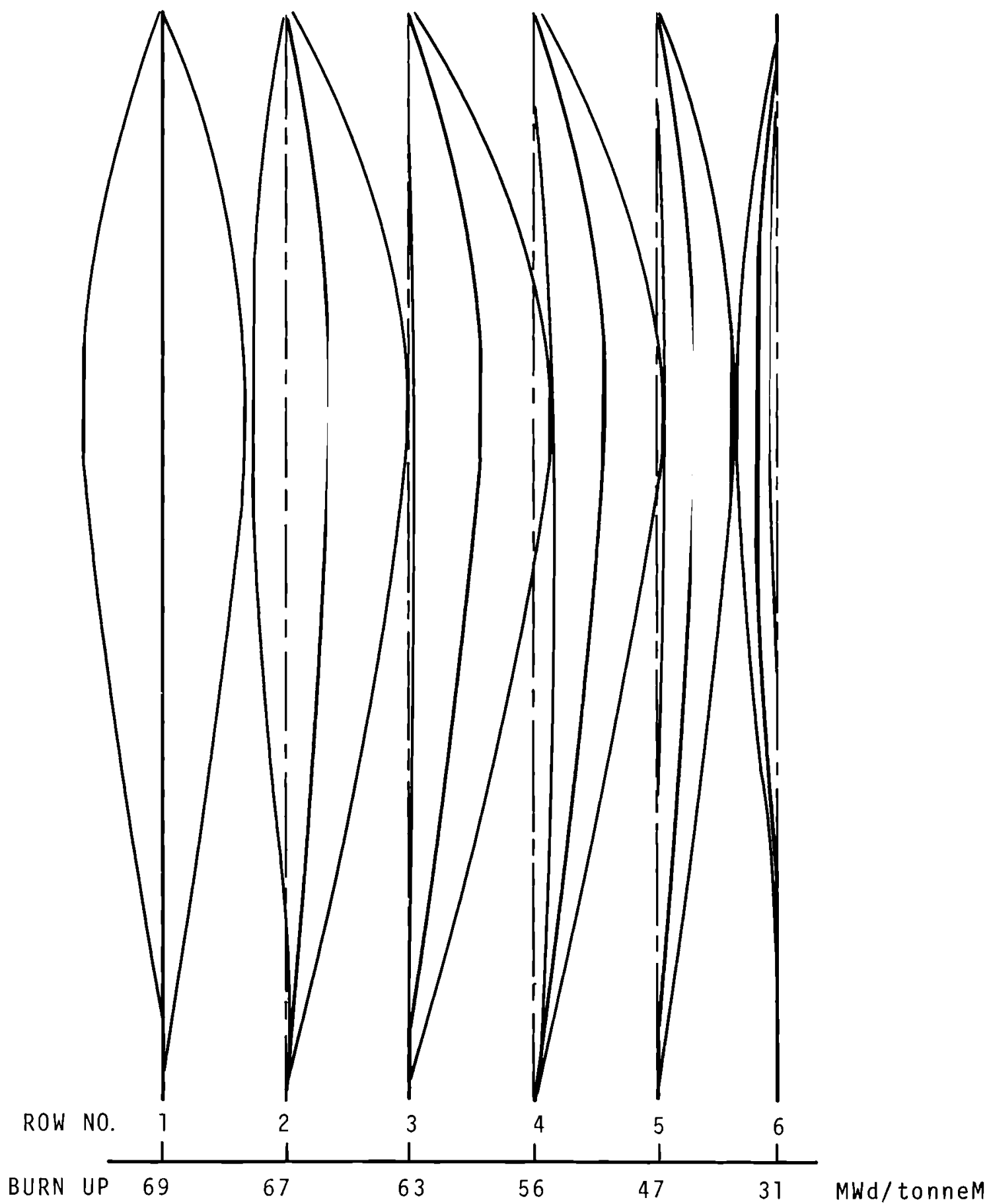

FIGURE 6.5. Effect of Metal Swelling on Duct Behavior in 325 Days with Type 304 solution Treated SS (Orificed Core). 


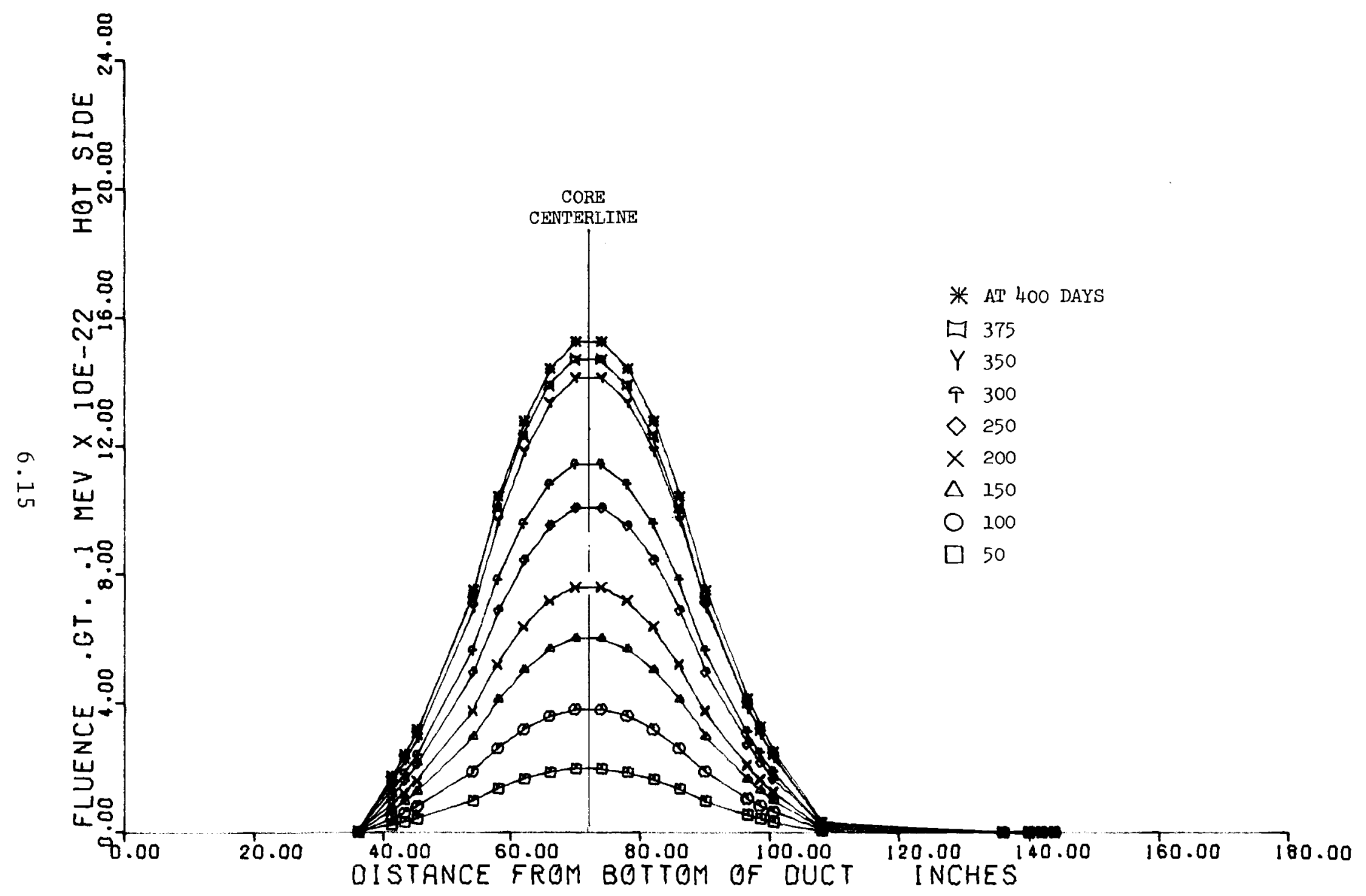




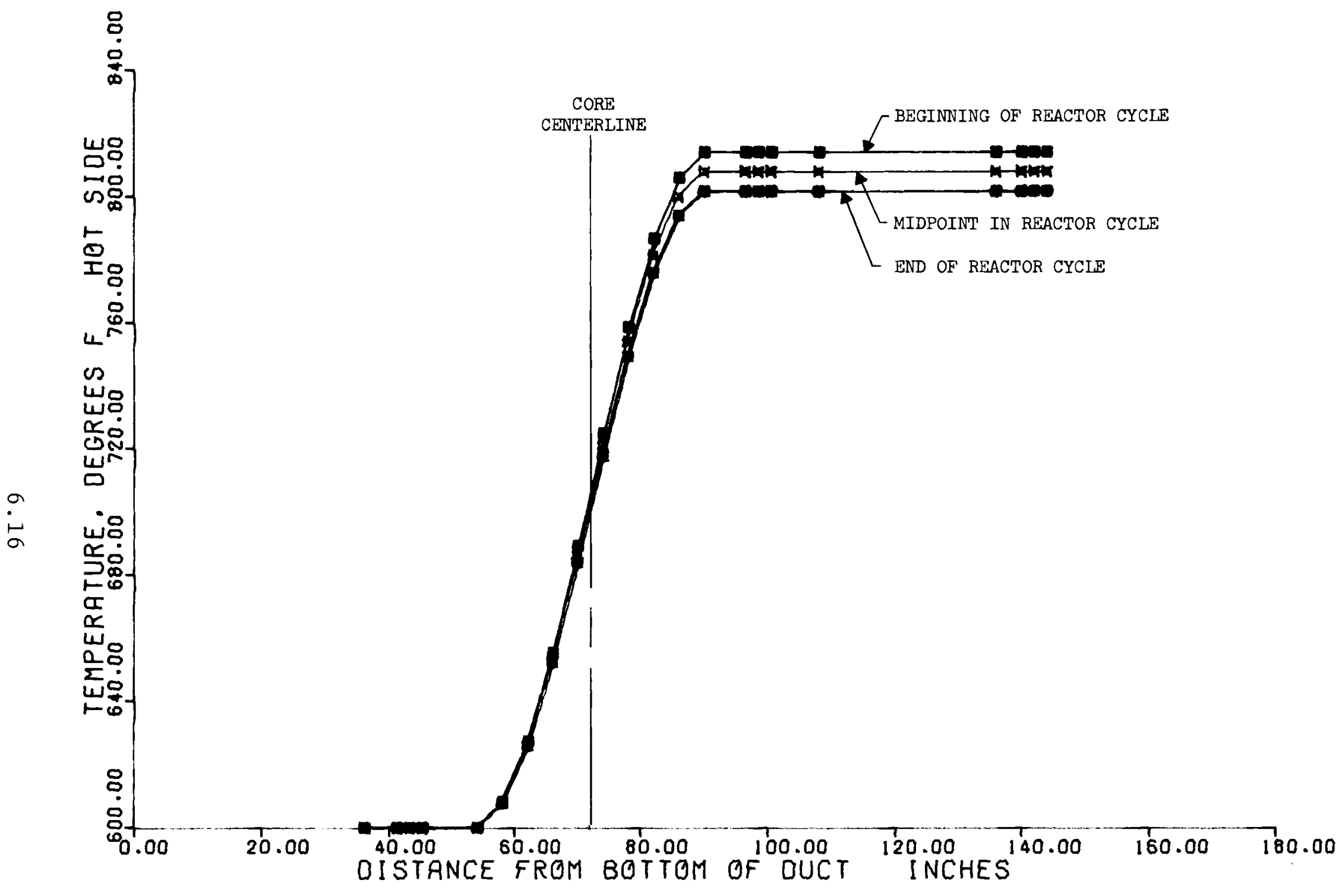

FIGURE 6.7. Duct Wall Temperature Versus Axial Elevation for Type 304 SS Driver Duct Zone 1 (Unorificed). 


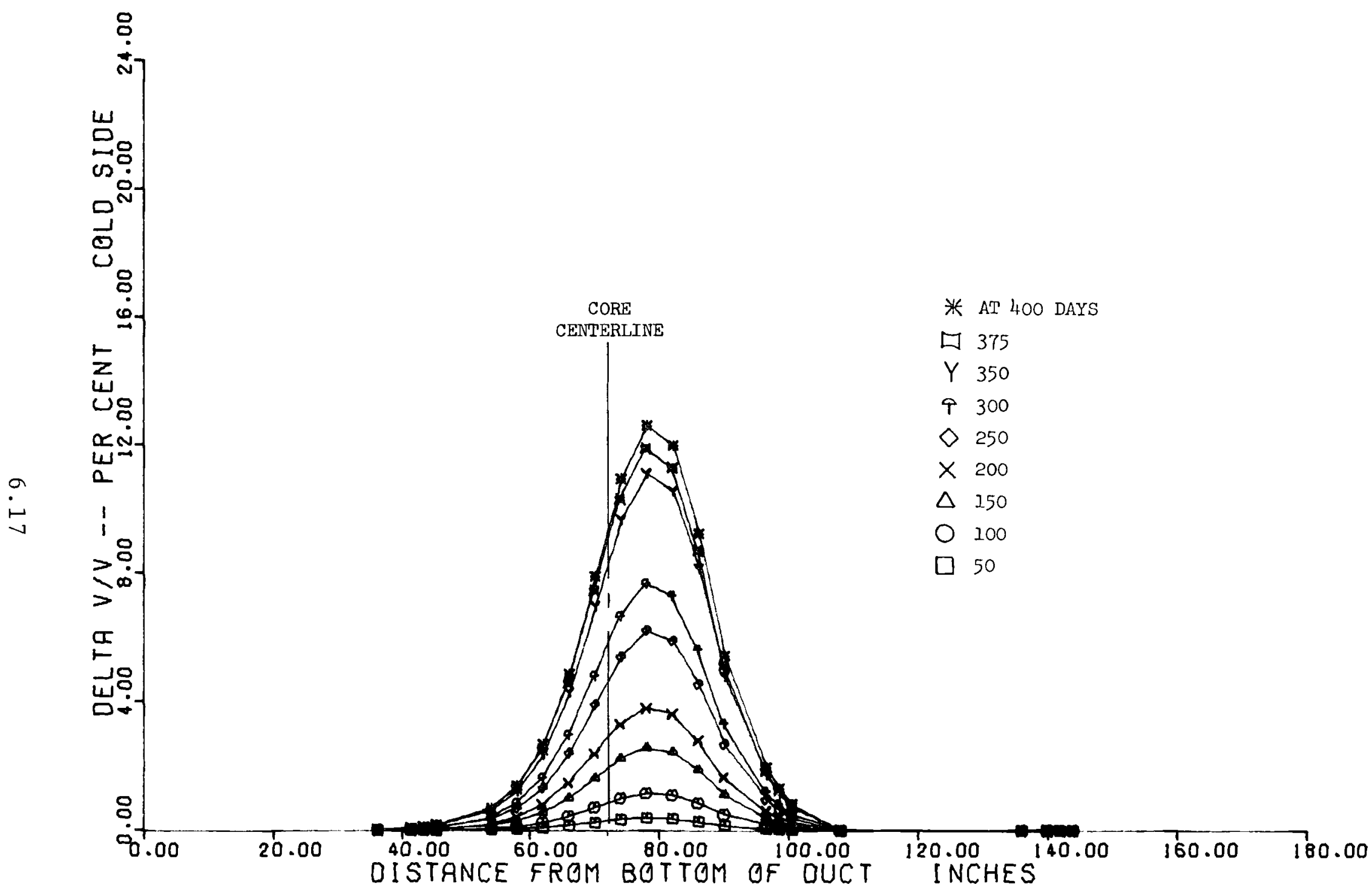

FIGURE 6.8. Delta V/V Versus Axial Elevation for Type 304 SS Driver Duct Zone 1 (Unorificed). 

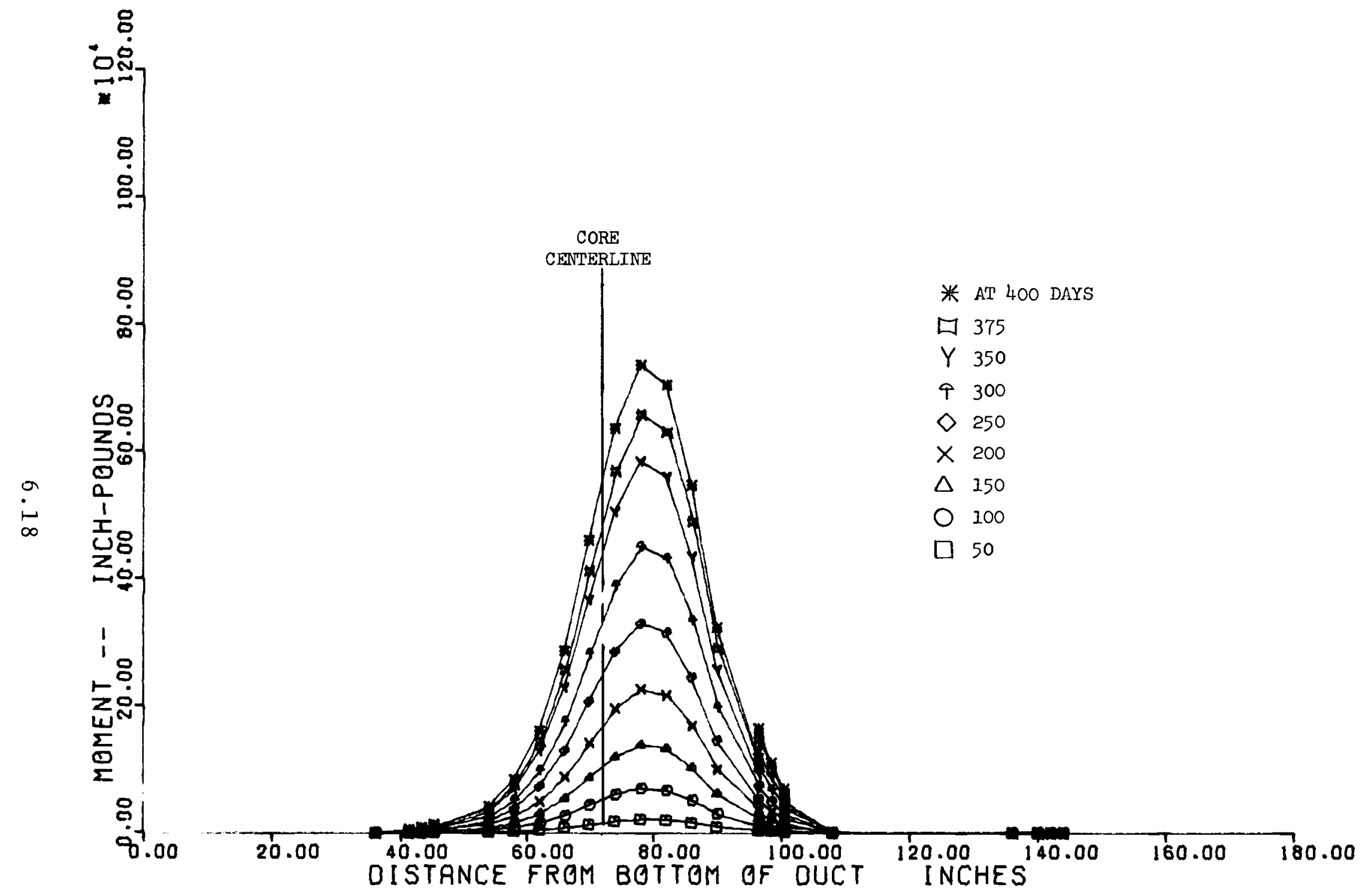
3. Beam Bending Code Development

P. D. Cohn,* V. B. Watwood, Jr.,**W. H. Sutherland,** and

J. Rector**

The general finite element procedure noted in the August monthly Technical Progress Report has been applied to beams with arbitrary cross-sections. To establish the validity of the approach the solution for a cantilever beam of rectangular cross-section loaded with a concentrated end load or an end moment was calculated by hand for two time intervals. Reasonable agreement was achieved between the hand calculated results and the results obtained for the same problem using the plane stress capability in AXICRP.

Insight was gained on the dependence of the creep solution upon the time interval selection and spatial integration routines during the hand calculations. These results will be presented in a forthcoming document.

Conclusions are that a finite element creep formulation has been achieved for beams which permits the same finite element structural idealization as has been used for the elastic analysis.

Coding has been completed for the subroutine DECOM and SOLVE associated with the solution of the matrix equations. Checkout is progressing with success indicated to date. 
BNWL -1217

D. CORE THERMAL HYDRAULICS

1. Therma1 Environment Within Control and Safety Assemblies D. C. Kolesar*

A modified version of the COBRA Code was employed to predict the thermal-hydraulic characteristics of the coolant passing through typical control and safety assemblies. Data supplied by Core Physics and Reactor Shielding Units on total flux and power distributions were crucial. Only neutron absorption in boron was considered when estimating the energy source. Furthermore, the guide pads between the guide and inner duct walls were assumed to completely halt the bypass flow within the assembly.

The peak coolant temperature may reach $1100^{\circ} \mathrm{F}$ if a fullyinserted control rod in the reflector region is orificed to yield a mixed mean outlet temperature which matches the comparable core value. A peak local temperature of an acceptable level $\left(900^{\circ} \mathrm{F}\right)$ is attained only if the mixed mean outlet of the rod is adjusted to approximately $800^{\circ} \mathrm{F}$. As the rod is withdrawn it is exposed to a softened spectrum and the temperatures reach even larger values. The peak temperati would occur when the rod is approximately one-sixth withdrawn. The assembly design must balance thermal fatigue or shock resulting from outlet temperature mismatch versus $\mathrm{B}_{4} \mathrm{C}$ damage resulting from elevated temperatures. Typical results are displayed in Table 6.I and Figure 6.10 for a mixed mean outlet temperature of $800^{\circ} \mathrm{F}$.

*(7N83-P.D. Cohn 


\section{TABLE 6.I. Typical Control and Safety Rod Results}

\begin{tabular}{|c|c|c|c|}
\hline $\begin{array}{c}\text { Control Rod } \\
\text { Location } \\
\end{array}$ & $\begin{array}{l}\text { Degree of } \\
\text { Insertion } \\
\end{array}$ & $\begin{array}{l}\text { Peak Coolant } \\
\text { Temp., }{ }^{\circ} \mathrm{F} \\
\end{array}$ & $\begin{array}{l}\text { Duct Wall Max. } \\
\text { Temp. Drop at } \\
\text { Fixed Elev., }{ }^{\circ} \mathrm{F}\end{array}$ \\
\hline Core Region I & $\begin{array}{l}\text { Fu11-in } \\
1 / 2 \text {-out }\end{array}$ & $\begin{array}{l}915 \\
960\end{array}$ & $\begin{array}{l}3 \\
4\end{array}$ \\
\hline Core Region II & $\begin{array}{l}\text { Ful1-in } \\
1 / 2 \text {-out }\end{array}$ & $\begin{array}{l}890 \\
930\end{array}$ & $\begin{array}{l}33 \\
38\end{array}$ \\
\hline Reflector & $\begin{array}{l}\text { Ful1-in } \\
1 / 2 \text {-out }\end{array}$ & $\begin{array}{l}940 \\
995\end{array}$ & $\begin{array}{l}106 \\
120\end{array}$ \\
\hline \multicolumn{4}{|c|}{ CORE REACTIVITY } \\
\hline \multicolumn{4}{|c|}{ Reactivity Transient Analysis } \\
\hline
\end{tabular}

C. L. Fies*

Reactivity transient analysis were performed using the current reference design for the protection system (including actuation). A $100 \mathrm{msec}$ time delay is assumed after the high power trip point is reached, the rods are placed at the axial core interface prior to scram, and the rods are accelerated over the first 14-in. of travel by a 14-in. spring with a spring constant of $640 \mathrm{lb}$. The performance of the system was analyzed assuming two of the three safety rods scram with a total worth of $3.2 \% \mathrm{\delta} / \mathrm{k}$ and assuming all in-core rods scram as expected with a total worth of $7 \% \delta \mathrm{k} / \mathrm{k}$. Figure 6.11 shows fuel temperature response to a $5 \$ / \mathrm{sec}$ reactivity ramp assuming the protection system performs as described above. The deviation from steady state maximum hot channel fuel temperature of $4445{ }^{\circ} \mathrm{F}$ is shown. It can be seen that the use of only two safety rods results in a temperature rise of approximately $400^{\circ} \mathrm{F}$, while the system performance with six in-core rods results in a temperature rise of only $200^{\circ} \mathrm{F}$.

* (7N82 D. D. Stepnewski) 
BNWL - 1217

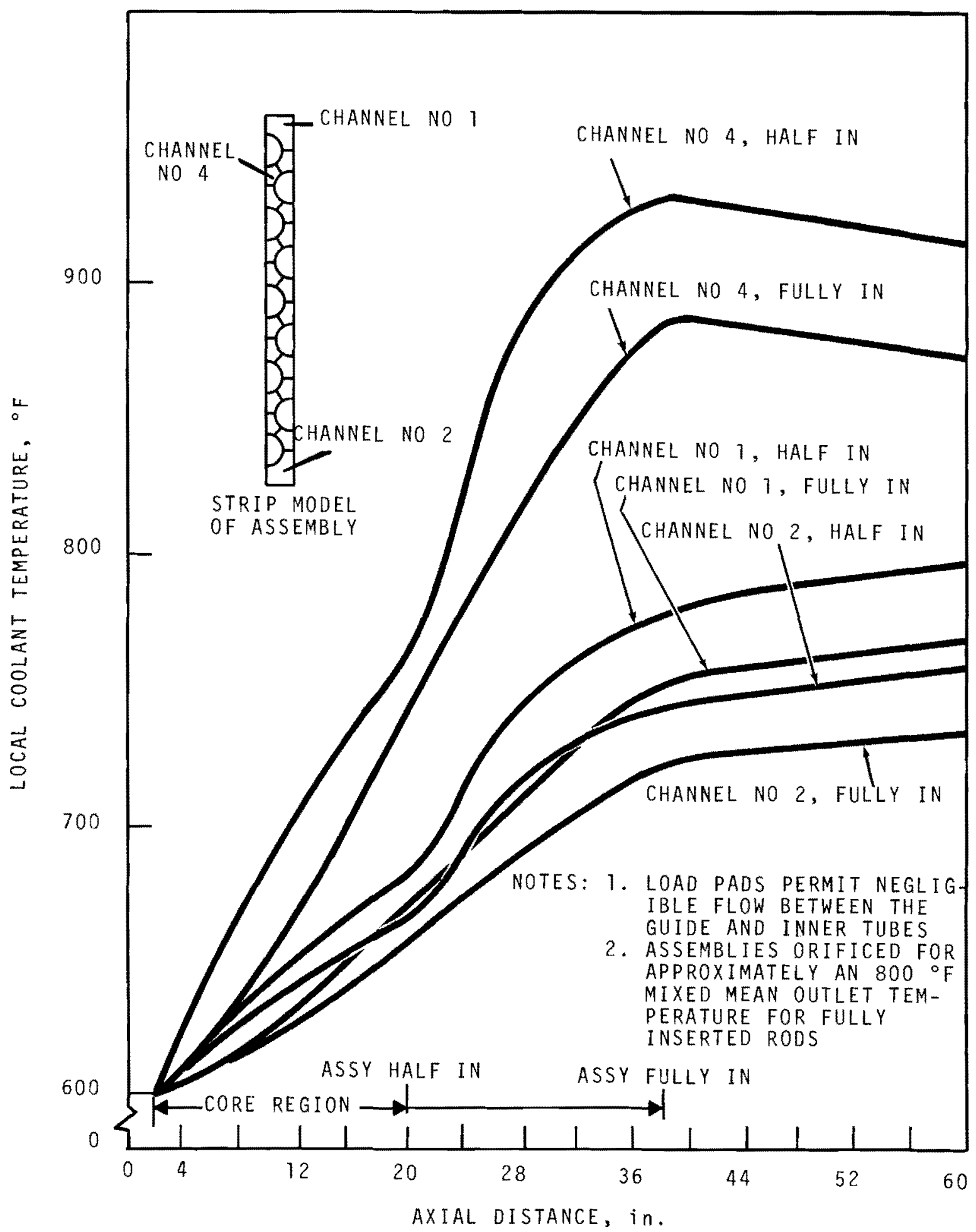

FIGURE 6.10. Coolant Temperature Distributions in a Typical Control Bundle Located in Rod Bundle No. 14 as a Function of Degree of Insertion in Region II of the core 
BNWL -1217

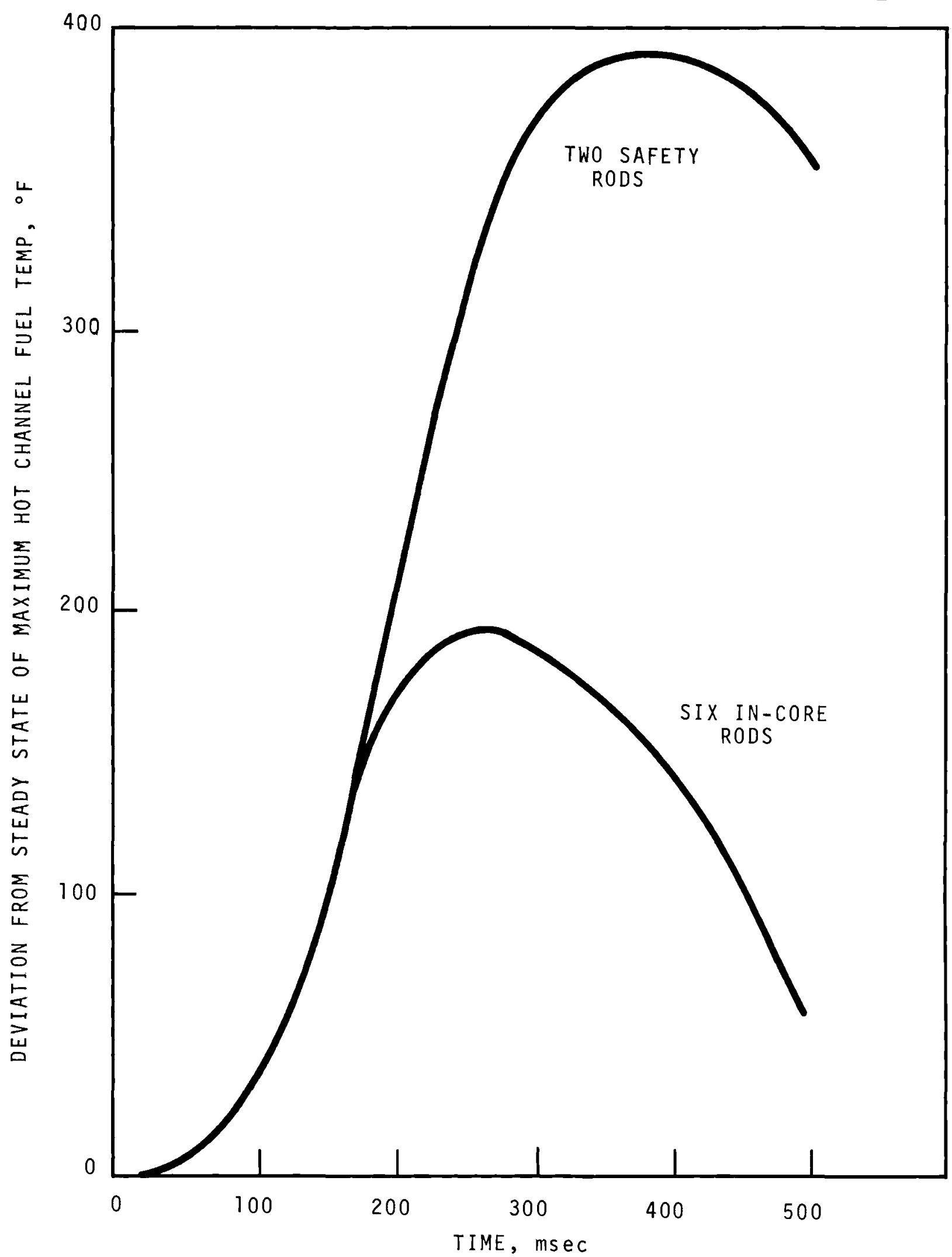

FIGURE 6.11. FTR Fuel Temperature Response to a $5 \$ / \mathrm{sec}$ Reactivity Ramp with Protection Trip 


\section{F. CORE INSTRUMENTATION REQUIREMENTS}

1. Driver Channel Instrumentation Analysis

R. A. Harvey*

The effectiveness of automatic scram action to prevent coolant boiling induced by channel flow loss was evaluated for the influence of thermocouple temperature trip settings. Figure 6.12 presents results for the case of a nominal hottest coolant channel (core outlet temperature of $1006^{\circ} \mathrm{F}$ ) and a suddenlyoccuring flow loss rate of $32 \% / \mathrm{sec}$ to a final steady flow of $20 \%$. Boiling would begin to take place if the trip level were relaxed to a value greater than $35^{\circ} \mathrm{F}$ above nominal.

2. Plant Protection System Reliability Analysis

o. B. Monteith**

A report on the unavailability of the PPS is in final preparation by Technical Publications, and it will be issued as document BNWL-1201.

Consideration is now being given to spurious responses (false scrams) of the P1ant Protection System that result from equipment failures. Investigation is present underway to evaluate spurious scram rates in the following situations:

a. Spurious scram from a combination of equipment failures.

b. Spurious scram resulting from one failed instrument channel and additional failures occurring before the first failure is bypassed.

c. Spurious scram from additional failures following a bypassed channe1.

d. Spurious scrams that result from ac or dc power supply failures.

e. Spurious scrams from failures occurring during test.

* (7N82)

** (7N82 - D. D. Stepnewski) 


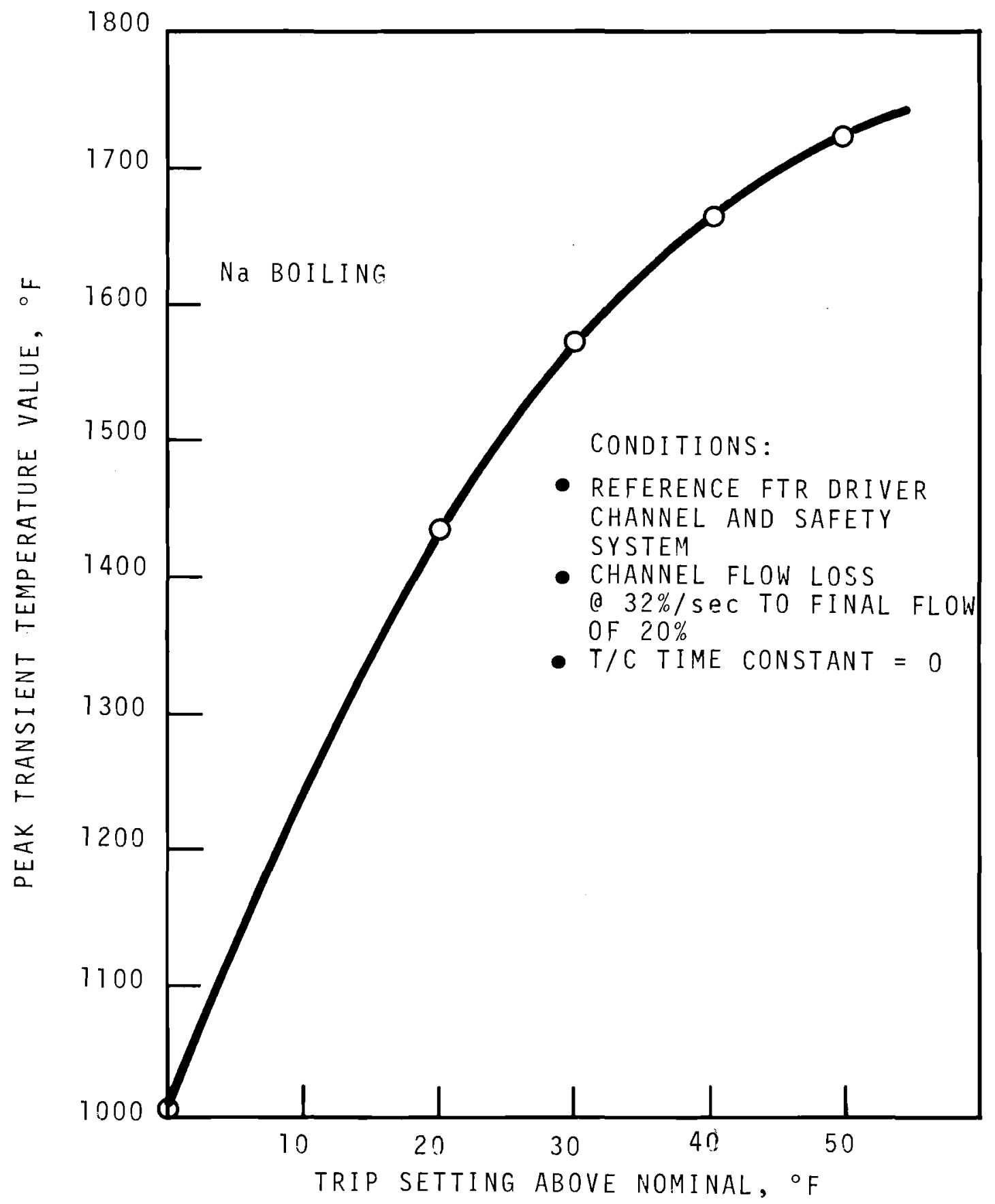

FIGURE 6.12. Typical Effect of Thermocoupie Trip Setting on Boiling Prevention Capabizity 



\section{FUELS AND MATERIALS}

\section{A. FUELS AND MATERIALS EVALUATION}

\section{Irradiation Induced Creep of Stainless Steels}

J. L. Straalsund * and H. R. Brager**

The objectives of this effort are to establish the irradiation induced swelling characteristics of FFTF alloys, relate fast fluence induced substructural changes in microstructure to corresponding changes in mechanical properties and to develop means for data extrapolation using both microscopic and empirical means.

A new swelling equation for solution treated AISI Type 316 and 304 SS was developed.

$$
100 \frac{\Delta V}{V}=4.9 \times 10^{-49}(\phi t)^{1.71} 10 \frac{\left(1.55 \times 10^{4}\right.}{\mathrm{T}}-\frac{\left.5.99 \times 10^{6}\right)}{\mathrm{T}^{2}}
$$

where $100 \frac{\Delta V}{V}=\frac{0}{0}$ volume change

$$
\begin{aligned}
\phi t & =\text { fluence, neutrons } / \mathrm{cm}^{2} \quad(\mathrm{E}>0.1 \mathrm{MeV}) \\
\mathrm{T} & =\text { temperature, }{ }^{\circ} \mathrm{K}
\end{aligned}
$$

Equation ( 1 ) is based on density measurement results from solution treated Type 304 SS EBR-II components and the results reported for solution treated Type 316 SS tensile specimens in a previous monthly report. This equation is recommended for design purposes.

No changes were made in the recommended equation for swelling in Type 316 SS with $20 \%$ cold work. The current equation is:

$$
\begin{aligned}
& 100 \frac{\Delta V}{V}=1.01 \times 10^{-36}(\phi t)^{1.69} \mathrm{e}^{-7800 / R T} \\
& -5480 \mathrm{e}^{-25,300 / R T}
\end{aligned}
$$

\footnotetext{
* (7N72-J.J. Holmes)

$* *(7 A 00)$
} 
The temperature dependence of swelling as predicted by these equations at a fluence of $5 \times 10^{22} \mathrm{n} / \mathrm{cm}^{2}(\mathrm{E}>0.1 \mathrm{MeV}$ ) is shown in Figure 7.1. The data used to develop the equations were normalized to $5 \times 10^{22} \mathrm{n} / \mathrm{cm}^{2}(\mathrm{E}>0.1 \mathrm{MeV})$, using the $\mathrm{flu}$ ence dependency indicated by the equations, and plotted on the figure for reference.

Density measurements were completed on AISI Type 304 and 348 SS solution treated tensile specimens that were irradiated in the $\mathrm{X}-018$ subassembly in the EBR-II reactor.

Analysis of the data is not yet complete, but initial considerations indicate that the temperature dependence of swe11ing may be significantly different in different grades of austenitic stainless steels. Figure 7.2 shows a plot of measured swelling as a function of absolute distance from the reactor midplane, for the Type 316 and 348 sS specimens. The Type 316 SS specimens were located below the midplane whereas the Type 348 SS specimens were above the midplane. Thus, the temperatures are not exactly the same for the two types of material at the same absolute distance from the midplane. Temperatures differ by about $125^{\circ} \mathrm{F}$ at dista s greater than 15 inches from the midplane $\left(700^{\circ} \mathrm{F}\right.$ for the Type $316 \mathrm{SS}$ and $825^{\circ} \mathrm{F}$ for the Type $348 \mathrm{SS}$ ) and have nearly the same values near the midplane. Since the flux profile in the reactor is thought to be symmetrical, the fluences are essentially equivalent for equivalent distances from the midplane. As may be seen from Figure 7.2, the Type 348 SS swells less than Type 316 SS at low temperatures (and/or fluence) whereas the trend is reversed at the higher temperatures. The temperature at which the curves for Types 316 and 348 SS cross is about $1000^{\circ} \mathrm{F}$, for both the center and edge specimens.

The maximum in the center specimen curves may be associated with the maximum in the temperature dependence. They appear to occur at about $1000^{\circ} \mathrm{F}$ for Type $316 \mathrm{SS}$ and $1100^{\circ} \mathrm{F}$ for Type 348 SS specimens. 


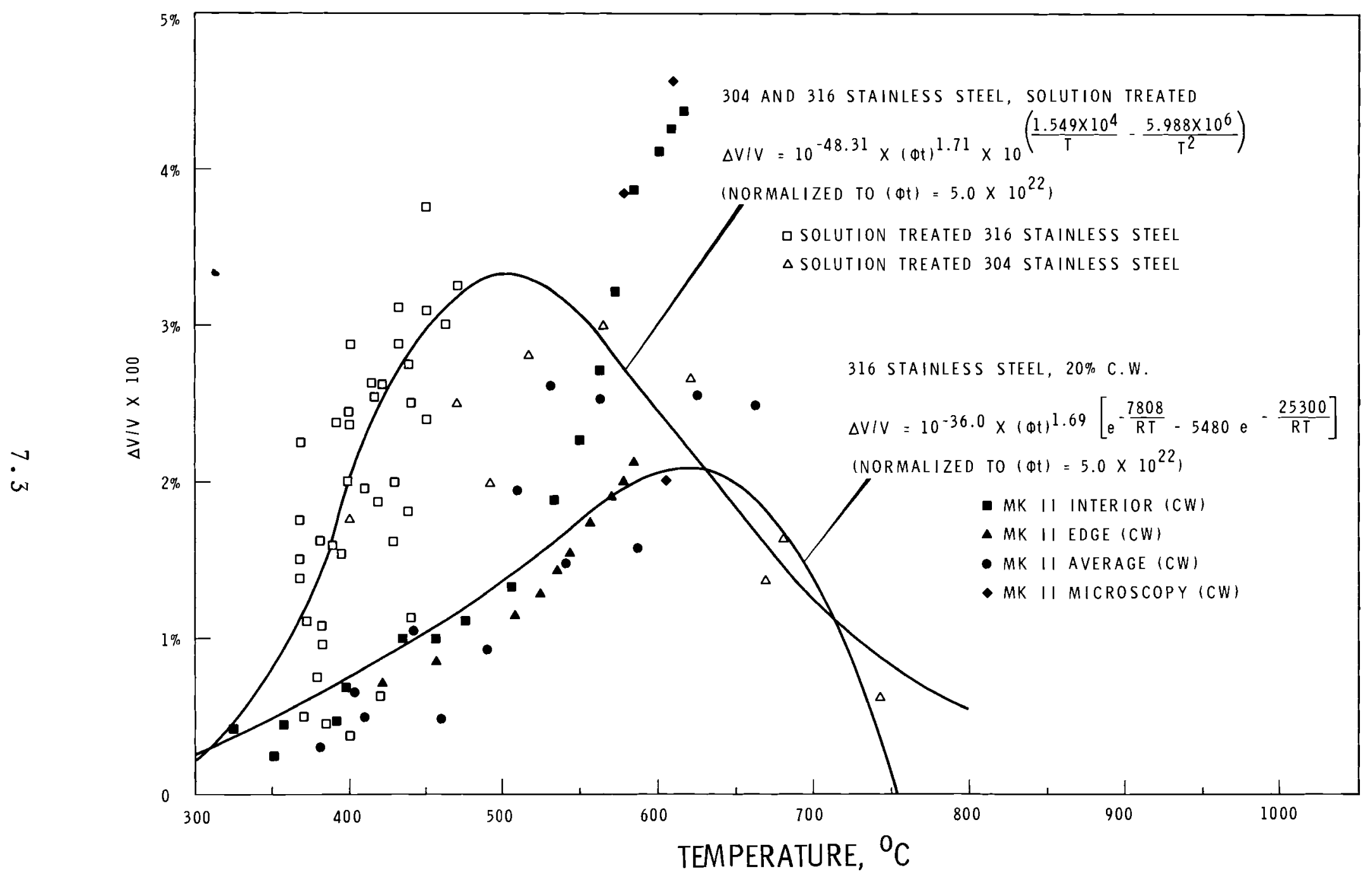

FIGURE 7.1. Temperature Dependencies Predicted by Swelling Equations for Solution Treated Type 316 and 304 SS and for Type 316 SS with 20\% Cold Worked. 


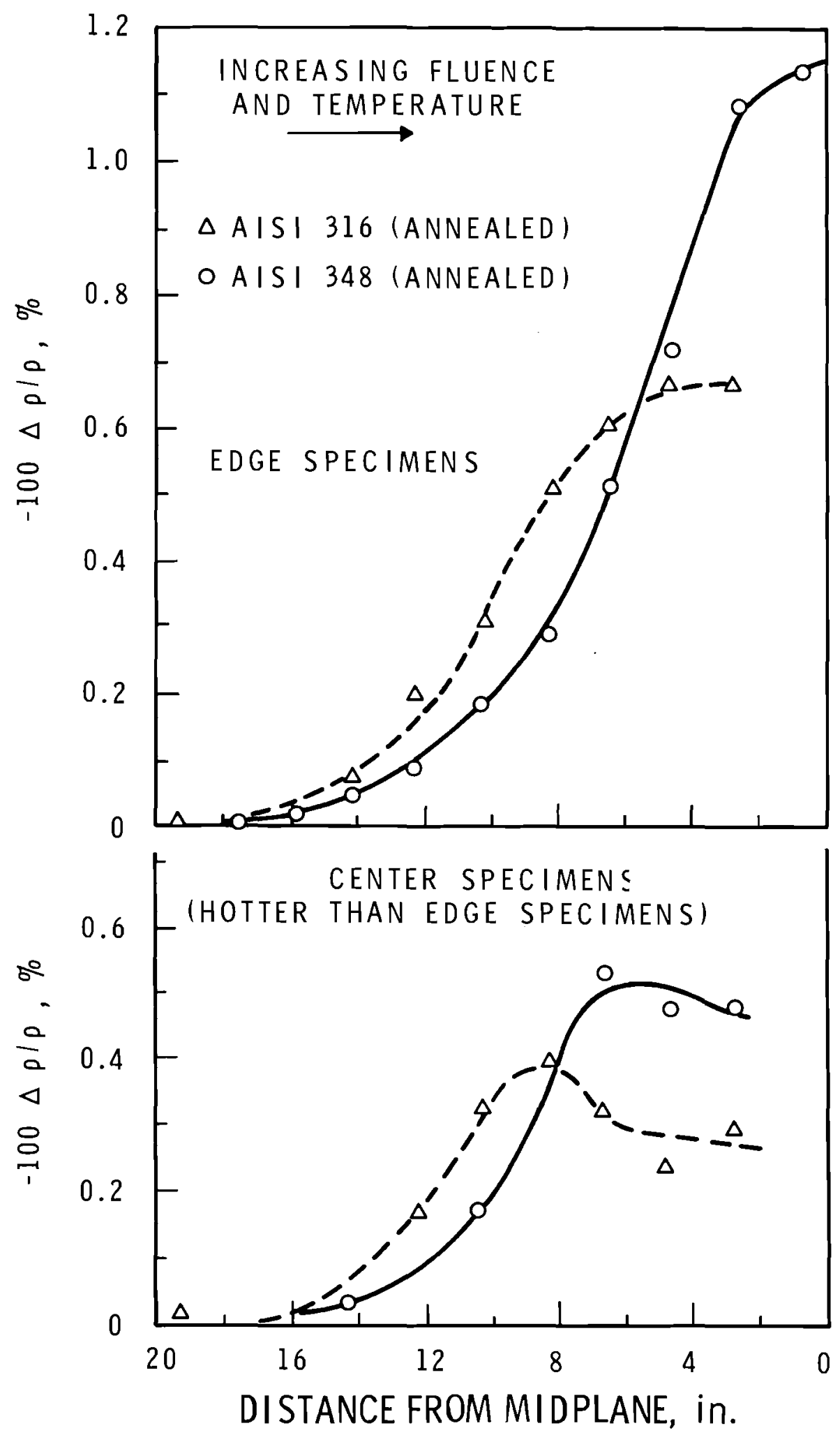

FIGURE 7.2. Comparison of Swelling in Type 348 and 316 SS. 
2. Uniaxial Creep

J. E. Irvin, ${ }^{*}$ A. J. Lovel1, ${ }^{* *}$ and J. F. Bates**

The creep-rupture properties of specimens from four weld processes (Sub-Arc, Stick Electrode, TIG, and MIG) at $1100^{\circ} \mathrm{F}$ are being investigated. The results are shown graphically in Figures 7.3 and 7.4. There is extensive scatter in the weld data from one process to the next, but fairly well-defined behavior is evident for each process.

Specimens of Type 304 SS irradiated in subassembly X018 to $4 \times 10^{22} \mathrm{n} / \mathrm{cm}^{2}$ (total; EBR-II calculated) are now being tested in hot cell units in the 321A Building.

3. Subcritical Crack Growth

J. E. Irvin, * E. B. Schwenk, ${ }^{\dagger}$ and L. A. 'James ${ }^{\dagger}$

The objective of the subcritical crack growth studies is to determine the effect of characteristic FTR temperature levels and sodium environment on the fatigue crack growth properties of LMFBR alloys that are to be used in the FFTF Primary Piping System. Knowledge of these properties are necessary to estimate the remaining service life or number of load cycles to grow a crack in a component from a finite size, below an NDT detection limit, to a size that can be detected. The technical approach, detailed in previous reports, uses linear elastic fracture mechanics and the power law of crack growth.

Fatigue crack growth testing of specimen RML- 6 at $1,000^{\circ} \mathrm{F}$ is continuing. Figure 7.5 shows a plot of crack length versus load cycles developed to date; the data shown have not been submitted for computer analysis but do indicate an increase in $\mathrm{da} / \mathrm{dN}$ by about $600 \%$ for the same value of $\Delta \mathrm{K}$ at room temperature. 


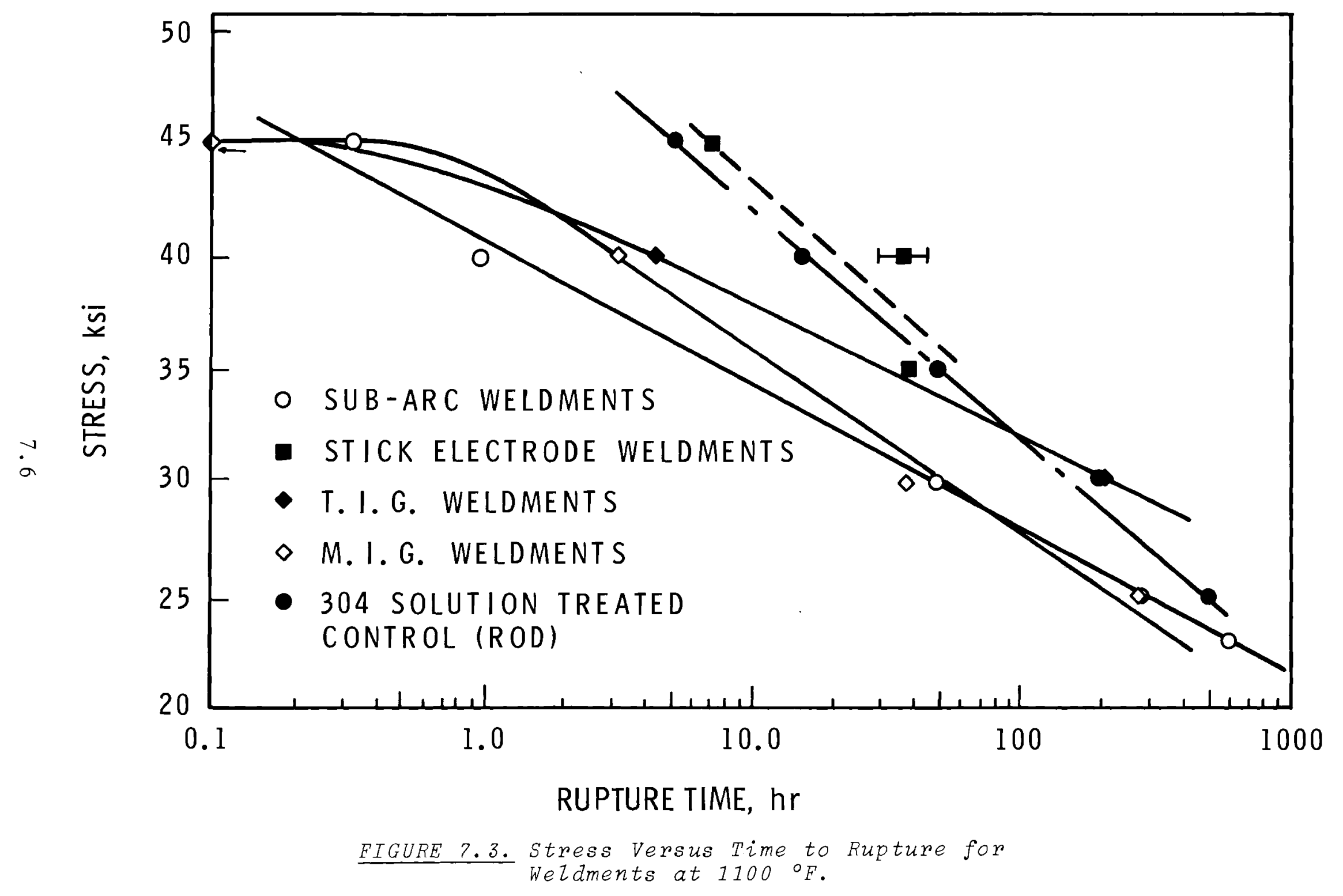




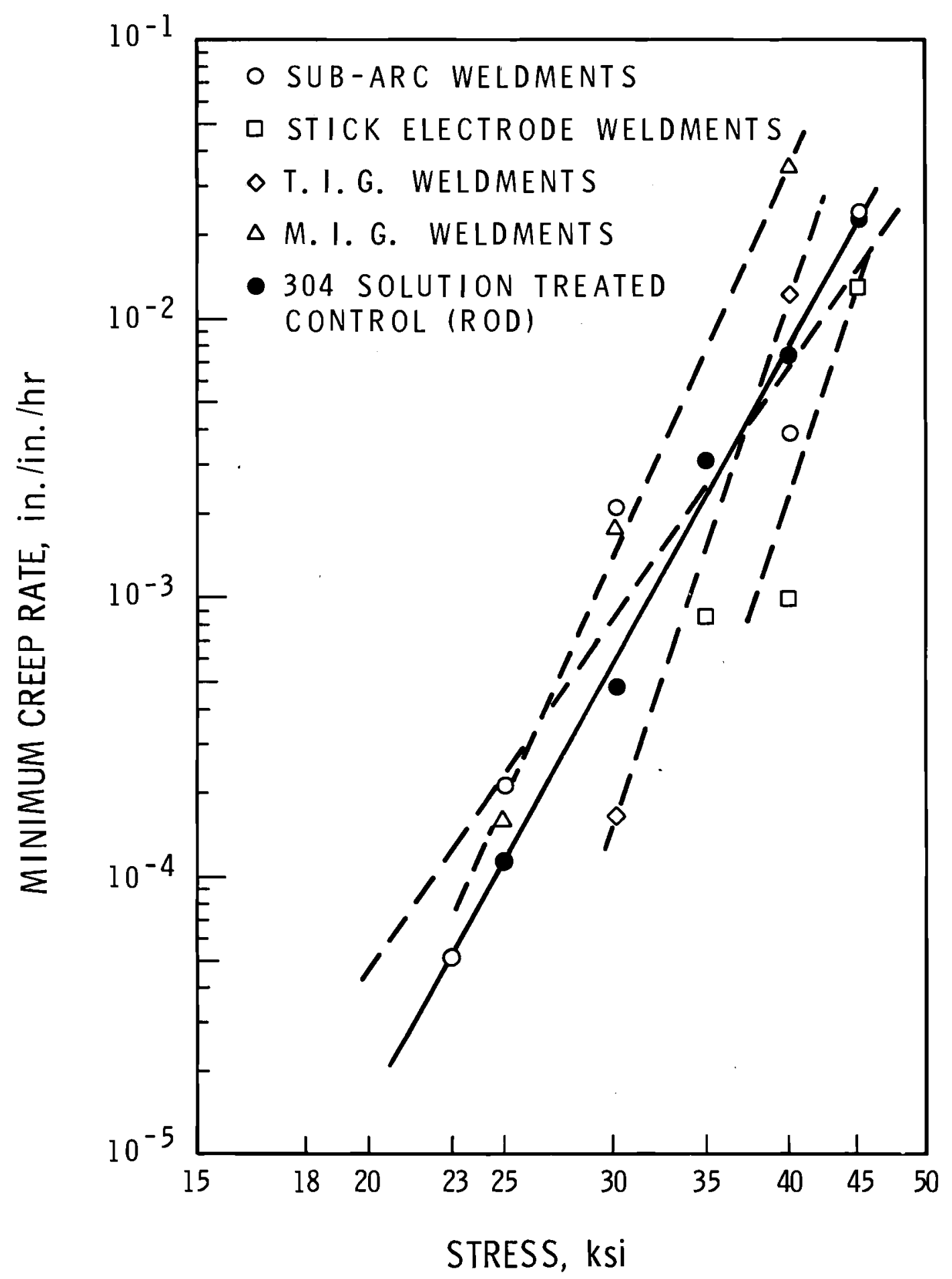

FIGURE 7.4. Creep Rate Versus Stress for We Idments at $1100{ }^{\circ} \mathrm{F}$. 


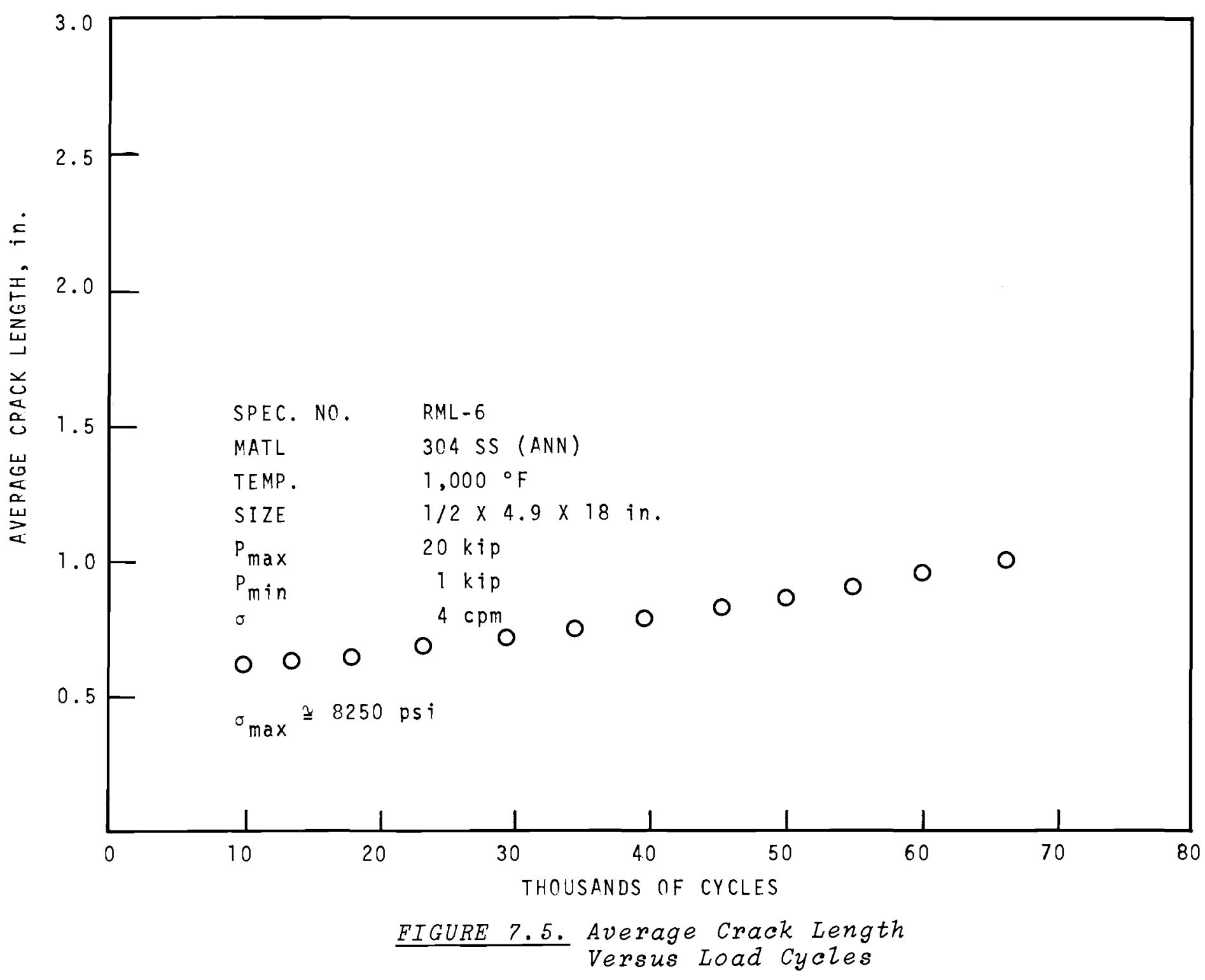


Crack length and cycle information is recorded routinely for data analysis by computer as well as other information such as specimen material, condition or heat treatment, size and test conditions such as environment and temperature. The average crack length is the mean of the crack lengths measured on both sides of the specimen (side - "A" and side - "B"). After completion of testing the maximum gross stress $\left(\sigma_{\mathrm{G}}\right)$, load ratio $\left(R=\sigma_{\min } / \sigma_{\max }=\mathrm{P}_{\min } / \mathrm{p}_{\max }\right) \cdot \operatorname{specimen}$ width $(W)$, crack lengths (a) and corresponding load cycles (N) information are submitted for computer processing.

Crack growth rate, da/dN is approximated by dividing the incremental extension $\Delta a\left(=a_{n}-a_{n-1}\right)$ required to extend the crack $\Delta \mathrm{a}$ for $\mathrm{m}$ crack length measurements from $\mathrm{n}=1$ to $\mathrm{n}=\mathrm{m}$. Corresponding. $\Delta \mathrm{K}$ values are determined by using the mean or average crack length $\frac{a_{n-1}+a_{n}}{2}$ and the relationship below. (1)

$$
\begin{aligned}
& \Delta K=\Delta \nabla \sqrt{\mathrm{a} a v}\left[1.99-0.41\left(\frac{\mathrm{a} a v g}{W}\right)+18.70\left(\frac{\mathrm{a}_{\mathrm{avg}}}{\mathrm{W}}\right)^{2}\right. \\
& \left.-38.48\left(\frac{\mathrm{a}_{\mathrm{avg}}}{\mathrm{W}}\right)^{3}+53.85\left(\frac{\mathrm{a}_{\mathrm{avg}}}{\mathrm{W}}\right)^{4}\right]
\end{aligned}
$$

Six different computer programs are used for handiing related K-data. SIEDNO-SIingle-EDge-NOtch is the program used specifically for SEN specimens and yields tabulated data for plotting variables such as "a" versus $N$ and $\Delta K$ (or $K_{\text {max }}$ ) versus $\mathrm{da} / \mathrm{dN}$.

A statistical analysis capability is being developed for establishing confidence limits on crack growth rate data. The capability is being factored into the least squared analysis (SUML06 program) for calculating $\Delta \mathrm{K}$, da/dN and fitting an

(1)"Plane Strain Crack Toughness Testing of High Strength Metallic Materials," ASTM Stp 410, pp 12. 
average power law curve through the same values. The program will be verified using Type 7075-T6 aluminum because there is a large volume of data on this alloy in the literature.

4. High Strain Rate Effects

J. E. Irvin* and J. M. Steichen**

The objective of the high strain rate studies is to evaluate the effects of high strain rates on the mechanical properties of LMFBR materials which are expected to be used in the FTR vessel and core components. The results of this program will provide information on the behavior of the vessel during impact from within and on the behavior of core components during thermal transients and other conditions of rapid loading.

During the past month, high strain rate testing was continued on Type 304 SS with tests at a strain rate of about $10 \mathrm{in./in./sec}$ in air at test temperatures from room temperature to $1400^{\circ} \mathrm{F}$. The photographs of the oscilloscope traces are being analyzed.

Prior to these tests the load and disf zement calibrations on the dynamic loader were calibrated and found to be in good agreement with the values obtained from calibrations performed in June.

Metallography of six specimens tested at strain rates of $0.1,1.0$, and $10 \mathrm{in./in./sec}$ at room temperature and $1000^{\circ} \mathrm{F}$ is under way.

5. Mechanical Testing of Irradiated Fue1 Pin Cladding R. L. Fish ${ }^{\dagger}$ and H. R. Brager ${ }^{+}$

The purpose of this program is to provide a basis for evaluating the combined effects of fuel cladding interaction, fluence and operating temperature on the postirradiation burst

* (7N96) + (7N72. J. J. Holmes)

$*$ * (7A41) + + (7A35) 
and stress-rupture properties of fuel pin cladding. The effort thus far has utilized fueled cladding from BNW-1 and BNW-59 series fuel pins.

As reported earlier, burst pressures on sections taken from the upper portion of BNW 1-3 and 1-6 were much 1 ower than for the controls, plenum or sections taken from the lower section of the fuel element. The corresponding ductility was also greatly reduced for the upper sections.

Scanning electron microscopy results indicate possible existence of ( $\mathrm{Fe}, \mathrm{Cr}$ ) carbide precipitation at the grain boundaries of cladding taken from an upper fueled specimen. Subsequent extraction replicas taken from this same sample and examined under an electron microscope confirmed the existence of an $\mathrm{M}_{23} \mathrm{C}_{6}$ precipitate along the grain boundaries. As shown in Figure 7.6 sigma phase was found in the same regions. No precipitation of any kind was observed in the extraction replica of cladding from a lower fueled specimen.

It is thought that the changes in burst strength are induced by the existence of a presently unknown corrosive agent that penetrated the grain boundaries under the action of the applied stress. This penetration weakened the grain boundaries of the sensitized cladding.

6. B $_{4}$ C Compatibility

J. E. Irvin* and L. R. Bunne $11^{* *}$

Boron carbide pellets of three densities $(75,85$, and 96\% TD), sodium-bonded for 100 hours to Type 316 SS, had previously been examined for compatibility with sodium. The results showed some cracking in the high density pellets, but the lower density pellets underwent little or no damage. Results from recently opened identical capsules, operated at $300{ }^{\circ} \mathrm{C}$ and $500{ }^{\circ} \mathrm{C}$ for $3450 \mathrm{hr}$, were more in line with expectations. The $75 \%$ TD pellets were badly cracked, both at $300{ }^{\circ} \mathrm{C}$

* (7N96) ** (7A32)




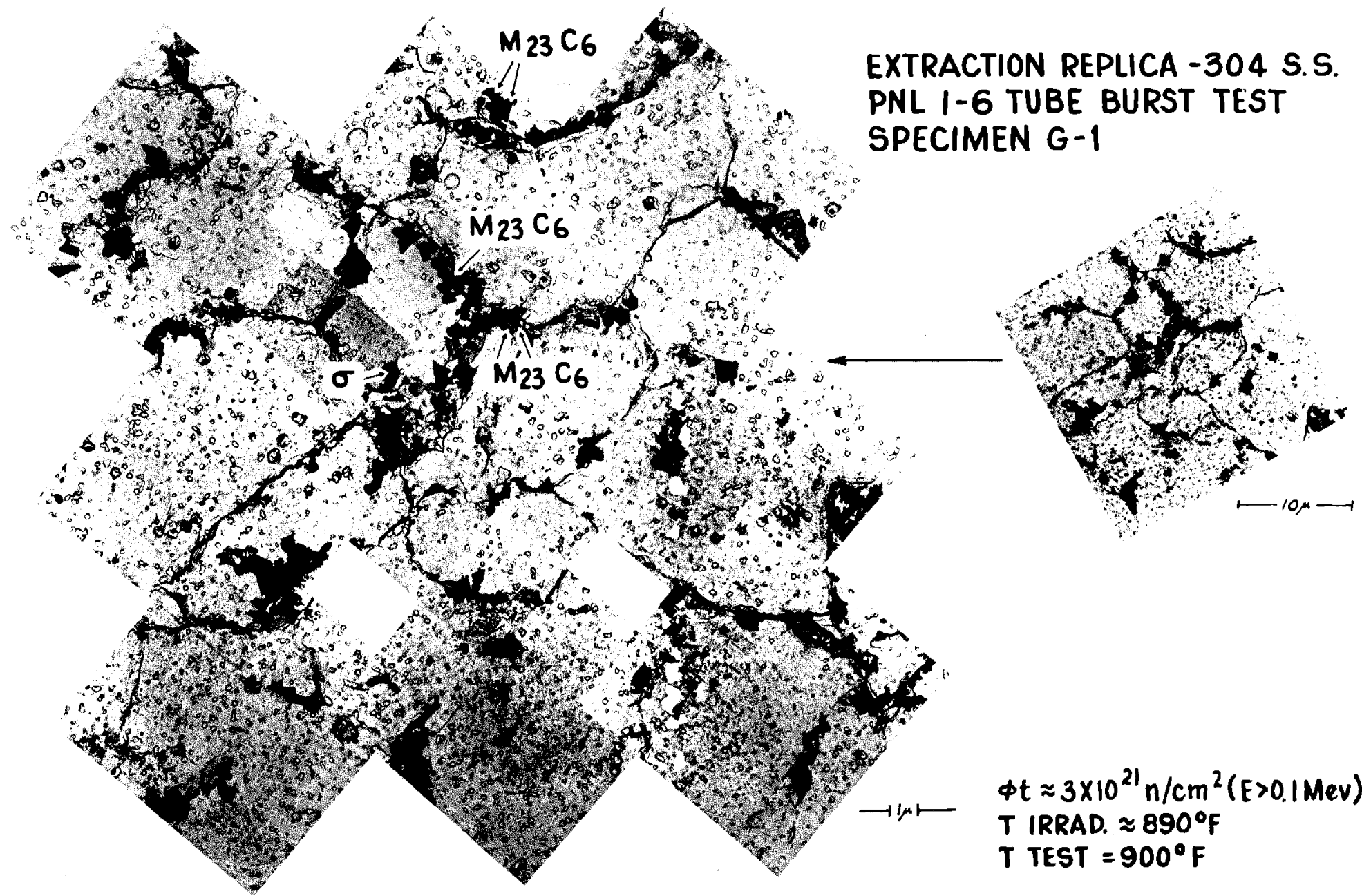

FIGURE 7.6. Extraction Replica of specimen from Above Fuel Midplane. 
and $500{ }^{\circ} \mathrm{C}$, and their microstructures showed regions of corrosion in zones where density was less than the average pellet density. Both the $85 \%$ and $95 \%$ TD pellets were more severely cracked at the outer surfaces than in the $100-\mathrm{hr}$ test. The Type 316 SS showed no signs of carburization by the long-term exposure. Actual boron and carbon pickup will be determined by spark-source mass spectroscopy.

7. Radiation Effects on $\mathrm{B}_{4}$ C

J. E. Irvin, ${ }^{*}$ A. L. Pitner, ${ }^{*}$ and D. E. Baker**

Postirradiation analysis was continued for two capsules of vibrationally-compacted boron carbide powder ( $280 \%$ TD) which were irradiated in EBR-II at $1125^{\circ} \mathrm{F}$. The average burnup was 1.59 atomic ${ }^{10} \mathrm{~B}$. After removing the boron carbide from the Type 304 SS cladding, some of the particles were observed to adhere to one another. However, when these particles aggregates were disturbed, they broke up easily.

Rather than sintering, it actually appears that generally the particle sizes decreased. Whereas $43 \%$ of the particles were in the 10 to 20 mesh size before irradiation, only $25 \%$ of the powder fell in this range after irradiation. While only $24 \%$ of the unirradiated material was -325 mesh, $33 \%$ of the irradiated $\mathrm{B}_{4} \mathrm{C}$ was comprised of these fine particles.

B. MATERIALS TECHNOLOGY

1. Vendor Development

D. E. Mahagin*

Experience with commercially available boron carbide has shown that the material exhibits variations in both its chemistry and its physical properties. Differences have been observed in products from different vendors; and in some cases,

* (7N96)

$* *(7 A 00)$ 
modifications have been noted within individual batches from the same supplier. From the standpoint of reliable in-reactor operation, characteristics of this sort are undesirable; and a major goal of this program is identification of firms who are capable of supplying high quality boron carbide pellets that conform to FTR control rod specifications. An additional, and more significant, objective is the development of commercial sources for complete control rod poison assemblies.

Provisiona $1 \mathrm{~B}_{4} \mathrm{C}$ pellet specifications have been prepared. Potential pellet vendors were contacted, and those who expressed an interest in supplying poison materials for the first FTR core loading were visited. The specifications were discussed with them, and possible points of exception were explored. Of the five firms visited, four appear capable and willing to furnish pellets for evaluation and development testing. 


\section{FUELS RECYCLE}

A. FUEL TECHNOLOGY

1. Pellet Fabrication for PNL-6

W. E. Warden* and R. M. Crawford*

Fuel pellet fabrication for EBR-II subassembly PNL-6 was completed. The fuel was $30 \%$ enriched $\left({ }^{235} \mathrm{U}\right)$ in the standard EBR-II test composition of $75 \% \mathrm{UO}_{2}-25 \% \mathrm{PuO}_{2}$. Six kilograms of fuel were sintered for the subassembly.

A11 of the fuel pellets required for EBR-II test subassembly PNL-6 were centerless ground and characterized. All required stainless steel components were cleaned, and all bottom end caps were welded into the tubes.

\section{Fractional Factorial Experiment}

M. J. Barr

Sintering of the 82 -cell fractional factorial experiment is essentially complete with 80 cells sintered, weighed, and measured. All information will be submitted for computer analysis when sintering is complete.

3. Density of $(\mathrm{U}, \mathrm{Pu}) \mathrm{O}_{2}$

M. J. Barr

The theoretical density of $(\mathrm{U}, \mathrm{Pu}) \mathrm{O}_{2}$ was calculated at $\mathrm{O} / \mathrm{M}$ ratios of 1.95 and 2.00 . Published lattice parameters were used as the basis of calculation. Figure 8.1 shows that the theoretical density increases with increasing $\mathrm{PuO}_{2}$ content and that changes in $0 / M$ ratio toward 1.95 substantially reduce the theoretical density. The theoretical density for fully enriched $(98.12 \%) \mathrm{UO}_{2}-\mathrm{PuO}_{2}$ compositions is also included in Figure 8.1 .

* (7N73-E. T. Weber) 


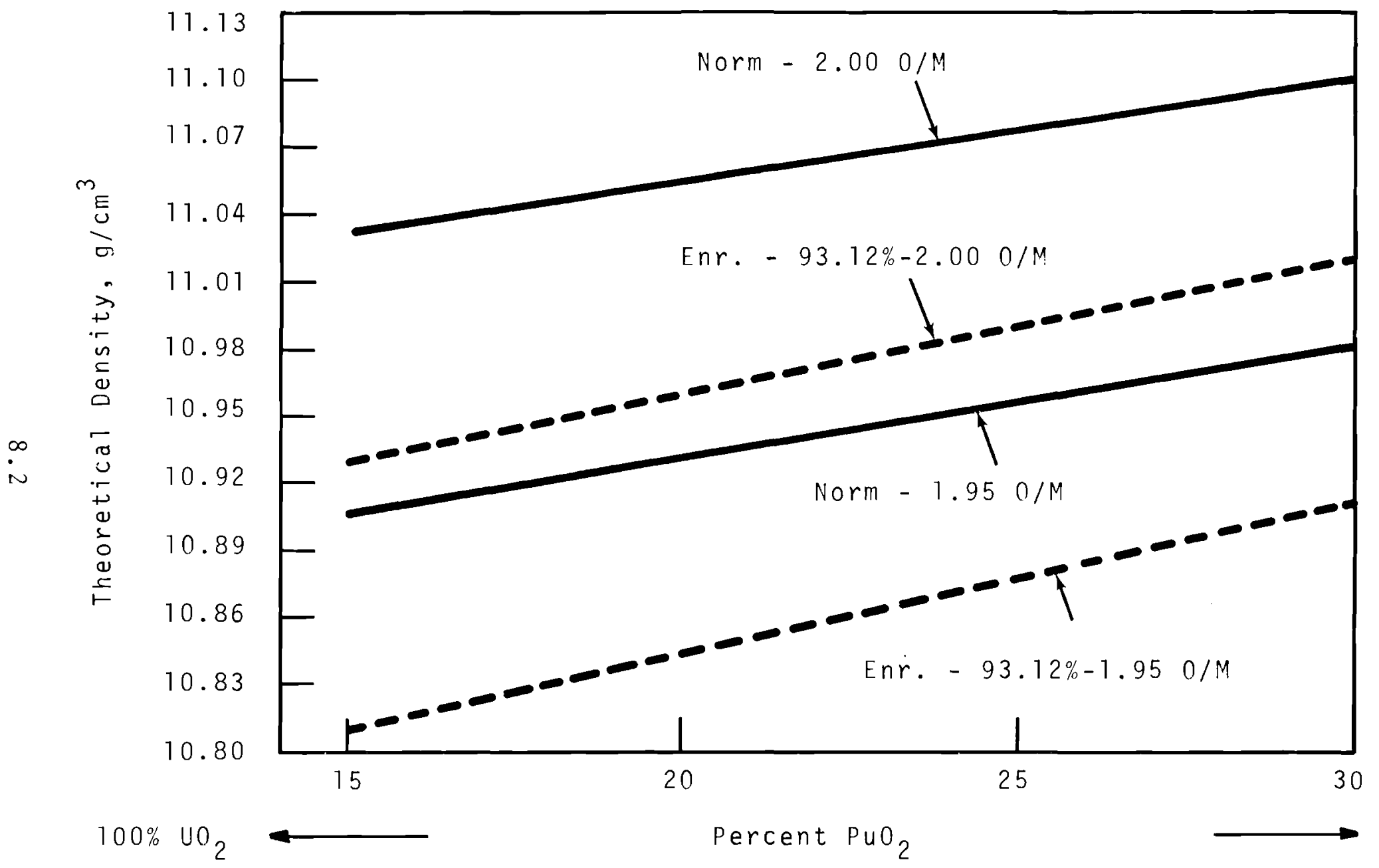

FIGURE 8.1. Theoretical Density Versus Percent $\mathrm{PuO}_{2}$ in $(U-\mathrm{Pu}) \mathrm{O}_{x}$
Based on Lattice Parameters 
4. Pellet Fabrication for EBR-II Test Subassemblies

PNL-9, 10, and 11

W. E. Warden*

Fuel material specifications for EBR-II test subassemblies PNL-9, 10, and 11 require pellet densities of $90.5 \pm 2.5 \% \mathrm{TD}$ and dished-end pellets $3 \pm 1.5 \mathrm{mil} \mathrm{dish}$ and $15 \pm 5$ mil land. A development effort to identify appropriate changes in the fuel fabrication process was partially completed.

The specified fuel pellet density $(90.5 \pm 2.5 \%$ TD $)$ requires modification of fuel processing conditions and operations. Four possible approaches to changing the fuel process were tested: (a) reduction of powder activity (sinterability), (b) use of volatile pore formers, (c) use of less efficient compaction lubricant, and (d) high pressure preslugging of powder.

All four of the process changes tested in the experiment lowered the sintered pellet density $1 \% \mathrm{TD}$ to $6 \% \mathrm{TD}$ below the density of the control batch fabricated using established procedures. (See Table 8.I) Al1 of the experimental batches reached densities, with the exception of MEE-66-4 (1 wt: PVA +0.5 wt: Sterotex binder), which were within the specified fuel pellet density range $(90.5 \pm 2.5 \% \mathrm{TD})$. The preslugged material produced sintered pellets with densities nearest the nominal specified density of $90.5 \%$ TD. This approach appears best suited to meeting the requirements of fuel fabrication for PNL-9, 10 , and 11 .

* (7N73-E. T. Weber $)$ 
BNWL -1217

TABLE 8.I. Effects of Process Variations

on Sintered Pellet Density*

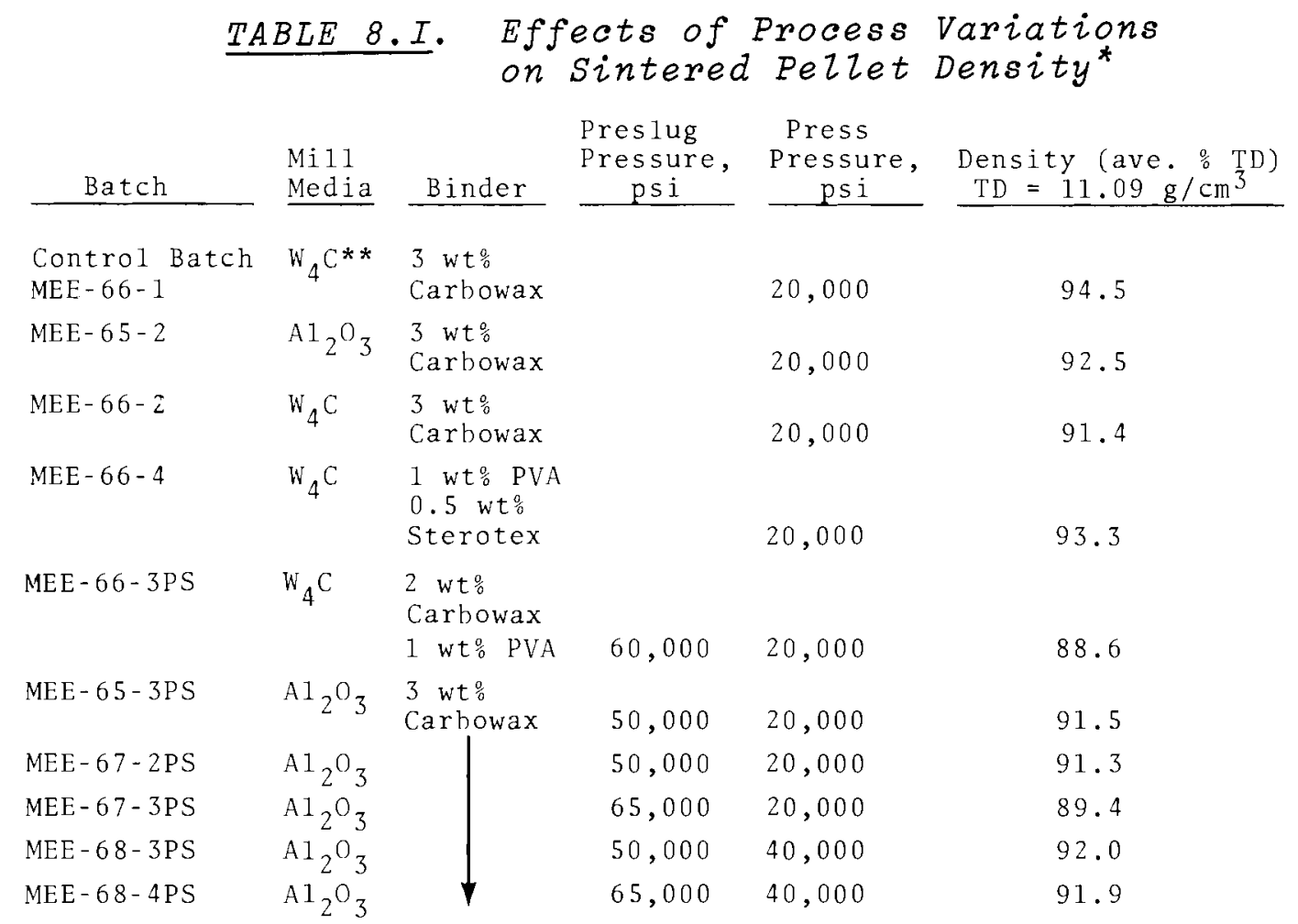

* NOTE: Test pelzets for the density change experiments were not dished. * Tungsten carbide radiused-end cylinders manufactured by Kennametal Inc.

5. Application of Scanning Electron Microscopy to Study of FFTF Fue1 Materia1s

E. T. Weber and J. L. Danie1**

The recently installed scanning electron micrographs (SEM) $\mathrm{X}$-ray analyzer was thoroughly tested on a number of materials. Its capability to determine the composition of areas as smal1 as $1000 \AA$ diameter has eliminated much of the guesswork associated with evaluation of micrographs, and in some corrosion studies the instrument has revealed the presence of several highly significant components previously unsuspected.

Study and characterization of oxide powder morphology using scanning electron microscopy was continued with the

* (7N73)

** (7A00) 
preparation of a series of specimens aimed at three different objectives. The first concerns developing a detailed understanding of reference materials and processes currently being used in FFTF fuel process demonstration. The second is for study of effects of changes in basic fabrication and sintering conditions, including the oxidation state of the components, extent and condition of powder milling, time and temperature of sintering, and other controllable variables. The final series provides for evaluating effects on sintered fuel characteristics of blending various proportions of $\mathrm{PuO}_{2}$ and ${ }^{235} \mathrm{UO}_{2}$ from different sources.

6. Fue1 Vendor Prequalification Program

J. F. Williams*

The three contractors (United Nuclear Corporation, Nuclear Materials and Equipment Corporation, and Babcock and Wilcox Company) participating in the program for prequalification as LMFBR fuel suppliers are processing raw materials, but none has yet started pressing and sintering fuel pellets.

Babcock and Wilcox was released to blend mixed oxides and has proceeded through the blending of three batches. The first batch blended was tested for sinterability and the resulting pellet was subjected to alpha autoradiography. The test determined that there were areas of plutonium enrichment in excess of the $50 \mu$ diameter specification. The sinterability test pellets are made by a different technique than prepared for the finished fuel and Babcock and Wilcox does not expect to encounter a homogeneity problem in the production fuel pellets. A waiver was granted Babcock and Wilcox to proceed with their processing. Fabrication of the metal components and the insulator pellets is nearly complete.

* (7N71) 
$\mathrm{A} \mathrm{PuO}_{2}$ accountability difference between NUMEC and ARHCO is being resolved by umpire analys is of NBL which is not yet complete. However, on the basis of both parties agreeing to accept the referee results, the material was released to production. NUMEC completed calcination of the $\mathrm{PuO}_{2}$.

Calcination of $\mathrm{UO}_{2}$ was completed by United Nuclear, and fabrication of insulator pellets is underway. UNC selected their subcontractor for metal component fabrication, and the subcontractor is preparing QA procedures as required.

7. Fuels Homogeneity

B. R. Hayward* and F. M. Smith*

Good progress was reported by GE in defining a homogeneity model and developing a quantitative method for measuring homogeneity. GE selected the track etch alpha autoradiograph technique as the most promising of the methods considered. The alpha track data are analyzed and quantified using Quantimet equipment.

A figure of merit which describes the homogeneity of mixed oxide fuels in terms of the uniformity of energy deposition in the $\mathrm{UO}_{2}$ of a fuel pellet is being developed and evaluated by BNW.

\section{NUMEC Tasks}

B. R. Hayward* and F. M. Smith*

NUMEC prepared a11 the mixed oxide powders for fabricating fuel pellets for their Task 7 irradiation pins. Preliminary sintering tests are being made to establish process parameters for making $90 \%$ dense pellets. A11 components for the pin assembly are fabricated except for the wire wrap and plenum springs. The revised Engineering Test Plan was completed. The detailed quality assurance plan was issued in draft form for review.

* (7N71) 
The NUMEC Task 1 capsule X012 was discharged from the EBR-II for interim examination at $90,000 \mathrm{MWd} / \mathrm{T}$. X012 contains mixed oxide pellets with flat and dished ends, fuel-cladding gaps of 0.5 to $2.2 \mathrm{mils}$, smear densities of 80 to $89 \%$, pellet densities of 83 to $90 \%, 0 / M$ ratios of 1.95 to 2.00 , and 0.015 and 0.030-in. thick Type 316L SS cladding. NUMEC is considering irradiating duplicate specimens to $130,000 \mathrm{MWd} / \mathrm{T}$.

B. Cladding Technology

1. Cladding Production

R. J. Lobsinger* and R. C. Aungst*

A total of 4,000 feet of Type 316 SS tubing was received from CarTech during the past month, produced as a limited production run by the best process obtained to date. This process involves a 20-min etch in nitric-hydrofluoric acid prior to the last three draw passes to remove any metallic inclusions that may have been introduced earlier in the processing operation. Histograms of eddy current test data indicate that the quality of the tubing is significantly improved over that of the control samples. The improved quality of this tubing places it in a category far above that of any tubing previously used in any irradiation test and represents the best cladding yet received on the FFTF/LMFBR Program.

\section{Cladding Acceptance}

M. M. Paxton**

The objective of this program is to ensure that acceptable cladding material is obtained and utilized throughout the FFTF fuel development and irradiation testing program.

\footnotetext{
* (7N72-J.C. Tverberg)

* (7N72-J.J. Holmes)
} 
Tensile tests on tubing lots $\mathrm{E}, \mathrm{F}, \mathrm{G}$ and $\mathrm{H}$ were completed at room temperature, $800,1000,1200,1400$ and $1600^{\circ} \mathrm{F}$ at strain rates $\dot{\varepsilon}$ of $0.01,1.0$ and $10.0 \mathrm{~min}^{-1}$.

3. Cladding Vendor Development

J. C. Tverberg*

In general all of the vendors have shown a great initiative and willingness to work with us in improving the overall tubing quality. They generally have the attitude of optimism that we will improve the quality of tubing and that eventually the prices will decrease.

\section{a. Carpenter Technology Corporation}

Quality assurance documentation was received and comments made on the process proposed. Gun drilling was continued at the subcontractor, Clarke and wheeler of Los Angeles, and tube hollows are being supplied to CarTech at the rate of 20 per week. Inspection of the tube hollows is progressing with emphasis on removal of chips and residual materials following the gun drilling operation.

\section{b. Sandvik}

Documentation continued to arrive from Sandviken, Sweden and evaluation of this documentation has been forwarded to them. Some difficulties were encountered in the production of the final tubing in the form of slight striations caused by the air gaging equipment. This has been corrected and we have been assured that high quality tubing is now being produced. The tubing is expected to be shipped by the end of september.

$(7 N 72)$ 


\section{c. Superior Tube Company}

Process documentation was received from the vendor during this past month, and comments made on it. Superior indicated that an order was placed with Allegheny Ludlum Corporation for stainless steel bar and a delivery is expected during October, 1969. Superior's schedule indicates they will complete the contract by the first week of April, 1970.

\section{d. Wolverine Tube Company}

Documentation continued to be received from the vendor for review and comment. Because of a disparity in the analyses between the induction melt ingot and the consumable vacuum remelt ingot we requested a re-run of the carbon analysis to determine if an error had been made during one of the analyses. Wolverine indicates tubing orders are on schedule and that they will begin to reduce tube hollows to tubing by early october. Wolverine is presently ahead of schedule.

4. Fuel and Cladding Center

F. R. Shober*

Design of programs for data storage, retrieval, and display were the major efforts of the LMFBR Fuel and Cladding Information Center during this reporting period. Existing storage files were updated with the mechanical property data from cladding characterization and irradiation effects studies.

The design of programs is part of a continuing effort to provide the capabilities needed to store data from all LMFBR type fuel pins now being irradiated or being prepared for irradiation. The status of a program related to storage of data on fuel pin materials, fabrication, irradiation and postirradiation examination is that all data fields have been identified and a data input format is being prepared. A

$(7 N 72)$ 
second program was initiated to provide computer plotting of all tabular data related to the above fields. A third program, about $90 \%$ complete, provides for computer data calculation and graphic plotting of creep data.

Five retrieval requests for materials property information were received and answered. Three were from onsite and two from offsite laboratories. They included the generation of 50 stress-versus-strain plots and three mechanical property versus neutron fluence plots.

The total number of tests for which data are on file is 6,386 tests on over 40 different a11oys. A11 of these data are from tests made at Battelle-Northwest.

C. FUEL PIN TECHNOLOGY

1. Fabrication of Physics Test Fuel Pins C. A. Strand*

A total of 310 fuel pins have been fabricated in the FFTF Fuel Demonstration Facility for test studies. Based on FTR specification, the fuel pins fabricated had a first-run assemb1y yield of $86.8 \%$. Most of the fuel pin rejects occurred at welding as a result of either low weld penetration or tungsten inclusions. (1) other reject categories included cracked pellets, improper loading, length, and other miscellaneous set-up rejects. Reject categories and the station reject rate for the first and second halves of the run and the entire run are itemized in the following tabulation:

(7N73 - R. E. Bardsley)

1. End caps for these test pins were designed specifically to meet the test end configuration requirements and are not prototypic of FETF Fuel pin design. 


\begin{tabular}{|c|c|c|}
\hline First Half & Second Half & Tota 1 \\
\hline $6.2 \%$ & $0.6 \%$ & $3.2 \%$ \\
\hline $9.6 \%$ & $11.6 \%$ & $10.4 \%$ \\
\hline $1.8 \%$ & None & $0.8 \%$ \\
\hline $3.6 \%$ & $0.6 \%$ & $2.0 \%$ \\
\hline
\end{tabular}

With the exception of upper end cap welding, all station reject rates were less for the second half of the run. The increase in upper end cap welding was attributed to modification of the upper end cap to reduce weld contamination problems experienced during the first half of the run.

2. Fabrication of Xenon-Tagged Fuel Pins

W. E. Warden* and K. M. Chidester*

Twelve pins for capsules FP-33 and FP-37 (Gap Closure Experiment) were tagged with various helium/xenon mixtures during the final closure weld operation. The following results were obtained:

\begin{tabular}{|c|c|c|}
\hline Pin Number & Gap & $\because$ Xenon $(a)$ \\
\hline $\begin{array}{r}\mathrm{FP}-33-2 \mathrm{~A} \\
2 \mathrm{~B} \\
3 \mathrm{~A} \\
3 \mathrm{~B} \\
4 \mathrm{~A} \\
4 \mathrm{~B}\end{array}$ & $\begin{array}{r}2 \\
11 \\
2 \\
11 \\
2 \\
11\end{array}$ & $\begin{array}{l}22.3 \\
22.3 \\
48.8 \\
48.8 \\
99.3 \\
99.3\end{array}$ \\
\hline $\begin{array}{r}F P-37-2 A \\
2 B \\
3 A \\
3 B \\
4 A \\
4 B\end{array}$ & $\begin{array}{r}2 \\
11 \\
2 \\
11 \\
2 \\
11\end{array}$ & $\begin{array}{l}41.2 \\
41.2 \\
75.6 \\
75.6 \\
99.6 \\
99.6\end{array}$ \\
\hline
\end{tabular}

(1) Not included in the $86.8 \%$ pin yield. * (7N73-E. T. Weber)

(a) Mass spectrometry of contents of dummy pin filled with the appropriate gas concurrent with closure of the test pins. 


\section{FUEL SUBASSEMBLY TECHNOLOGY}

\section{Project Status \\ M. D. Jackson*}

Project BCP-034 (Fue1 Subassemb1y Fabrication Demonstration Facility) provides for a facility for demonstrating fabrication methods to produce fast reactor fuel pin subassemblies. The overall project is $70 \%$ complete with a forecasted construction completion date of November 15.

Project BAP-022 (P1utonium Fue1s Laboratory Addition) provides for special facilities required for initial storage, handling, testing, assembly, and instrumentation of nonirradiated fue 1 .

The design phase of this project is $50 \%$ complete and it too has a scheduled design completion date of November 15.

2. Mark II CCTL Test Assembly Fabrication

D. E. Blahnik,*R. B. Baker,* R. L. Myers*

A11 fuel pin hardware except the one-inch reflector pieces have been fabricated. New upper end caps may have to be made if the upper end cap design is changed by Westinghouse.

Al1 duct nosepiece components are fabricated. The duct piece is to be expanded to 4.345 in. across the flats, straightened, machined, and characterized. The duct and nosepiece designs may be modified by Westinghouse.

The upper and lower grid and locking bar design is being revised. Grid and locking bar parts were already fabricated to the last approved design. However, they may have to be scrapped if current design studies dictate such a course.

Fuel pin, locking bar, grid plate and duct welding development is in process.

* (7N73-J.W. Thornton) 


\section{PHYSICS}

\section{A. VERIFICATION OF PERT-V REACTIVITY COEFFICIENTS}

L. D. O'De 11*

The reactivity coefficients calculated by PERT-V were compared with those obtained from a series of 1DX runs. S1ab geometry was used for the comparison with a core thickness of $30 \mathrm{~cm}$ and a reflector thickness of $40 \mathrm{~cm}$. The core contained 30 equally spaced mesh intervals and the reflector contained 20. There were five small zones (1 mesh interval each), three in the core and two in the reflector, in which the sodium density was varied for the $1 \mathrm{DX}$ runs. The slab configuration is shown in Figure 9.1.

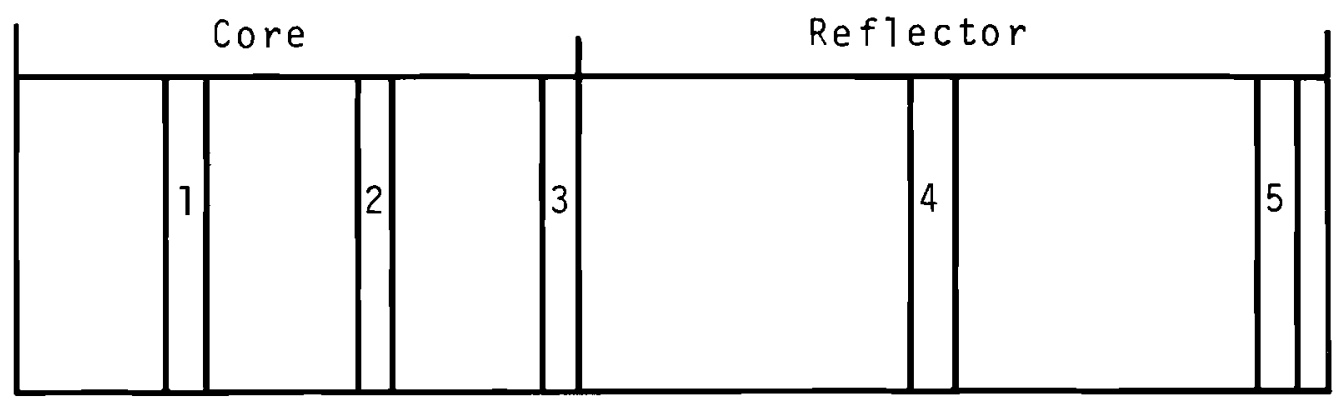

FIGURE 9.1. Geometry Configuration

The 26-group 1DX runs were performed for each of the small test zones with the sodium density varied from half its initial value to 1.5 times its initial value. The zero sample size reactivity coefficient for each test zone was then calculated by averaging the $\delta \mathrm{k} / \mathrm{k}$ values obtained from the two $1 \mathrm{DX}$ runs. A PERT-V run was also made using the 26 group cross sections and fluxes generated by 1DX. Table 9.I shows the calculation

* $7 N 83-$ W. W. Littze 
TABLE 9.I. Comparison of Reactivity Coefficients Calculated by PERT-V and $1 D X$

\begin{tabular}{|c|c|c|c|c|c|c|c|c|}
\hline & $\begin{array}{l}\text { Reactor } \\
\text { Zone } \\
\text { Midnoint }\end{array}$ & $\begin{array}{c}\text { Relative } \\
\text { Sodium }\end{array}$ & $\begin{array}{l}\text { Sodium } \\
\text { Mass } \\
\text { Change }\end{array}$ & & & $\delta k_{\text {eff }}$ & $\begin{array}{l}\text { Sample Size } \\
\delta \mathrm{k} \text { eff } \\
\mathrm{k} \cdot \delta \mathrm{M}\end{array}$ & $\begin{array}{c}\text { Coefficients } \\
\text { skeff }\end{array}$ \\
\hline Zone & $\underset{\mathrm{cm}}{\mathrm{M} 1 \mathrm{apoln} \tau,}$ & Density & $\delta \mathrm{M}(\mathrm{kg})$ & $\mathrm{k}_{\mathrm{eff}}$ & $\delta \mathrm{k}_{\mathrm{eff}}$ & $\overline{\mathrm{k}}_{\mathrm{eff}} \cdot \delta \mathrm{M}$ & $\mathrm{K}_{\mathrm{eff}} \cdot \mathrm{dM}$ & $\mathrm{k}_{\text {eff }} \cdot \delta \mathrm{M}$ \\
\hline Total & -- & $N_{0}$ & 0.0 & 1.0023074 & 0.0 & -- & -- & -- \\
\hline 1 & 9.5 & $0.5 \mathrm{~N}_{0}$ & -0.00017 & 1.0026325 & +0.000235 & -1.90795 & -1.898 & -1.898 \\
\hline & & $1.5 \mathrm{~N}_{\mathrm{o}}$ & +0.00017 & 1.0019858 & -0.000322 & -1.88741 & & \\
\hline 2 & 19.5 & $0.5 \mathrm{~N}_{\mathrm{o}}$ & -0.00017 & 1.0023768 & +0.0000694 & -0.407295 & -0.4014 & -0.4015 \\
\hline & & $1.5 \mathrm{~N}_{\mathrm{o}}$ & +0.00017 & 1.0022400 & -0.0000674 & -0.395558 & & \\
\hline 3 & 29.5 & $0.5 \mathrm{~N}$ 。 & -0.00017 & 1.0020389 & -0.000269 & +1.57578 & +1.574 & +1.574 \\
\hline & & $1.5 \mathrm{~N}$ & +0.00017 & 1.0025753 & +0.000268 & +1.57225 & & \\
\hline 5 & 51.0 & $0.5 \mathrm{~N}_{\mathrm{o}}$ & -0.000384 & 1.0021565 & -0.000151 & +0.392064 & +0.3878 & +0.3881 \\
\hline & & $1.5 \mathrm{~N}_{\mathrm{O}}$ & +0.000384 & 1.0024550 & +0.000148 & +0.383490 & & \\
\hline 5 & 67.0 & $0.5 \mathrm{~N}$ & -0.000384 & 1.0021547 & -0.000153 & +0.396741 & +0.3922 & +0.3925 \\
\hline & & $1.5 \mathrm{~N}$ & +0.000384 & 1.0024566 & +0.000149 & +0.387647 & & \\
\hline
\end{tabular}


of the 1DX zero sample size reactivity coefficients and compares them with the appropriate PERT-V reactivity coefficients. A comparison of the two sets of reactivity coefficients is also shown in Figure 9.2 .

\section{B. USE OF SPATIALLY DEPENDENT CROSS SECTIONS}

R. W. Hardie*

The most common method of generating few-group crosssection data is to collapse multi-group data over fundamental mode spectra. The purpose of this report is to give a numerical comparison between this approach and the more rigorous method of generating cross sections by collapsing over spatially dependent spectra.

Calculations were performed using the 1-D diffusion theory code 1DX for two reactor configurations - - identica1 core compositions and either a $\mathrm{Ni}$ or a U reflector (see Table 9.II). Spherical geometry with a core radius of $50 \mathrm{~cm}$ and a reflector thickness of $40 \mathrm{~cm}$ was used for all cases. The multi-group cross section input consisted of a modified version of the Bondarenko 26-group data set.

\section{TABLE 9.II. Material Compositions}

\begin{tabular}{|c|c|c|c|}
\hline Material & Core & $\mathrm{Ni} \operatorname{Re} f 1$. & $\underline{\mathrm{U}} \operatorname{Re} \mathrm{f} 1$. \\
\hline${ }^{239} \mathrm{Pu}$ & 0.0016 & 0.0 & 0.0 \\
\hline${ }^{23} 8_{\mathrm{U}}$ & 0.0050 & 0.0 & 0.0100 \\
\hline 0 & 0.0100 & 0.0 & 0.0200 \\
\hline $\mathrm{Na}$ & 0.0100 & 0.0050 & 0.0050 \\
\hline $\mathrm{Ni}$ & 0.0200 & 0.0500 & 0.0100 \\
\hline
\end{tabular}

For the fundamental mode calculations, the spectrum used to average core cross sections was generated for $k_{\text {eff }}=1.0$ (i.e., a bucking search calculation) and for the reflector,

* $7 N 83-W . W$. Littze 


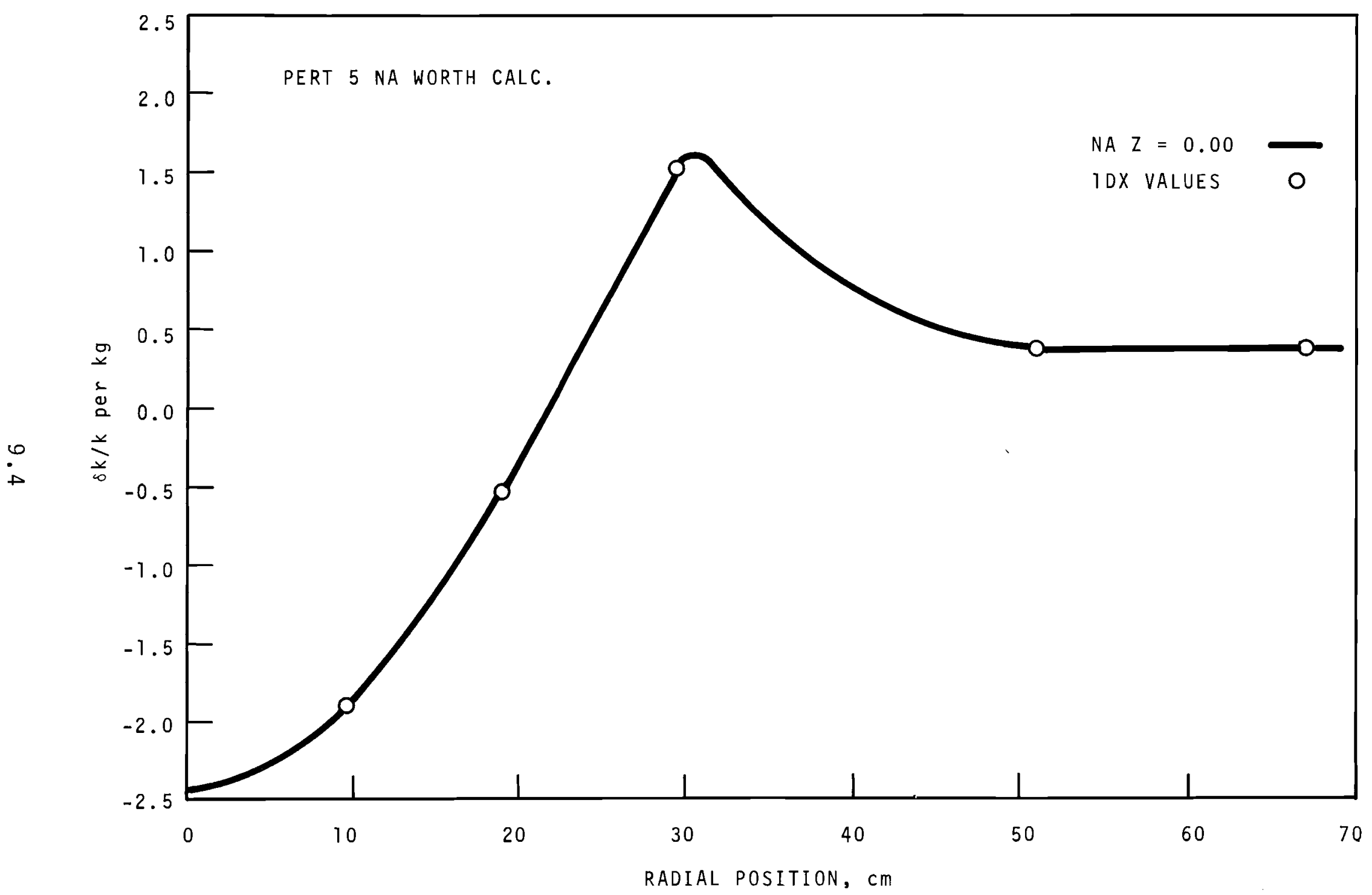

EIGURE 9.2. Comparison of Pert $V$ and 1DX Reactivity Coefficients 
the spectrum was calculated for $B^{2}=0.0$. Four series of runs were made for spatially dependent cross sections. For the simplest case, the core and reflector were treated as individual zones. Then, the core and reflector were broken down into separate zones and cross sections generated for each zone. For a description of the zone breakdown, see Table 9.III.

TABLE 9.III. Zone Breakdown for Generating spatialzy Dependent Cross Sections

\begin{tabular}{|c|c|c|c|c|c|c|c|c|c|c|}
\hline $\begin{array}{c}\text { No. of Core } \\
\text { Zones } \\
\end{array}$ & $\begin{array}{l}\text { Out } \\
1 \\
\end{array}$ & $\begin{array}{l}\mathrm{Ra} \\
\mathrm{Ca} \\
2 \\
\end{array}$ & $\begin{array}{c}\text { us } \\
\text { Zc } \\
3 \\
\end{array}$ & & $\begin{array}{l}\text { No. of } \operatorname{Ref} 1 . \\
\text { Zones }\end{array}$ & $\begin{array}{r}\text { Ou } \\
1 \\
\end{array}$ & $\begin{array}{r}\mathrm{R} \\
\mathrm{Re} \\
2 \\
\end{array}$ & & $\begin{array}{l}\text { Zo } \\
3\end{array}$ & m) \\
\hline 1 & 50 & -- & -- & -- & 1 & 90 & -- & & - & - - \\
\hline 2 & 30 & 50 & -- & -- & 1 & 90 & -- & & - & -- \\
\hline 2 & 30 & 50 & -- & -- & 2 & 70 & 90 & & - & -- \\
\hline 4 & 20 & 30 & 40 & 50 & 4 & 60 & 70 & & 0 & 90 \\
\hline
\end{tabular}

Collapsed cross sections were generated for 8 and 4 groups and $k_{\text {eff }}$ computed. The results are shown in Table 9.IV. The difference between the 26 group values evolves from the $\sigma_{\mathrm{d}}, \mathrm{e}$ iteration scheme in 1DX. It is clear from these calculations that collapsing over fundamental mode1 spectra is entirely adequate. In fact, subdividing the core and reflector into more zones gives a slightly worse eigenvalue -- at least for the two reactors studied.

\section{FTR STABILITY ANALYSIS \\ James R. Sheff*}

A second program capable of generating FTR stability analysis calculations has been placed in operation. The new program is being used for two basic reasons: (1) It is significantly more general in some respects and thus it will eventually

* $7 N 83-W . W$. Littze 


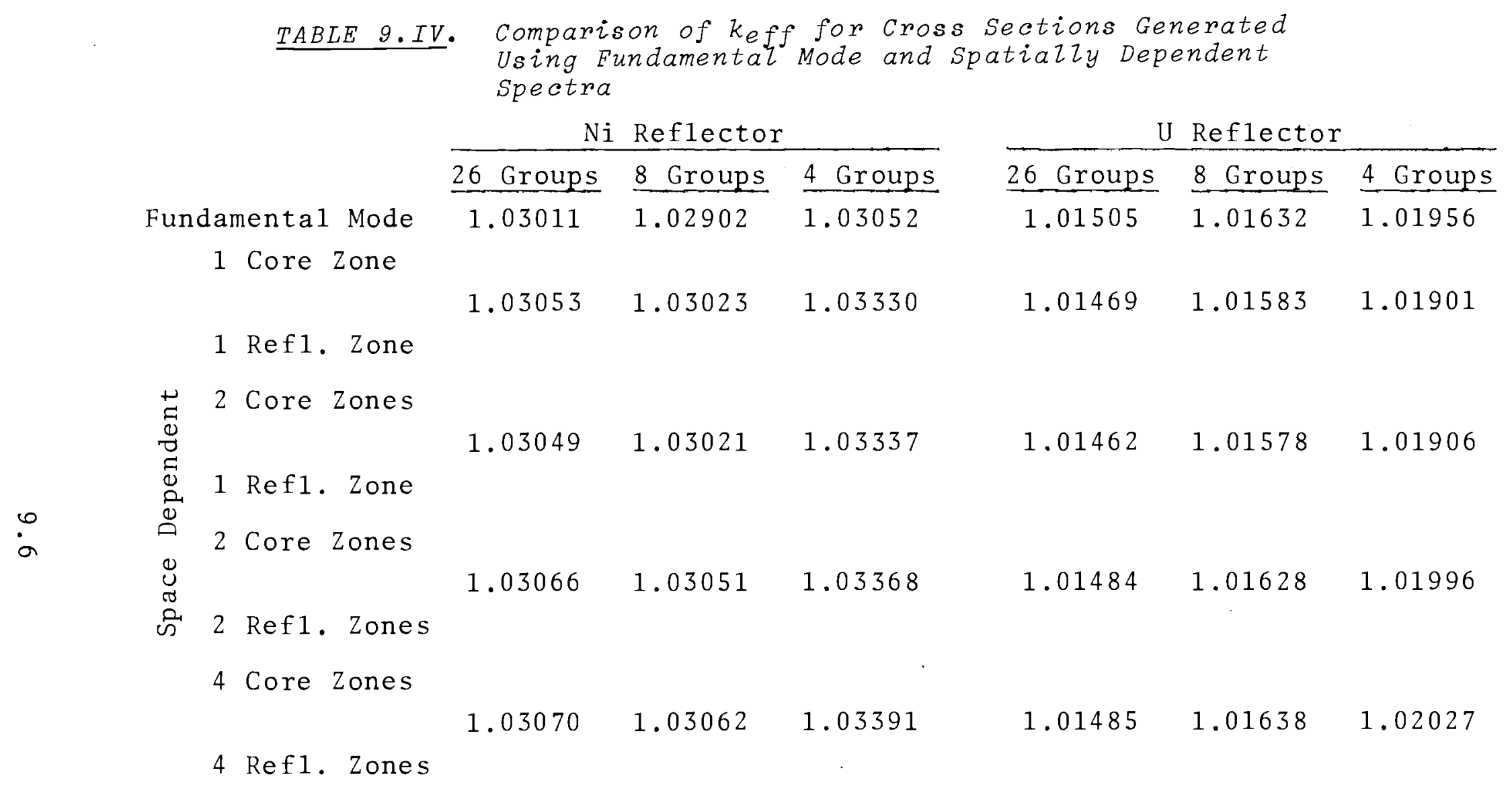


yield more complete results; (2) Because it is quite different in structure from the first program, it will provide a significant check upon the correctness of the current results.

At this time, the two zero-power runs agree, but a11 other pairs of runs do not agree. The problem appears to be in part numerical trouble with a matrix inversion routine, but of more importance, for those cases where there appears to be no numerical problems, a quantitatively large disagreement still exists. The cause is being sought in both programs and data sets.

\section{REACTIVITY MEASUREMENT \\ James $R$. She ff*}

Static subcritical source level measurements currently being made upon the HTLTR reactor have shown up a potential1y serious problem with respect to this type of reactivity meter as we11 as being demonstrated even more clearly the general need for a reliable reactivity meter. Basically, the problem arises because the meter based upon the static subcritical source method must be initially extensively calibrated in situ or it will not indicate reactivities. In HTLTR there is in operation no adequate scheme capable of doing this calibration. That is, since the reactor has no reactivity meter, it can not easily calibrate the one being installed.

A number of potential ways to solve this dilemma are being considered.

E. RSYN

K. B. Stewart and D. P. Taylor*

RSYN was modified to use the fact that $D(X, Y) \operatorname{grad} \phi(X, Y)$ is continuous across material boundaries in the calculation

* 7 N83-W. W. Little 
of the partial derivatives of the trail functions. The changes in the partial derivative calculation yielded values of $k_{\text {eff }}$ that changed less than 0.1 percent for the sample problem. The major difference between the value of $k_{\text {eff }}$ calculated by $2 \mathrm{DB}$ and RSYN was caused by the surface leakage calculation. The leakage calculation was allowed only on a zero-flux boundary condition. This change yielded a value for $k_{\text {eff }}$ of $1.0366 \mathrm{com}-$ pared to $2 \mathrm{DB}$ 's value of 1.0364 or about a $0.02 \%$ difference.

\section{F. EXPONENTIAL AND CRITICAL APPROACH EXPERIMENTS WITH $25 \mathrm{wt} \%$ \\ $\mathrm{PU}_{2}-\mathrm{U}(\mathrm{Nat}) 0_{2}$ PINS IN WATER \\ C. L. Brown and C. A. Rogers*}

Exponential and critical approach experiments with 25 wt: $\mathrm{PuO}_{2}-\mathrm{U}(\mathrm{Nat}) \mathrm{O}_{2}$ fuel pins in water were continued. Dimensions of the clad pins are 0.230-in. in diameter $x$ 28.7-in. 1ong. The fuel columns are $0.195-i n$. in diameter $\times 27.25$-in. 1ong. Each pin contains about $30.5 \mathrm{~g} \mathrm{Pu}$ with about $12 \% 240 \mathrm{Pu}$; fue 1 density is about 93\% TD.

In the experimental lattices, the pins were arranged in triangular pitch and the lattices were fully reflected by water.

To date, measurements have been completed for two lattice pitches: $0.779-i n$, and $0.900-i n$. Results are given in Tables $9 . \mathrm{V}$ and 9.VI. The critical number of pins for each lattice was obtained from backoff measurements with the neutron source out. This technique gives a more accurate estimate of the critical number than the critical approach data with the source in. Least squares fits of the data were obtained with the program LEARN.

Measurements will continue when the remaining 140 of the 300 pins required for the experiments are delivered next month.

* $7 N 83-$ W. W. Little 
BNWL -1217

TABLE 9.V. Results of Exponential Experiments with 25 wt\% $\mathrm{PuO}_{2}-U(\mathrm{Nat}) \mathrm{O}_{2}$ Fuel Pins in Water

\begin{tabular}{|c|c|c|c|c|c|}
\hline $\begin{array}{c}\text { Lattice } \\
\text { Pitch, in. }\end{array}$ & $\begin{array}{c}\text { Water to } \\
\text { Fue1 Volume } \\
\text { Ratio } \\
\end{array}$ & $\begin{array}{l}\text { No. Pins } \\
\text { in Experimenta1 } \\
\text { Lattice } \\
\end{array}$ & $\begin{array}{c}\text { Measured } \\
\text { b11 }\end{array}$ & $\begin{array}{l}\text { Measured } \\
\text { Buck1ing, } \\
m^{-2}\end{array}$ & $\begin{array}{c}\text { Extrapolation } \\
\text { Distance, } \\
\mathrm{cm}\end{array}$ \\
\hline 0.779 & 15.41 & 78 & $-12.85 \pm 0.04$ & $159.3 \pm 1.2$ & $6.98 \pm 0.05$ \\
\hline \multirow[t]{2}{*}{0.779} & 15.41 & 90 & $-15.05 \pm 0.05$ & $160.8 \pm 1.3$ & $6.89 \pm 0.06$ \\
\hline & & & Average & $160.1 \pm 0.9$ & $6.94 \pm 0.04$ \\
\hline 0.900 & 21.01 & 66 & $-12.16 \pm 0.06$ & $137.6 \pm 0.9$ & $6.96 \pm 0.04$ \\
\hline 0.900 & 21.01 & 78 & $-14.26 \pm 0.05$ & $138.6 \pm 0.9$ & $6.83 \pm 0.04$ \\
\hline & & & Average & $138.1 \pm 0.6$ & $6.92 \pm 0.03$ \\
\hline
\end{tabular}

TABLE 9.VI. Results of Approach-to-Critical Experiments with 25 wt\% $\mathrm{PuO}_{2}-\mathrm{U}(\mathrm{Nat}) \mathrm{O}_{2}$ Fuel Pins in Water

$\begin{array}{ll}\text { Maximum } & \text { Extrapolated } \\ \text { Water to } & \text { No. of Pins } \\ \text { No. of Pins Critical }\end{array}$ \begin{tabular}{ccc} 
Lattice Fuel Volume in Experimental & $\begin{array}{c}\text { for } \\
\text { Ratio }\end{array}$ Lattice \\
\hline
\end{tabular}
0.779
15.41
148
156.3
$\sim 4.7$
0.900
21.01
141
$149.6 \pm 0.6$
$\sim 4.5$

\section{G. STATUS OF PHASE B CRITICAL EXPERIMENTS}

\section{R. A. Bennett*}

Following a three-to four-week ZPPR outage, for containment test, the FTR shielding experiments were begun on september 3 . A11 incore reactivity measurements of control strengths and test loop worths were deleted in favor of earlier shield experiments and scheduled start of FTR-3 experiments on zoned cores. Deleted experiments will be performed in the latter. Central fission rate ratios in FTR-2, a repeat of suspect $Z$ PR-3 Assembly 56B measurements, have been delayed until completion of shielding experiments. 
BNW personnel have requested a completion date in the first week of November so that FTR-3 can be built and criticality achieved by about December 1, 1969. Criticality by December 1 , will allow completion of FTR-3 zoned core experiments, and the Phase B program by late June 1970, in time for the scheduled start of the FTR Engineering Mockup on July 1, 1970.

H. FTR-3 PLANNING STATUS

R. A. Bennett*

Requirements for the FTR-3 zone core experiments have been specified and sent to ANL for use in the preparation of time schedule estimates and detailed experimental plans. This program emphasizes measurements of typical FTR control worths, Doppler effects, sodium voiding, and power density measurements in a two-zone 1000 liter critical assembly. The zone atom densities will approximate those of two-zone homogenized FTR.

\section{SUBCRITICAL REACTIVITY MEASUREMENTS}

V. O. Uotinen**

Inference of the worths of peripheral control strengths in ZPR-III Assemb1y 56B from central and extra-core sensors were different by 12 and $3.3 \% 2$ and $1 \% \Delta \mathrm{k} / \mathrm{k}$ strengths, respectively. Values inferred from centrally located sensors were lower.

Intuitively, one would expect sensors in various locations to respond differently to large reactivity changes and, of course, the prime issue is what sensor position is most reliable and more correct.

Two-dimensional diffusion-theory correlations indicate that centrally located sensors were most correct in Assembly 56B experiments. Extra core sensors have been used for most FTR measurements and may need some corrections. The magnitude of

\footnotetext{
* $7 N 83$

** $7 N 83-R$. A. Bennett
} 
the corrections is worth-dependent and is not expected to be as large as the worst situation here and it is expected that diffusion calculation can be used to make the corrections.

J. PIN-FUELED SODIUM VOID EXPERIMENTS

Q. L. Baird*

Argonne National Laboratory personnel have noted, in a review of $B N W$ pin-fueled sodium void experiment proposal, that

(1) The use of 28-in. pins in ANL facilities would be mechanically difficult as well as requiring extensive safety analysis and review;

(2) The use of shorter or half-strength pins would relieve both problems;

(3) ANL pins, (expected to be available Spring of 1970) may be used.

In view of this the entire proposal is being re-evaluated by BNW personne1.

K. ENGINEERING MOCKUP - MATERIAL STATUS

\section{R. A. Bennett**}

In initial planning for the engineering mockup of the FTR preliminary design, it has been established that the present ANL inventory of $300 \mathrm{~kg}$ of natural $\mathrm{B}_{4} \mathrm{C}$ is sufficient to mockup the 7 incore and 22 peripheral rods in the range of 1.0 to $2.2 \mathrm{~kg}$ of ${ }^{10} \mathrm{~B}$ per rod. This corresponds to a range of 19 to 43 volume percent natural $\mathrm{B}_{4} \mathrm{C}$. It is anticipated further that, if necessary, studies of enrichment effects may be a study on a rod by rod basis, using $A N L$ existing enriched $B_{4} C$ inventory.

$* 7 N 83-R \cdot A \cdot$ Bennett
$* * 7 N 83$ 


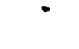




\section{SAFETY}

A. CHANGES IN THE EFFECTIVE DOPPLER COEFFICIENT DURING LARGE ACCIDENTS

A. E. Waltar*

With the successful coupling of the MELT-II and VENUS codes now completed, it is possible, in principle, to follow the course of a major transient from inception through disassembly. During the course of an accident, however, the effective Doppler coefficient may change substantially and, because of its dominating influence, proper characterization attendant with changing core conditions is important.

Figure 10.1 illustrates the change in the effective Doppler coefficient during a hypothetical pipe rupture accident. The initial drop from the assumed starting $\mathrm{T} \frac{\mathrm{dk}}{\mathrm{dT}}$ value of -0.005 results from the asymmetric fuel temperature rise (fuel near the core top rising more rapidly than elsewhere because of the rapid increase in the outlet coolant temperature). "Effective Doppler" is here defined as the coefficient resulting from the use of an average fue 1 temperature for Doppler calculations (See Ju1y 1969 Fast F1ux Test Facility Month1y Informa1 Technical Progress Report for the spatially weighed scheme presently used).

The second major drop is induced by the spectrum hardening which results from coolant voiding. Approximately one half of the core was voided at the termination of the accident.

B. DBA CALCULATIONS

A. E. Waltar*

The consequences of several DBA initiating events have been analyzed using the coupled MELT-II - VENUS computer system. As an example of the type of quantities computed during a major

* 7N83-W. W. Littie 


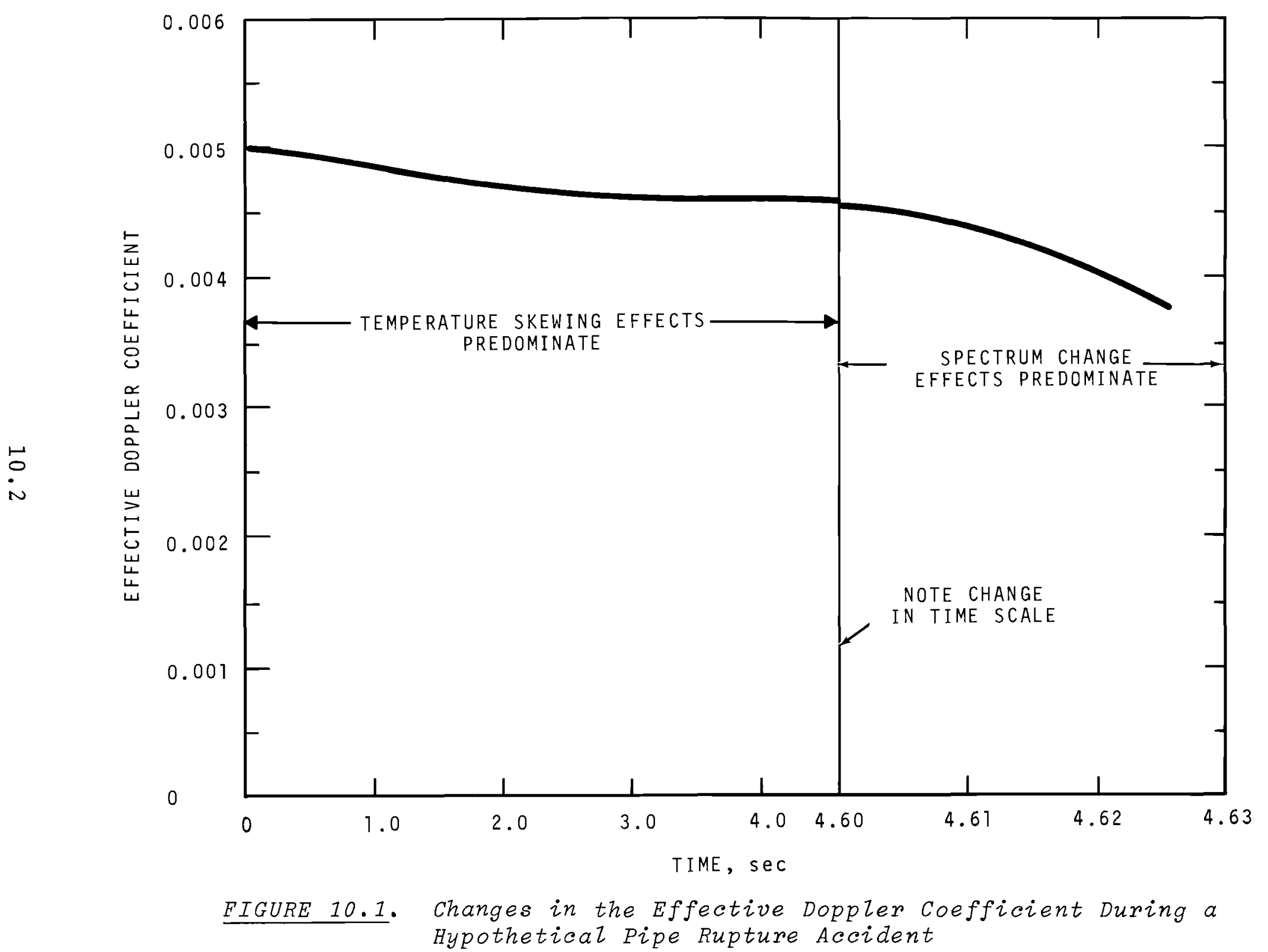


excursion, Figure 10.2 illustrates the reactor response to the passage of a large void through the center of the core. Upon entering the lower reflector, the bubble causes a negative reactivity which, in turn, lowers the power level. As the bubble nears the core center, however, the reactivity effects are positive and the power level quickly rises. Ascending fuel temperatures cause a substantial Doppler feedback but, ultimately, the temperature becomes so high that the core disassembles. Once disassembly starts, the nuclear excursion is terminated within a few milliseconds.

\section{SODIUM VOIDING MECHANISMS}

\section{A. Padilla*}

The rate of sodium voiding from the core, in accident analyses, is of major importance because of the associated reactivity effects. Three possible voiding mechanisms have been identified in the analysis of both power excursions and loss of flow accidents: (1) sodium boiling, (2) release and expansion of fission gases, and (3) a molten fuel-sodium interaction. These three voiding mechanisms have been incorporated into the MELT-II accident analysis code.

During loss-of-flow accidents (e.g., flow coastdown, pipe rupture, complete blockage at subassembly inlet), conditions for sodium boiling are attained within several seconds depending on the severity of the flow decrease and the incipientboiling superheat. Experimental observations with alkali metals such as sodium and potassium and with fluids simulating alkali metals such as freon have shown that the rate of vapor growth can occur as a single bubble which grows and occupies the entire channel and then expands in a piston-1ike manner. Therefore, a simplified expulsion model assuming a slug-type flow regime has been developed.

* 7N83 - P. D. Cohn 
BNWL - 1217

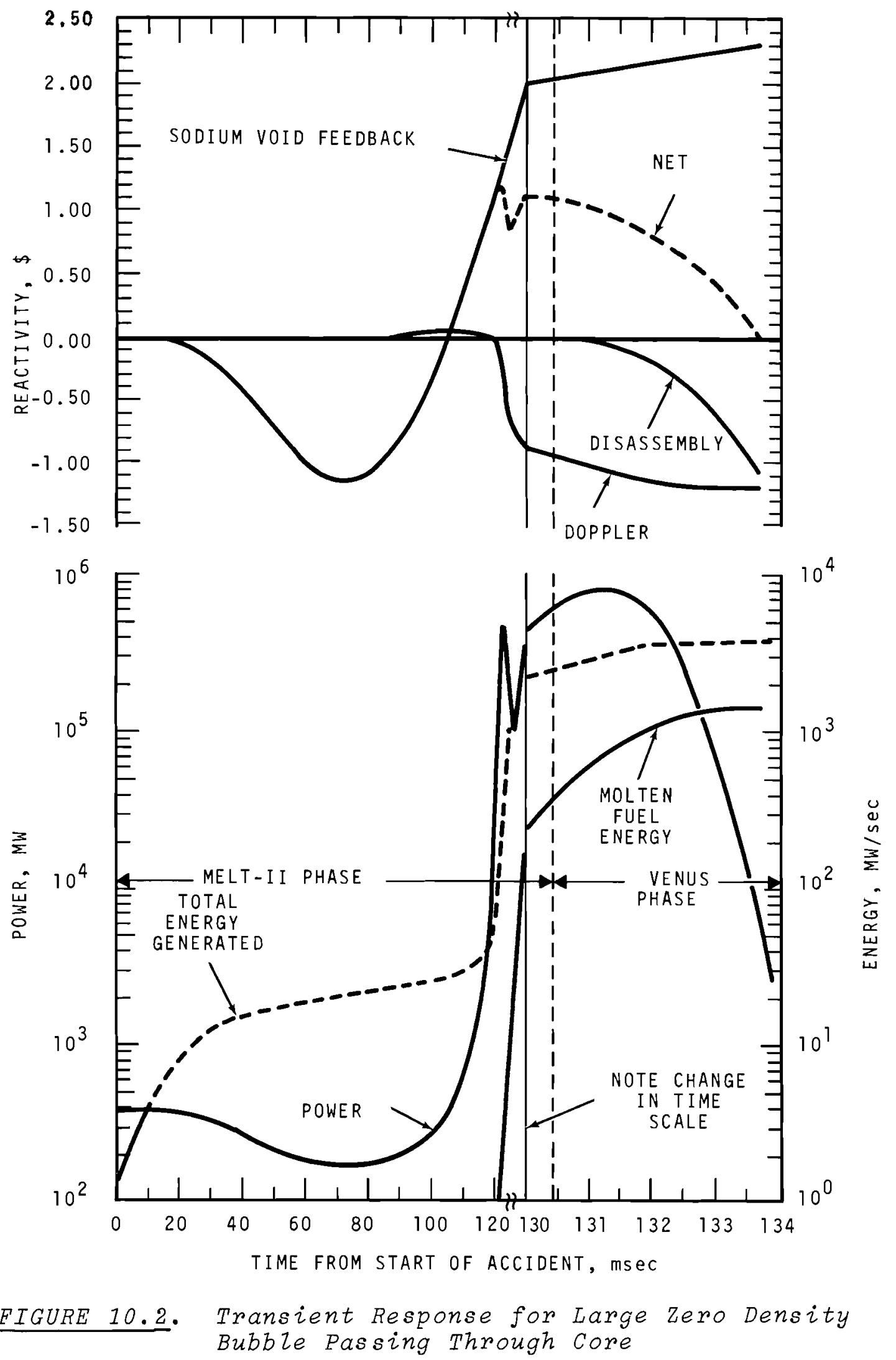


The conditions for boiling are specified by a boiling temperature which includes both the assumed saturation temperature and the superheat. Whenever the sodium temperature reaches the boiling point, the driving force for expulsion of the sodium from the core is obtained by using the cladding temperature at the point of boiling initiation to calculate a pressure according to the sodium vapor pressure equation. The rate of rise of the cladding temperature, and hence the pressure for sodium expulsion, can be controlled within certain limits by an adjustable parameter. Further analytical studies are currently in progress to assess the accuracy of this simplified sodium boiling mode1.

However, the boiling temperature for these loss-of-flow accidents will be above $1700^{\circ} \mathrm{F}$ even for zero superheat. The cladding is relatively weak at these temperatures and may rupture before sodium boiling conditions are attained. The release of fission gases from the plenum above the core can be very rapid because the gases do not have to diffuse through the fue 1 to reach the cladding rupture, if the rupture takes place at the top of the core. This would be the expected location except for a complete flow blockage. The pressure in the fission gas plenum will be of the order of several hundreds of psi if the accident takes place near the end of 1 ife of the fuel. The expansion of the released fission gases could result in much faster voiding rates than sodium boiling depending on how many pins rupture at the same time.

Fuel melting will occur before sodium boiling for rapid power excursions (e.g., reactivity insertions of the order of $2 \$ / \mathrm{sec})$. It is possible for the molten fuel to be expelled into the coolant flow channel and be mixed with the sodium if cladding rupture also occurs. There is experimental evidence that the violent boiling process could result in a vapor 
explosion which would give extremely rapid expulsion of the remaining coolant from the core. It is assumed that the heat transfer rates are so rapid that thermal equilibrium between the molten fuel and the sodium is attained in the expulsion model for the molten fuel-sodium interaction. It is assumed further that the relative amounts of molten fuel and sodium relate in such a manner that the sodium in one axial layer of the MELT-II simulation of the core is heated to the melting point of the fuel (approximately $3040^{\circ} \mathrm{K}$ ). At this supercritical temperature the pressure of the sodium is approximately $700 \mathrm{~atm}$. The decrease in pressure as the sodium volume increases as a result of voiding is determined from a thermodynamic analysis of an adiabatic expansion process.

It is possible that a molten fuel-sodium interaction may not take place even though molten fuel is expelled in to the coolant flow channels. Recent experiments using a sodium autoclave in the TREAT reactor have indicated that the fission and/or fill gas contained within the fuel region can blanket the molten fuel particles from the sodium and prevent the rapid energy transfer. The expansion of this gas could also be sufficient for expelling the sodium from the core. However, it is difficult to determine how much gas is available within the core region and whether the gas in the fission gas plenum would also be available.

Figures 10.3 and 10.4 compare the sodium voiding mechanisms for loss-of-flow accidents and power excursions, respectively. FFTF fuel subassembly geometry and operating conditions were used for the analysis. The conditions in Figure 10.3 correspond to a flow coastdown and the voiding is assumed to start at the top of the core where the coolant and cladding temperatures are the highest. The voiding in the downward direction takes longer because the initial momentum of the coolant flow 
BNWL -1217

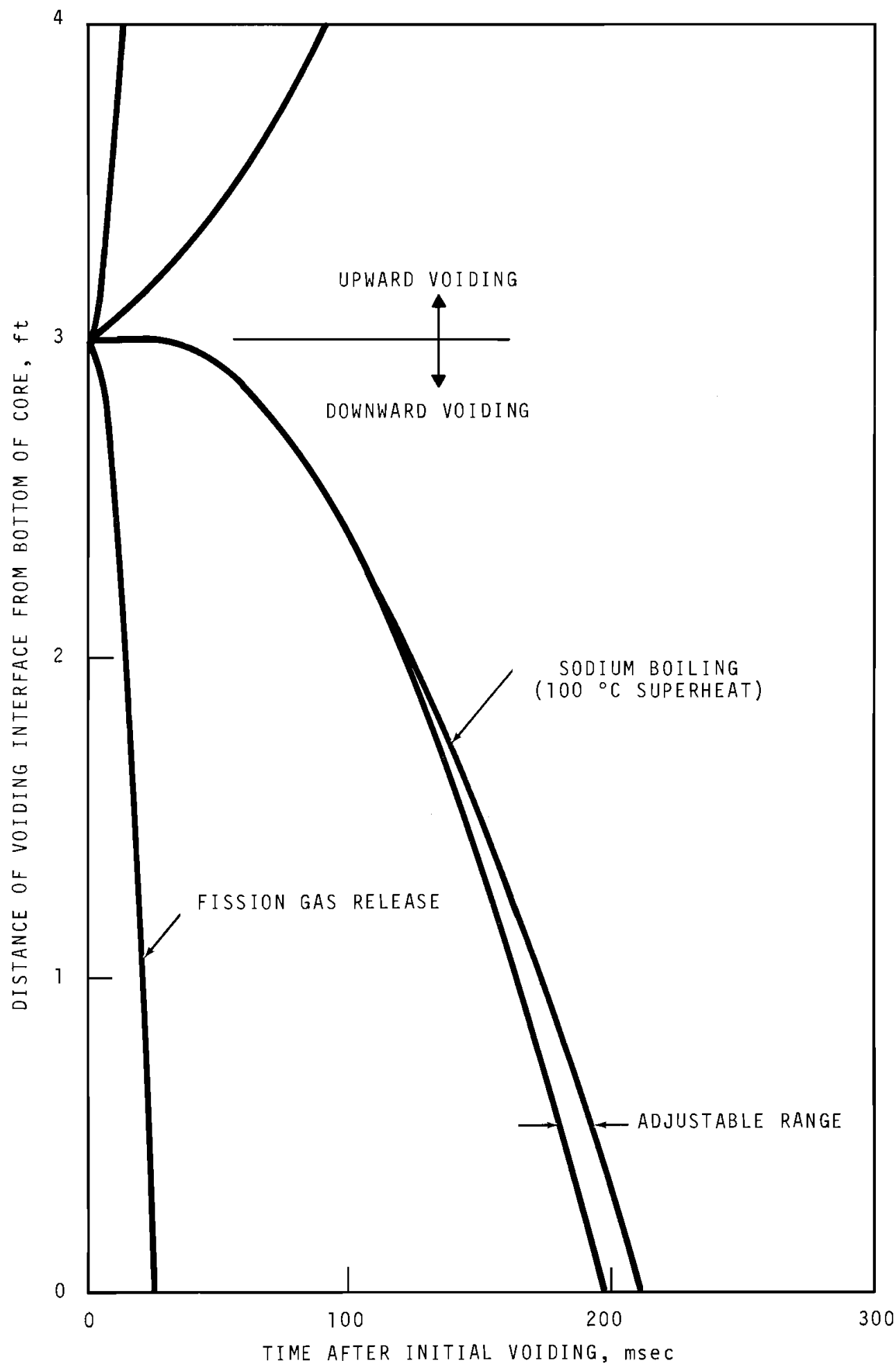

FIGURE 10.3. Sodium Voiding During Flow Coastdown Accident 
BNWL - 1217

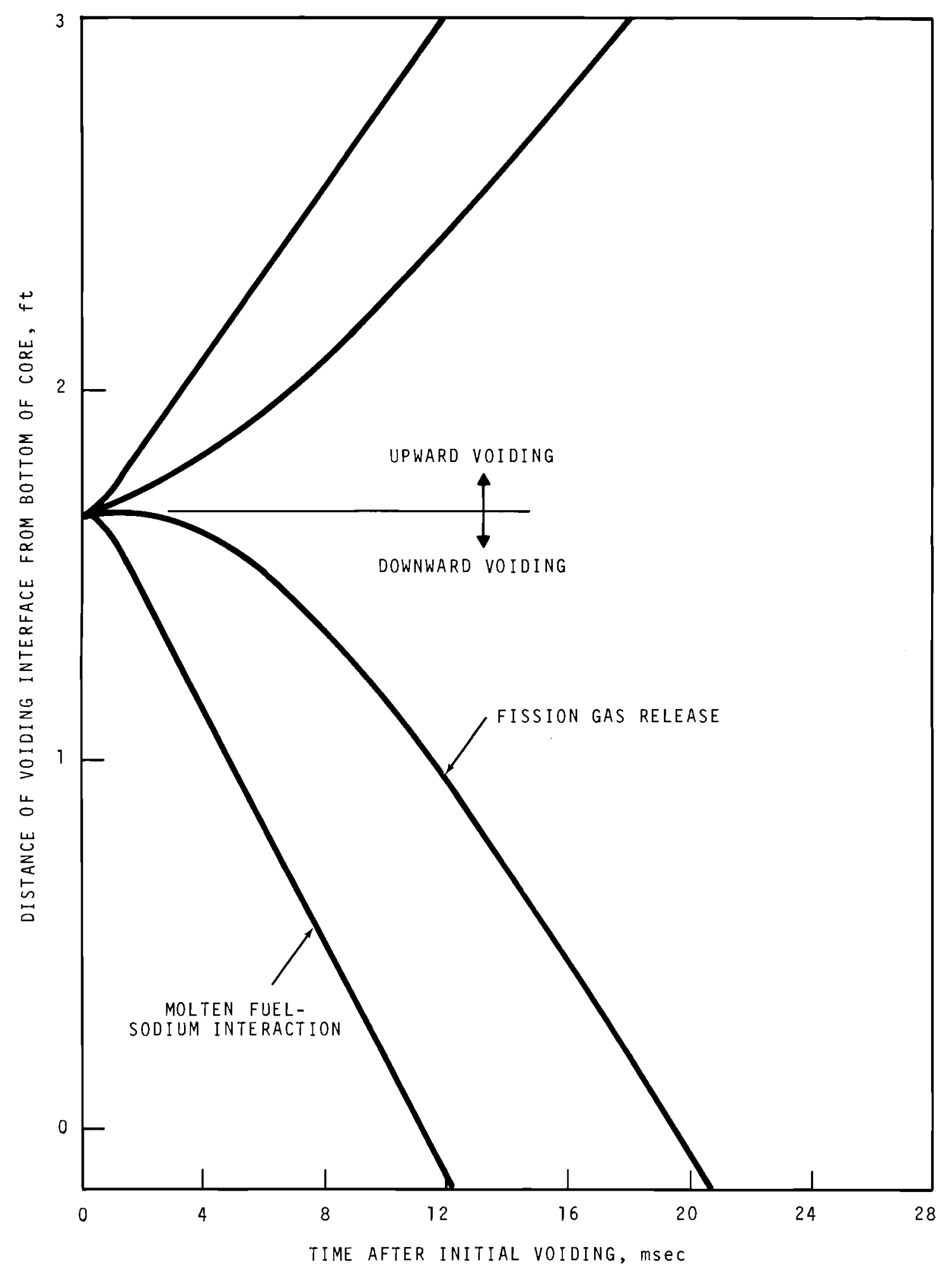

FIGURE 10.4. Sodium Voiding During Rapid Power Excursion 
at the start of voiding has to be overcome. It is seen that the fission gas release, assuming that all the pins are ruptured simultaneously, results in a voiding rate that is approximately seven times faster than sodium boiling assuming $100{ }^{\circ} \mathrm{C}$ superheat.

Figure 10.4 compares the voiding rates for the molten fuel-sodium interaction and fission gas release during a large reactivity insertion accident. The voiding is assumed to start near the center of the core since the maximum amount of fue 1 melting occurs at that location. The sodium expansion following the molten fuel-sodium interaction gives a $40 \%$ faster voiding rate than the fission gas release even though all of the fission gas in the plenum was assumed to be available for expansion. The extremely rapid voiding rate (approximately 12 milliseconds) would result in a very large rate of reactivity insertion if a molten fuel-sodium interaction could take place from the center of the core.

D. REACTOR VESSEL RESPONSE TO HYPOTHETICAL DBA

G. L. Fox*

An investigation was conducted of the maximum work energy release within the reactor vessel which would not cause vessel rupture. Results are shown in Table 10.I based on two calculational models as applied to a $17 \mathrm{ft}$ diameter vessel with a 2 in. wall thickness.

TABLE 10.I. Maximum AZZowable Work Energy

\begin{tabular}{|c|c|c|c|}
\hline Mode 1 & $\begin{array}{c}\text { Gas Gap, } \\
\mathrm{ft} \\
\end{array}$ & $\begin{array}{c}\text { Ideal Vesse } 1 \\
\mathrm{MW} / \mathrm{sec} \\
\end{array}$ & $\begin{array}{c}\text { Real Vesse } 1 \\
\mathrm{MW} / \mathrm{sec} \\
\end{array}$ \\
\hline TNT & None & 285 & 95 \\
\hline ASPRIN & 0.5 & 160 & 23 \\
\hline ASPRIN & 8 & 58 & 13 \\
\hline
\end{tabular}

* 7N82-D.D. Stepnewski 
The value based on TNT was obtained by using the explosion containment laws of Wise and Proctor. (1) The "Real Vessel" results differ from "Ideal Vessel" in that allowable strain is limited to $1 / 3$ the ultimate strain as an allowance for the presence of weldments, nozzles and other stress risers which are unavoidable in an actual vesse1. The results in Table $10 . \mathrm{I}$ used a $10 \%$ allowable wall strain. This value is currently under evaluation and could be anywhere between 5 and $10 \%$.

The ASPRIN computer code has been described in previous issues of this report. This code concentrates energy release in a slug of coolant in order to estimate impact damage on the vessel cover. The validity of this effect has been demonstrated by the results of the $\mathrm{SL}-1$ accident. As a result of this approach, damage in the upper section of the vessel from a given work energy release is greater than that estimated by the TNT model since the TNT explosion effects are assumed to be dispersed more or less uniformly in all directions. Figure 10.5 shows vessel wall strain as a function of DBA work energy for the $8 \mathrm{ft}$ gas gap case. It will be noted that based on lower wall deformation and the $10 \%$ ductility criterion predicted vessel rupture occurs at about the same energy level that is indicated by the TNT 1aws.

\section{E. CHINA SYNDROME ANALYSIS}

G. Jansen*

The history of the fuel core and structural material after a meltdown is being estimated with special emphasis on the downward progress of the molten material and on the heat transfer into the concrete and the soil.

1. W. R. Wise and J.J. Proctor. Explosion Containment Laws for Nuclear Reactor Vessels, U.S. Naval Ordnance Laboratory,

* 7N82 - D. D. Stepnewski 


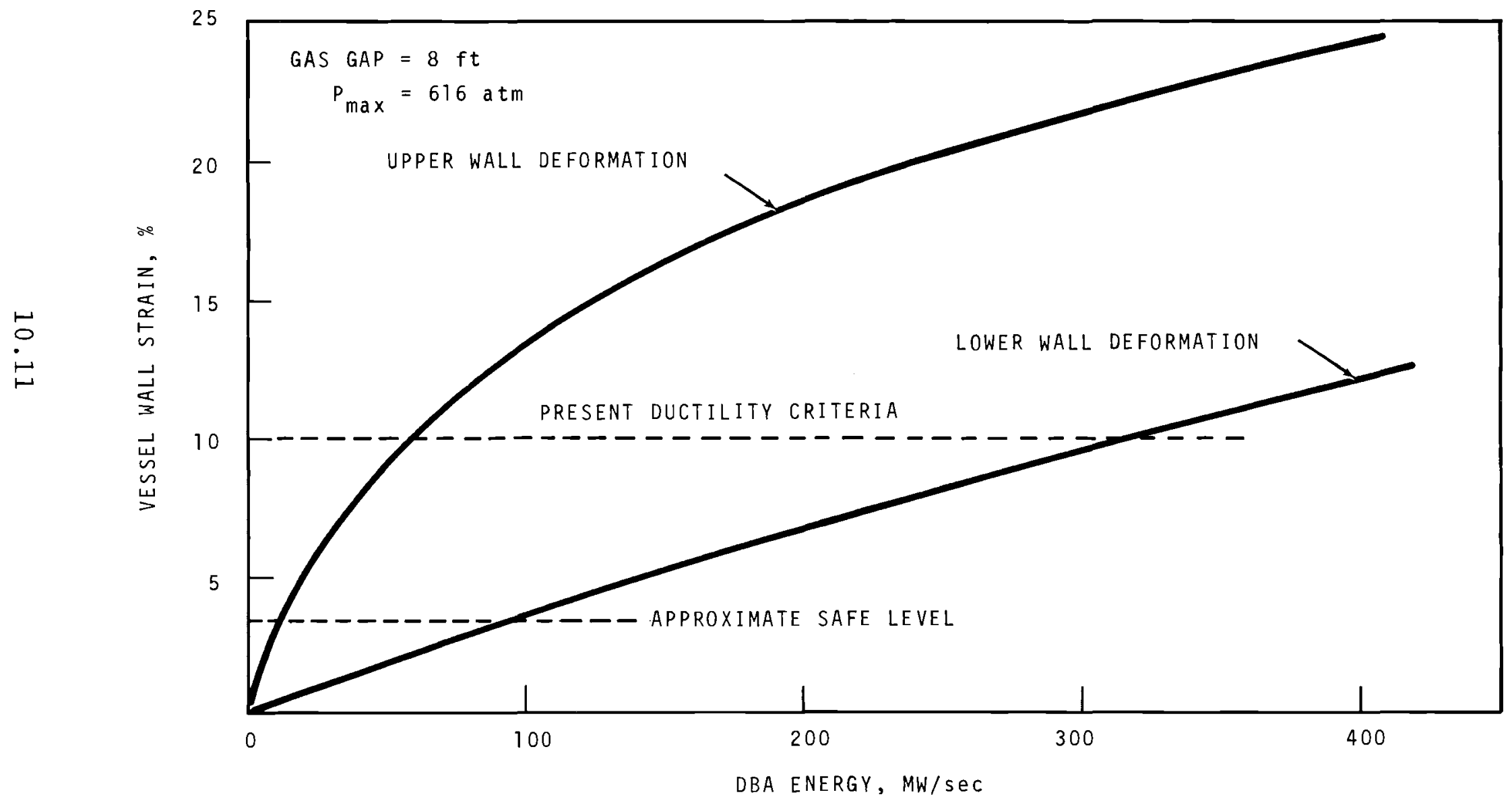

EIGURE 10.5. Vessel Wall Deformation (SIug Effect) 
Preliminary calculations were based on no upward heat losses and on the contacting of a 1 -in. thickness of molten fue 1 and stee 1 at $3550{ }^{\circ} \mathrm{C}$ with concrete at $100{ }^{\circ} \mathrm{C}$. In a very short time, the fuel dissolves $0.6 \mathrm{in}$. of concrete to produce a solution at $2475^{\circ} \mathrm{C}$ saturated with solid $\mathrm{UO}_{2}$. At the advancing molten front, a negligibly thin multiphase region is assumed with precipitated $\mathrm{UO}_{2}$ in equilibrium with melt above $1380{ }^{\circ} \mathrm{C}$, $\mathrm{UO}_{2}$ and $\mathrm{SiO}_{2}$ in equilibrium with melt in the range $1350^{\circ} \mathrm{C}$ to $1100{ }^{\circ} \mathrm{C}$ and all solid below $1100{ }^{\circ} \mathrm{C}$. Differential thermal analysis of powdered concrete samples show a melting range of 1100 to $1300{ }^{\circ} \mathrm{C}$ with a low viscosity liquid above this temperature range. The transient temperature gradient in the concrete at the bottom of the two-phase region is calculated for a stationary front.

As the front advances, the me1t temperature is assumed to be lowered by rapid liquid mixing. Significant events that occur during pool formation are sinking of the molten iron to the bottom of the pool at a pool temperature of $2400{ }^{\circ} \mathrm{C}$ ( $0.8 \mathrm{in}$. of concrete melted at about $1.5 \mathrm{hr}$ ), and complete redissolution of the precipitated $\mathrm{UO}_{2}$ after 22 in. of concrete has been melted (at $1300^{\circ} \mathrm{C}$ and $48 \mathrm{hr}$ after melting). After 20 days, the pool has penetrated $8.5 \mathrm{ft}$ of concrete. The maximum pool depth for slab geometry of $25 \mathrm{ft}$ is reached in about two years, after which the pool begins to shrink.

Heat loss estimates from the pool surface show that a frozen crust will probably form and that rates of advance and the time of farthest penetration of the pool will be appreciably lower than those given above for no upward heat flow. The change in shape of the pool from slablike toward hemispherical will also decrease the maximum pool depth and the time to reach it. 
BNWL -1217

\section{F. SODIUM SPRAY FIRES}

$P$. R. Shire*

A parametric study of mixing efficiency effect on containment sphere pressures resulting from sodium-oxygen reaction has been completed. A containment concept with no machinery dome may hypothetically permit large mass expulsion of sodium into the sphere volume following the DBA with reactor head lift. Previous data have been reported ${ }^{(1)}$ for the case of perfect mixing of containment air with the ejected liquid sodium spray. This study varied mixing efficiency so that the reaction was assumed to take place in a restricted volume of the sphere. Following combustion, complete mixing of the reaction products and the balance of the air was assumed to give a mixed mean temperature adiabatic with respect to the sphere boundary, i.e., no heat transfer to sphere steel and concrete floor.

Mixing efficiencies of $10 \%$ and $50 \%$ correspond to hemispherical reaction volumes of radius $50 \mathrm{ft}$ and $85 \mathrm{ft}$ respectively, while $100 \%$ efficiency corresponds to the total 2.7 million $\mathrm{ft}^{3}$. Results are shown in Figure 10.6. They were computed with the NAFIRE ${ }^{(2)}$ computer code utilizing the method of free energy minimization.

\section{G. SODIUM BOILING}

R. J. Schroder*

A portion of the $\mathrm{Na}$ Boiling fault tree involving loss of coolant flow was evaluated using the Monte Carlo fault tree simulation program, MFTS. Only independent failures were considered, i.e., "generic" failures were not included. The results indicated that the probability of $\mathrm{Na}$ Boiling as a result of independent failure of coolant loops and protective system components is less than $10^{-10}$.

* $7 N 82-$ D. D. Stepnewski

1. Apriz 1969 MITPR

2. J. Anderson. "Chemical Equilibrium Calculations," Program B-194 (ANL) March 9, 1966. 


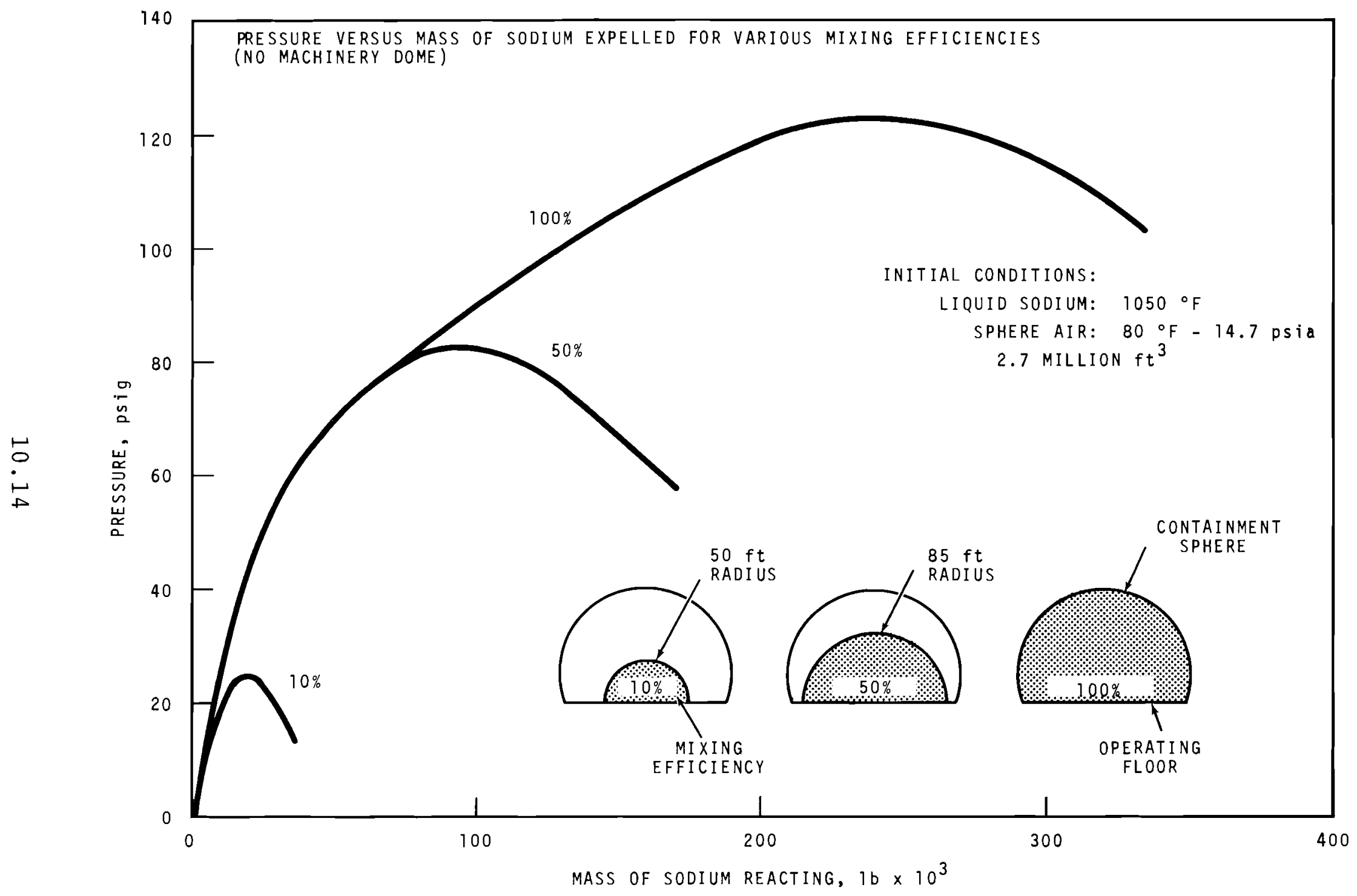

EIGURE 10.6. Pressure in Containment Sphere for Sodium Spray Expulsion 


\section{H. SAFETY PROGRAMS}

J. W. Hagan*

A review of the ANL preliminary draft report, Project Report: Studies of Safety Test Facilities, has been completed. The BNW comments have been compiled and formally transmitted to the Argonne National Laboratory for consideration in subsequent reports to be issued by ANL under the designated LMFBR Task 10-5.1, "Analysis of Facility Requirements."

A review of reported abnormal operating experiences is being made of those experiences involving components of plant protective systems. This information was extracted from data compiled by the Nuclear Safety Information Center through their formal documents $(1,2,3)$ and a special search performed for BNW.

* $7 N 82$

1. Abnormal Reactor operating Experiences, ORNL-NSIC-17, Nuclear Safety Information Center, Oak Ridge, Tennessee, August 1966.

2. Abnormal Reactor Operating Experiences - 1966-1968, ORNLNSIC-64, Nuclear Safety Information Center, oak Ridge, Tennessee, Preliminary Draft.

3. E. N. Cramer. "Safety-Related occurrences in Reactor and Radioactivity-Handiing Operations as Reported in 1966," Nuclear Safety, vol. 9, no. 3, May-June 1968. 



\section{DISTRIBUTION}

No. of

Copies

OFFSITE
AEC Division of Reactor Development and Technology*

M. Shaw, Director, RDT

Asst Dir for Nuclear Safety

Analysis \& Evaluation Br, RDT:NS

Environmental \& Sanitary Engrg Br, RDT:NS

Research \& Development Br, RDT:NS

Asst Dir for Plant Engrg, RDT

Facilities $\mathrm{Br}$, RDT:PE

Components $\mathrm{Br}, \mathrm{RDT}: \mathrm{PE}$

Instrumentation \& Control Br, RDT:PE

Iiquid Metal Systems Br, RDT:PE

Asst Dir for Program Analysis, RDT

Asst Dir for Project Mgmt, RDT

Liquid Metals Project Br, RDT:PM

FFTF Project Manager, RDT:PM (3)

Asst Dir for Reactor Engrg, RDT

Control Mechanisms $\mathrm{Br}$, RDT:RE

Core Design Br, RDT:RE (2)

Fuel Engineering $\mathrm{Br}$, RDT:RE

Fuel Handling $\mathrm{Br}$, RDT: RE

Reactor Vessels Br, RDT:RE.

Asst Dir for Reactor Tech, RDT

Coolant Chemistry Br, RDT:RT

Fue1 Recycle Br, RDT:RT

Fuels \& Materials Br, RDT:RT

Reactor Physics Br, RDT:RT

Special Technology Br, RDT:RT

Asst Dir for Engrg Standards, RDT

EBR-II Project Manager, RDT:PM

AEC Idaho Operations office

Nuclear Technology Division

C. W. Bills,Director

AEC San Francisco Operations Office

Director, Reactor Division

* Distribution by FFTF 
No. of

Copies

4

10

15

1

2

3

1

7 Atomic Energy Division

S. H. Esleeck

G. B. Garton

$1 \quad$ BNW Representative

N. A. Hill (ZPR III)

AEC Site Representatives*

Internationa 1

General Electric Co.

Bechte 1 Corporation*

Westinghouse Electric Corp*

Atomic Power Division

Advanced Reactor Systems

D. C. Spencer

AEC Chicago Patent Group

G. H. Lee

Argonne Nationa1 Laboratory

R. A. Jaross

LMFBR Program office

N. J. Swanson

Document Librarian

Atomics International

FFTF Program office (5)

2

Babcock \& Wilcox Co

Argonne National Laboratory

Atomic Power Development Assoc.

J. J. Teachnor, Project Administrator, FFTF

AEC Division of Technical Information Extention

Atomic Power Development Associates

Liquid Metal Information Center - J. J. Droher 
No. of

Copies

1

Combustion Engineering

1000 MWe Follow-on Study

W. P. Staker, Project Manager

5

General Electric Co.

Advanced Products Operation

Kar 1 Cohen (3)

Nuclear Systems Programs

D. H. Ahmann

Gulf General Atomic Inc. General Atomic Div

D. Coburn

1

Idaho Nuclear Corporation

D. R. DeBoisblanc

1

Oak Ridge National Laboratory

W. O. Harms

Stanford University

Nuclear Division

Division of Mechanical Engrg

R. Sher

1 United Nuclear Corporation

Research and Engineering Center

R. F. DeAngelis

ONSITE-HANFORD

1

AEC Chicago Patent Group

R. K. Sharp (Richland)

3

Battelle Memorial Institute

104

Batte11e-Northwest
F. W. Albaugh
A. L. Bement, Jr.
G. J. Alkire
R. A. Bennett
S. O. Arneson
T. K. Bierlein
J. M. Batch
L. D. Blackburn

Distr -3 


\section{Battelle-Northwest (contd)}

C. L. Boyd

R. L. Brown

W. L. Bunch

C. A. Burgess

J. J. Cadwe 11

A. C. Callen

C. M. Cantre11

J. R. Carrell

T. D. Chikalla

T. T. Claudson

P. D. Cohn

J. H. Cox

G. M. Dalen

J. M. Davidson

F. G. Dawson

D. R. de Halas

A. W. DeMerschman

D. R. Doman

G. E. Driver

K. Drumheller

R. V. Dulin

T. W. Evans

P. L. Farnsworth

L. M. Finch

J. C. Fox

E. E. Garrett

W. L. Hampson

J. E. Hanson

K. M. Harmon

H. Harty

R. A. Harvey

B. R. Hayward

R. E. Heineman

J. W. He $1 \mathrm{~m}$

R. J. Hennig

G. M. Hesson

J. J. Holmes

H. G. Johnson

E. M. Johnston

J. N. Judy

F. J. Kempf

D. D. Lanning

G. A. Last

D. C. Lehfeldt

H. D. Lenkersdorfer

C. W. Lindenmeier

W. W. Little, Jr.

C. E. Love

B. Mann
D. Marinos

C. A. Munro

R. E. Nightingale

L. T. Pedersen

G. S. Petersen

R. E. Peterson

H. G. Powers

H. S. Pringle

W. D. Richmond

W. E. Roake

R. L. Roske

F. H. Shade 1

D. W. Shannon

F. R. Shober

D. E. Simpson

C. R. F. Smith

D. D. Stepnewski

G. H. Strong

C. D. Swanson

J. W. Thornton

J. C. Tobin

K. G. Toyoda

J. C. Tverberg

C. E. Voge 1

M. Voge 1

R. C. Walker

E. T. Webber

J. H. Westsik

J. F. Wett

R. G. Wheeler

F. J. Williams

N. G. Wittenbrock

T. W. Withers

M. R. Wood

F. W. Woodfield

D. C. Worlton

H. H. Yoshikawa

Technical Information (5)

Technical Publications (3)

Legal-703 Bldg.

Lega1-ROB, $221-A$ 
No. of

Copies

4

AEC RDT Site Representatives*

P. G. Holsted

T. A. Nemzek

3

AEC Richland Operations Office*

J. M. Shivley
C. L. Robinson

1 Bechte1 Corporation*

M. 0. Rothwe11

1 Westinghouse Electric Corp. *

R. Strzelecki (Richland)

25

Batte11e-Northwest*

E. R. Astley

J. C. Cochran

D. L. Condotta

J. F. Erben

E. A. Evans

F. C. Gronemeyer

P. L. Hofmann

H. E. Little

W. B. McDonald

J. S. McMahon

R. J. Squires

W. R. Wykoff

FFTF Files (10)

FFTF TPO Files (List "M")

* Distribution by FFTF 
